Illinois State University

ISU ReD: Research and eData

Theses and Dissertations

$5-19-2018$

\title{
Bladelet Polish: a lithic analysis of Spracklen (33GR1585), an upland Hopewell campsite
}

Tyler R. E. Heneghan

Illinois State University, tyler.heneghan@outlook.com

Follow this and additional works at: https://ir.library.illinoisstate.edu/etd

Part of the Ancient History, Greek and Roman through Late Antiquity Commons, and the History of Art, Architecture, and Archaeology Commons

\section{Recommended Citation}

Heneghan, Tyler R. E., "Bladelet Polish: a lithic analysis of Spracklen (33GR1585), an upland Hopewell campsite" (2018). Theses and Dissertations. 928.

https://ir.library.illinoisstate.edu/etd/928

This Thesis is brought to you for free and open access by ISU ReD: Research and eData. It has been accepted for inclusion in Theses and Dissertations by an authorized administrator of ISU ReD: Research and eData. For more information, please contact ISUReD@ilstu.edu. 


\section{BLADELET POLISH: A LITHIC ANALYSIS OF SPRACKLEN (33GR1585), AN UPLAND HOPEWELL CAMPSITE}

\section{TYLER R. E. HENEGHAN}

\section{Pages}

This thesis builds upon recent investigations at Spracklen (33GR1585), a small upland site in Greene County, Ohio. The presence of non-local cherts, bladelets, and bladelet cores indicates a Middle Woodland Ohio Hopewell occupation. Raw material sourcing, debitage analyses, and a use-wear analysis uncovered that Spracklen functioned as a logistical hunting campsite. Its people utilized bladelets for butchery and hide-working processes. This information provides new insights into Hopewellian life in the uplands and its place within Hopewell community organization.

KEYWORDS: Settlement patterns, Hopewell, Bladelets, Use-wear, GIS 
BLADELET POLISH: A LITHIC ANALYSIS OF SPRACKLEN (33GR1585), AN UPLAND

HOPEWELL CAMPSITE

TYLER R. E. HENEGHAN

A Thesis Submitted in Partial

Fulfillment of the Requirements

for the Degree of

MASTER OF SCIENCE

Department of Sociology and Anthropology

ILLINOIS STATE UNIVERSITY

2018 
(C) 2018 Tyler R. E. Heneghan 
BLADELET POLISH: A LITHIC ANALYSIS OF SPRACKLEN (33GR1585), AN UPLAND HOPEWELL CAMPSITE

TYLER R. E. HENEGHAN

COMMITTEE MEMBERS:

G. Logan Miller, Chair

James M. Skibo 


\section{ACKNOWLEDGMENTS}

From an oral surgeon to an exotic veterinarian or paleontologist, my dreams shifted during my youth and into college. I was completely ignorant of anthropology until a few courses during undergrad, and like most of us, I thought archaeologists were restricted to the fictional characters in literature and on the big screen. I eventually found out through first-hand experience that a true archaeologist spends their time in a laboratory or writing hundred-page papers. I did not do this for the discovery, but to gain a holistic understanding of the past in hopes of better protecting it for the future. To me, that is what being an archaeologist is all about.

Just as a boxer has a trainer in their corner to get them through the fight, I have always had my family to help me in life. Without my mom and dad, I would never have had the opportunity to pursue what's truly important to me, and I am extremely grateful for that. When I needed it most, my sister and her budding family always provided me an escape from the papers and writing. My family's unconditional love and support never went unnoticed.

After hundreds of hours reconstructing a prehistoric structure at SunWatch Archaeological Park in the rain, snow, and heat, Bill Kennedy taught me most about the importance of chasing your passion and taking chances. I would like to thank Dr. Amelia Hubbard, whose guidance and mentorship gave me the tools necessary to succeed in graduate school and life. Dr. Logan Miller showed me that we can learn a lot more about people and culture from rocks than most archaeologists would care to admit. I would have never been able to see this thesis through without Dr. Miller and Dr. Jim Skibos's enthusiasm and continued support. Lastly, I want to say thank you to everyone mentioned above and those not; you all had a large part in making this paper happen.

T. R. E. H. 


\section{CONTENTS}

Page

ACKNOWLEDGMENTS

TABLES

FIGURES

CHAPTER I: INTRODUCTION 1

CHAPTER II: INVESTIGATING THE PAST $\quad 6$

Community Organization Among the Ohio Hopewell 6

$\begin{array}{ll}\text { Prufer's Model } & 7\end{array}$

$\begin{array}{ll}\text { Upland Sites } & 8\end{array}$

$\begin{array}{ll}\text { Hopewell Interaction Sphere } & 9\end{array}$

Archaeological Investigations of Spracklen and the Surrounding Areas 11

$\begin{array}{ll}\text { Spracklen (33GR1585) } & 11\end{array}$

Pollock Works (33GR5) 14

$\begin{array}{ll}\text { Fort Ancient (33WA2) } & 17\end{array}$

$\begin{array}{ll}\text { Murphy (33LI212) } & 20\end{array}$

$\begin{array}{ll}\text { Blade Production and Use } & 21\end{array}$

$\begin{array}{ll}\text { The Blade } & 22\end{array}$

$\begin{array}{ll}\text { The Blade Core } & 23\end{array}$

$\begin{array}{ll}\text { Summing It Up } & 24\end{array}$

Studies of the Hopewellian Bladelet $\quad 24$

The Study of Lithic Use-Wear and Behavioral Chain Analysis 28

Use-Wear Methods are Grounded in Processual Thought 28 
$\begin{array}{ll}\text { Behavioral Chain Analysis } & 31\end{array}$

In Summary 33

CHAPTER III: LITHIC INVESTIGATIONS AT SPRACKLEN 34

Materials and Methods $\quad 34$

$\begin{array}{ll}\text { Materials } & 34\end{array}$

$\begin{array}{ll}\text { Chert Sourcing Methods } & 35\end{array}$

Debitage Categorization Methods 35

Complete Flake Analysis Methods 37

$\begin{array}{ll}\text { Microwear Analysis Methods } & 37\end{array}$

$\begin{array}{ll}\text { Results and Discussions } & 39\end{array}$

Chert Sourcing Results 39

$\begin{array}{ll}\text { Chert Sourcing Discussion } & 42\end{array}$

Debitage Categorization Results 44

$\begin{array}{ll}\text { Debitage Categorization Discussion } & 47\end{array}$

$\begin{array}{ll}\text { Microwear Analysis Results } & 50\end{array}$

Microwear Analysis Discussion $\quad 55$

$\begin{array}{ll}\text { How This Fits } & 58\end{array}$

CHAPTER IV: FUTURE RESEARCH AND CONCLUSIONS 60

Searching the Uplands: Using GIS to Identify Sites 60

A Brief Insight into GIS's Archaeological Application 60

$\begin{array}{ll}\text { Reverse Site Suitability } & 62\end{array}$

Materials and Methods $\quad 63$ 
Reverse Site Suitability Results $\quad 64$

$\begin{array}{ll}\text { Discussion and Future Considerations } & 65\end{array}$

How Spracklen Fits within Hopewell Community Organization 67

$\begin{array}{ll}\text { New Insights into Upland Life } & 67\end{array}$

How This Fits into What We Know $\quad 69$

Anthropological Importance and Where We Go from Here 72

$\begin{array}{ll}\text { REFERENCES CITED } & 74\end{array}$

APPENDIX A: BLADELET MICROWEAR IMAGERY 91

APPENDIX B: FLAKE MICROWEAR IMAGERY 105 


\section{TABLES}

Table $\quad$ Page

1. Complete Flakes Recovered from Spracklen 45

2. Spracklen Lithic Utilization $\quad 50$ 


\section{FIGURES}

Figure

1. Magnetic susceptibility data 12

2. Geophysical survey overlaid by Miller's excavation units 13

3. Pollock Works survey completed by S.T. Owens and L.K. Dille 15

4. Fort Ancient Earthworks survey completed by John Locke 18

5. Sample of bladelets recovered from Spracklen 25

6. Dichotomous key for debitage categorization 36

7. Chert types of debitage at Spracklen 40

8. Chert types of bladelets at Spracklen $\quad 41$

9. Bladelet core rejuvenation flake and bladelet cores from Spracklen 41

10. Debitage types at Spracklen 44

11. Plotting median relative thickness against median thickness for complete flakes recovered from Spracklen $\quad 46$

12. Plotting median relative thickness against median weight for complete flakes recovered from Spracklen

13. Comparison of Spracklen debitage with Sullivan and Rozen's classification signatures and Connolly's Fort Ancient findings $\quad 48$

14. Summarization of bladelet use-wear on various contact materials 51

15. Examples of microwear traces from Spracklen lithics 52

16. Hafting microwear traces on Spracklen lithics 54

17. Summarization of flake use-wear on various contact materials 55

18. Regions to focus investigations for inquiry into upland Hopewell life 66 


\section{CHAPTER I: INTRODUCTION}

In its most rudimentary sense, prehistoric archaeology investigates the cultures of past people. Like other sub-disciplines of anthropology, this inquiry into a culture must be completed holistically. To obtain this holistic understanding of any individual culture, archaeologists must investigate the sacred and domestic lives of these people. Yet, dating back to the mid to late 19th century, a majority of investigations into Ohio Hopewell, both documentary and intrusive, focused predominantly on their sacred and largely uninhabited earthworks (see Atwater 1820; Burks and Cook 2011; Connolly 2004a, 2004b; Lazazzera 2004; MacLean 1879; Miller 2014, 2015; Moorehead 1890; O’Sheal 2007; Otto 2004; Riordan 1995, 2007, 2010, 2013; Squier and Davis 1848; Whittlesey 1850). Today, these sites attract thousands of visitors, both colloquial and scholarly alike, all the while still grabbing the attention of the archaeological community and their accompanying research.

Although the sacred and domestic lives of the Hopewellian peoples were likely conjoined and synonymous, the people did not live at earthworks. Instead, earthworks represented the epicenter of community for these dispersed sedentary farmers (Bernardini 2004; Dancey and Pacheco 1997; Pacheco and Dancey 2006). Yet, research still centers predominantly on earthworks and the archaeoastronomy, burials, ritual-like structures, economy, and community organization associated with these places (see Burks and Cook 2011; Lepper 2004; Miller 2015; Riordan 1995, 2010). While the multi-generational building of these earthworks created a sense of community between the Hopewell people living in nucleated hamlets just outside of these vacant centers, a holistic understanding of community organization must involve investigation of all regions within and surrounding these earthworks (Pacheco 1997; Pacheco and Dancey 2006; 
Prufer 1965, 1967). One of the regions that has received little attention in Olaf Prufer's (1965, 1967) community organization model, are the uplands. The small hamlets, campsites, and upland dwellings where the Hopewell populations resided when not congregating at earthworks have not garnered the same research attention as their sacred counterparts (Dancey and Pacheco 1997). Without investigation, the function and continuity of upland sites within Hopewell community organization is largely unknown. The Spracklen site (33GR1585), the focus of this investigation, is an example of one such short-term, upland site situated three kilometers south of the closest earthworks (Pollock Works), and it garners a large lithic assemblage (Miller and Heneghan 2018).

Similarly, lithic tools, predominantly the Hopewell bladelet (the most commonly recovered tool in the Hopewellian toolkit), have undergone analyses to understand their function in the ritual economy associated within earthworks (see Kay and Mainfort 2014; Miller 2014, 2015) and domestic settings (see Genheimer 1996; Kimball 1991, 1992; Lemons and Church 1998; Yerkes 1990, 1994). Similar studies have not been conducted on upland sites outside of the earthworks. An inquiry into lithic tool function within these domestic locales would provide a more comprehensive understanding of the bladelet regarding domestic life, its place within the Hopewell culture in its entirety, and the function of upland sites.

Excavated during the summer of 2016 in Greene County, Ohio, the Spracklen site (33GR1585) represents a small upland domestic site occupied for a short period of time by people of the Ohio Hopewell culture. Sites such as Spracklen can aid in filling in the record regarding lithic tool usage in an upland setting outside of earthworks, while also providing insight into upland Hopewell dwellings. Moreover, it is within proximal distance to both the Fort Ancient Earthworks (33WA2) and Pollock Works (33GR5), which have undergone extensive 
excavation and investigation throughout the past century (see Connolly 2004a, 2004b; Lazazzera 2004; Miller 2015; O’Sheal 2007; Otto 2004; Riordan 1995, 2007, 2010, 2013). The domestic occupation of Spracklen, its abundance of lithic assemblage, and its proximity to thoroughly investigated earthworks will allow for the investigation of:

1) Lithic tool acquisition, production, consumption, and use at a domestic upland site (Spracklen)

2) Comparison with the lithic tool assemblages at the Fort Ancient Earthworks and Pollock Works

3) Spatial inquiry into Greene County's upland regions

4) Upland sites within Ohio Hopewell community organization

This study will make use of (a) lithic debitage analysis, (b) a microwear analysis, and (c) a reverse site suitability of Spracklen using ArcGIS. Debitage analysis will note the raw materials used in the production of the tools, which will then undergo Sullivan and Rozen's (1985) debitage categorization. Further, complete flakes will be characterized utilizing their methods for comparison with Connolly's $(1991,1997)$ investigation of debitage recovered from Fort Ancient. The microwear analysis will mimic previous bladelet examinations conducted by Kay and Mainfort (2014) and Miller (2015) to uncover the use and consumption of the bladelets. Utilizing ArcGIS and Spracklen's spatial attributes, the entirety of Greene County will be investigated to identify regions with similar spatial characteristics. This information will provide a visualization of regions where additional inquiries can be made to uncover sites like Spracklen that may not have been destroyed by agricultural disturbances. As Spracklen is just the beginning of inquiry into non-rockshelter upland sites, a reverse site suitability will highlight regions for 
further examination. In the end, additional sites will need to be documented and examined with their artifact assemblages undergoing further analysis.

Through understanding how the lithics were produced and used at Spracklen, their function in this upland setting will be uncovered. This will allow for an understanding of the occupation occurring at Spracklen. Together, these techniques and the research in its entirety aim to contribute to the previously understood knowledge regarding community organization and lithic tools in the Ohio Hopewell culture, while also providing a fresh perspective into aspects of the Hopewellian daily life through lithic tools.

The Ohio Hopewell culture experienced unity through community earthworks, with people coming far and wide to gather for ceremony and trade. While Prufer's $(1965,1967)$ model discusses this community organization, which encompasses the earthworks and surrounding domestic hamlets and campsites in the floodplains, upland contexts are poorly understood and vastly understudied. However, with an increase in cultural resource management (CRM) and academic archaeology in these upland regions, sites such as Jonah's Run and Spracklen have been located and excavated. Yet, little is known about their function and place within the Hopewell community. Before the study began, I hypothesized that Spracklen was a subsistence camp for resource gathering. Through the investigation of the utilized bladelets, unifaces, bifaces, and flakes at Spracklen, combined with their comparison with Fort Ancient and Pollock Works tools, an understanding of upland settlement structure and tool usage can be obtained.

This investigation begins with Chapter II's detailed examination of the Ohio Hopewell. Review of the academic literature provides the framework for this study by describing the culture's community organization before delving into previously excavated Hopewellian sites. 
From here, background on the Hopewellian bladelet and conducted lithic analyses are provided. Chapter III begins by describing the lithic assemblage investigated and providing procedural information regarding the steps taken throughout the raw-material sourcing, debitage analysis, and microwear analysis. This chapter concludes with the presentation of the results and offering discussions based upon the findings and comparison with nearby sites. In the final section, Chapter IV, GIS data is presented to initiate discussions on where future research into the uplands should be directed as well as conclude on Spracklen as a hunting camp. 


\section{CHAPTER II: INVESTIGATING THE PAST}

\section{Community Organization Among the Ohio Hopewell}

Commonly characterized by earthworks, mounds, and exotic goods, the Hopewell culture arose within Ohio approximately 2,100 B.P. before dispersing some 600 years later, circa 1,500 B.P. (Abrams 2009; Burks and Cooke 2011; Lepper 2005; Miller 2015; Yerkes 2002). Although they occupied the region for over half a millennium, little is definitively known about this Middle Woodland culture outside of these isolated anthropogenic mounds, vast and geometric earthworks, and the artifacts that have come from within them. Pacheco $(1988,1997)$ argues that understanding the daily lives of these peoples will remove the mystery that is often associated with the culture once known as, "The Mound Builders." It is through investigation of their community organization and living spaces, such as campsites and hamlets, that we can begin to fully understand the Ohio Hopewell peoples.

The visible earthwork remnants throughout much of the Midwest led the earliest archaeologists and surveyors to associated sites such as, Fort Ancient, Fort Hill, Mound City, Newark, and the Pollock Works, among numerous others (Atwater 1820; MacLean 1879; Moorehead 1890; Squier and Davis 1848; Whittlesey 1850). Some of the earliest excavations within Ohio were conducted on the sites mentioned above to recover artifacts for display at the World Columbian Exposition and for private collections (Atwater 1820; MacLean 1879; Moorehead 1890). Many of the early antiquarian-style archaeologists and surveyors described the earthworks as, "impregnable [and] military" in function (Squier and Davis 1848:21). Over 40 years later, Moorehead (1890:110-111) agreed that these earthworks were defensive complexes; he was also the first to suggest that these places were not permanent settlements, but centers that 
nearby people could aggregate to in times of distress. Though these defensive structure and settlement postulations were incorrect, it was not until Olaf Prufer, in the 1960s, that a theory on community organization among the Ohio Hopewell became formally discussed.

\section{Prufer's Model}

Prufer $(1965,1967)$ introduced what is now known as the Dispersed Sedentary Community model (originally referred to as the Dispersed Hamlet/Vacant Center Model), which argues that ceremonial earthworks are void of long-term habitation, with community members dispersed and living in small farmsteads in the floodplains just outside of the earthworks. In this model, Prufer (1965) argued for three distinct settlement types: earthworks with burial grounds, hamlets or farmsteads, and specialized campsites. It was through the building of these earthworks and the ceremonies that occurred within them that the community was built. Additionally, he suggested that the nucleated hamlets garnered a sense of community with the earthworks serving as a centralized place. All the while, these specialized campsites limited to just outside of the earthworks, are regions of craft specialization for ceremonial purposes within the earthworks (Dancey and Pacheco 1997). While there has not been any evidence that contradicts Prufer's model of community organization, this model has not be subjected to intensive scrutiny.

Prufer's model, although still accepted today, fails to explicitly mention the possibility of campsites or hamlets in far reaching uplands, kilometers away from any earthworks. Albeit, his inclusion of the specialized campsite may encompass the sites found in these regions, thus implying logistical campsites. To gain a full understanding of the community organization within the Ohio Hopewell culture, however, sites such as these need to be investigated and their 
functions identified. Unfortunately, many of these sites have been severely disturbed by historical plowing and other impacts and thus have little to no features remaining except, often, an abundant lithic scatter. The Spracklen site, which was the focus of my study, is an example of one such upland/hinterland site, with an abundant lithic assemblage, that was seemingly overlooked in Prufer's model.

\section{Upland Sites}

As mentioned above, investigations into earthworks and the surrounding floodplains has led to a lack of comparable data of upland and hinterland Hopewell sites in the Ohio region, with very few inquiries into their function and continuity within the community (see Brose and White 1979; Miller and Heneghan 2018; Pacheco and Dancey 2006; Seeman 1996). Much of the work that has been done in the uplands has focused on rockshelters (Pacheco and Dancey 2006; Seeman 1996).

Because these rockshelter sites have a low abundance of ceramics and lithic debitage and an abundance of tools, Pacheco and Dancey (2006:6) argue that these sites are the product of logistical mobility, meaning "resources are moved to the people by work groups, as opposed to... the entire group seasonally mov[ing] to the resources" (see Binford 1980, 1982; Kozarek 1997). These logistical sites have been characterized by Rafferty (1985) as those with low (1) maintenance of settlement space, (2) degree of layout clarity, (3) incidence of artifact fragmentation, and (4) incidence of recycled tools.

Again, it must be stated that many upland site investigations have been within rockshelters, with Pacheco and Dancey (2006) only briefly mentioning the non-rockshelter site of Jonah's Run (33WA82) (Brose and White 1979). Located near the Fort Ancient Earthworks, 
Jonah's was excavated during a CRM investigation in 1976 and is characterized by an abundance of tools and little debitage. Pacheco and Dancey (2006) argue that these two attributes, along with no identifiable pit features and only scattered post molds, provides evidence that Jonah's Run was an upland logistical mobile site that functioned as a hunting camp. Outside of the low abundance of lithic debitage and incidence of artifact fragmentation, which dominate the assemblage at Spracklen, Rafferty (1985) and Pacheco and Dancey's (2006) logistically mobile definition fits well with the site in question. A closer examination into the proposed logistical mobility function of upland sites, through lithic analysis, will be one of the primary foci of this investigation.

\section{Hopewell Interaction Sphere}

While recognizing a greater tradition among the Hopewell culture, archaeologists have distinguished regionalized subsets. It is the dispersal of ideas (e.g. shift from foraging to farming, mound building, and ceremonialism), technology (e.g. blade and core technique), and trade goods (e.g. mica from NC, copper from MI, shells from the Gulf of Mexico etc.) that constituted the Hopewell Interaction Sphere (Caldwell 1964; Hall 1979, 1997; Yerkes 2002). Understanding the regional differences between the Ohio Hopewell (IN, OH, PA, TN, and WV), Havana Hopewell (IL, IA, and MO), Kansas City Hopewell (KS and MO), and Cooper Hopewell (AR, $\mathrm{OK}, \mathrm{KS}$, and $\mathrm{MO}$ ) is what creates a holistic understanding of the culture as an entity with distinct regional variation. This interaction was so complex and spatially vast that much of the Midwest, along with regions in the Plains and southern Canada, participated in the movement of goods. It is this complex movement of exotic artifacts and association with burials, mounds, and earthworks that exemplifies the Hopewell culture. 
Unlike trading in Mississippian chiefdoms, in which wealth was accrued by the elites within the community, Hall (1997) proposed that people within the Hopewell culture were egalitarian, and thus increased their status by the giving of goods to others. The abundance of exotic (non-local) cherts and ceremonial resources as well as the accompanying community creation of earthworks and mounds would support this idea of accruing status through gift giving. With blade and core technology requiring high-quality cherts not often found close by, the abundance of non-local cherts can often be noted throughout Hopewell sites (Pacheco 1997; Yerkes 2002).

An example of such an instance was noted by Pacheco (1997), where sites near the Newark Earthworks contain both Ohio Flint Ridge (originating near Newark, Ohio) and Harrison County (originating $300 \mathrm{~km}$ away in Indiana and Kentucky) chert types. Additionally, while Ohio Flint Ridge bladelets were twice as common as those crafted from Harrison County, ten times the amount of Ohio Flint Ridge flakes have been collected from the same area. When coupled together, this would suggest that bladelets were being crafted and subsequently gifted to other regions. Lepper (2006) provided another example of the long-distance movement of artifacts at the Newark Earthworks. He identified a road connecting the earthworks to the High Bank Works (over 90km away) that would have provided a route for the transportation of artifacts to differing regions (Abrams 2009). These examples follow in line with the thoughts of the Hopewell Interaction Sphere and the gift giving to obtain status within the community. 


\section{Archaeological Investigations of Spracklen and the Surrounding Areas}

Spracklen (33GR1585)

Identified during a surface survey by the 2003 Wright State University field school, led by Robert Riordan, the Spracklen site is a multi-component, non-earthwork lithic scatter located south of Cedarville, Ohio (Miller and Heneghan 2018) (Figure 17). Presently, Spracklen is a 2,100-square meter site in an upland farm field, three kilometers south of the Pollock Works and not within proximity of a stable water source. Riordan's survey collected 152 artifacts that included six bladelets, one bladelet core, two projectile points, and numerous flakes. With hopes of conducting an excavation, Logan Miller, along with Jarrod Burks, conducted a surface survey and geophysical survey in April 2015 and March 2016, respectively. The surface survey recovered an additional 212 artifacts, including 12 bladelets, two bladelet cores, and a projectile point. Additionally, Burks' (2016) geophysical survey identified numerous anomalies, including a possible $11 \mathrm{~m}$ long structure with midden features within and around it (Figure 1). 


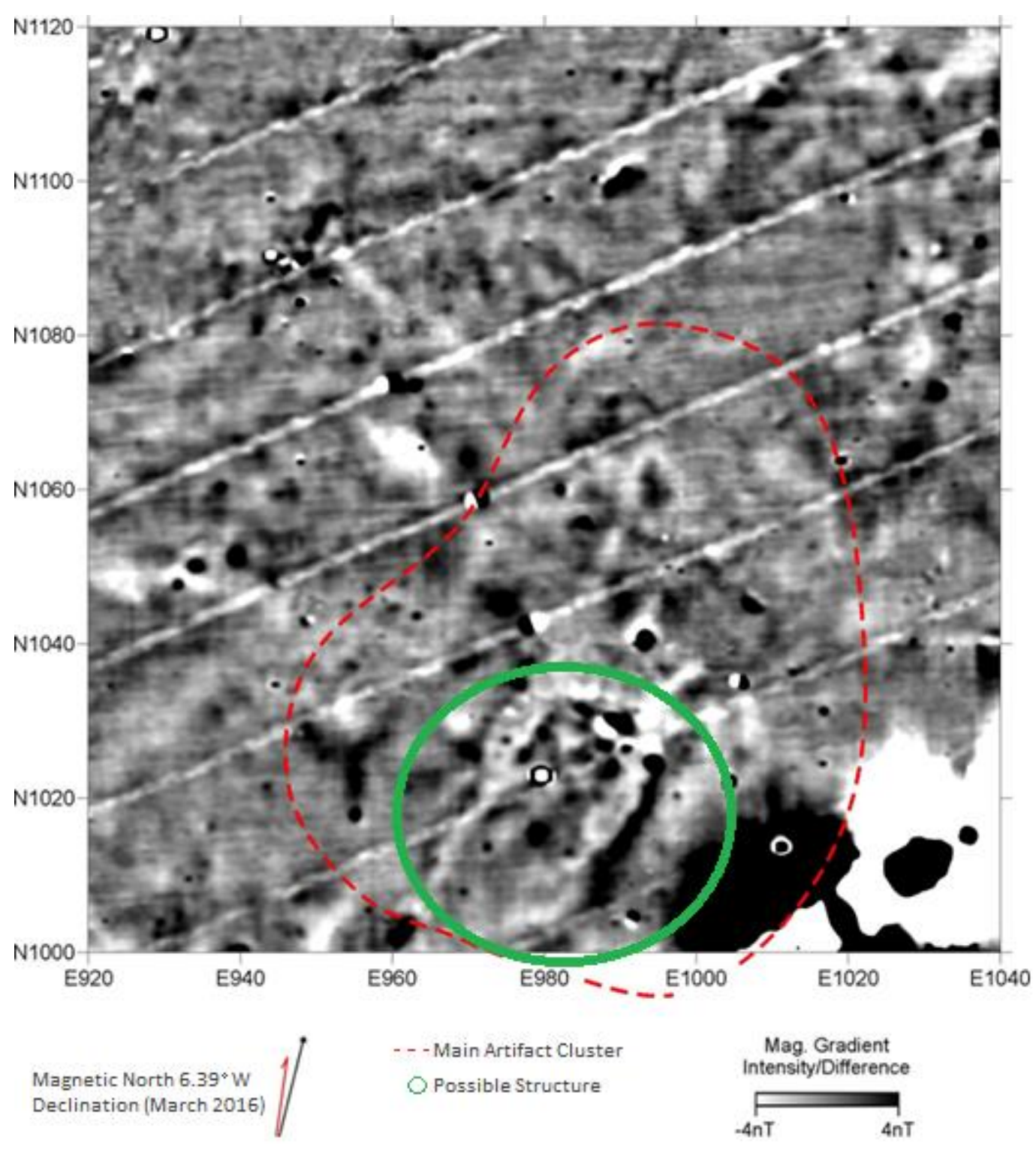

Figure 1: Magnetic susceptibility data (collected by Jarrod Burks 2016)

The Illinois State University field school excavation, led by Logan Miller, intended to investigate the possible structure and features to gain insights into upland Hopewell life (Miller and Heneghan 2018). Throughout a four-week field season, fifteen $2 \times 2$ meter units were excavated, along with a 1x1 meter unit (Figure 2). While no structure nor Hopewell features were uncovered throughout excavation, preliminary analysis by Miller and Heneghan (2018) 
described an abundance of lithic artifacts, including 47 bladelet fragments and five bladelet cores. Raw materials used to manufacture the bladelets originated from Ohio, Indiana, and Tennessee. Outside of the fire cracked rock, lithic debitage, and lithic tools, only a few ground stone tools and 12 ceramic sherds were recovered.

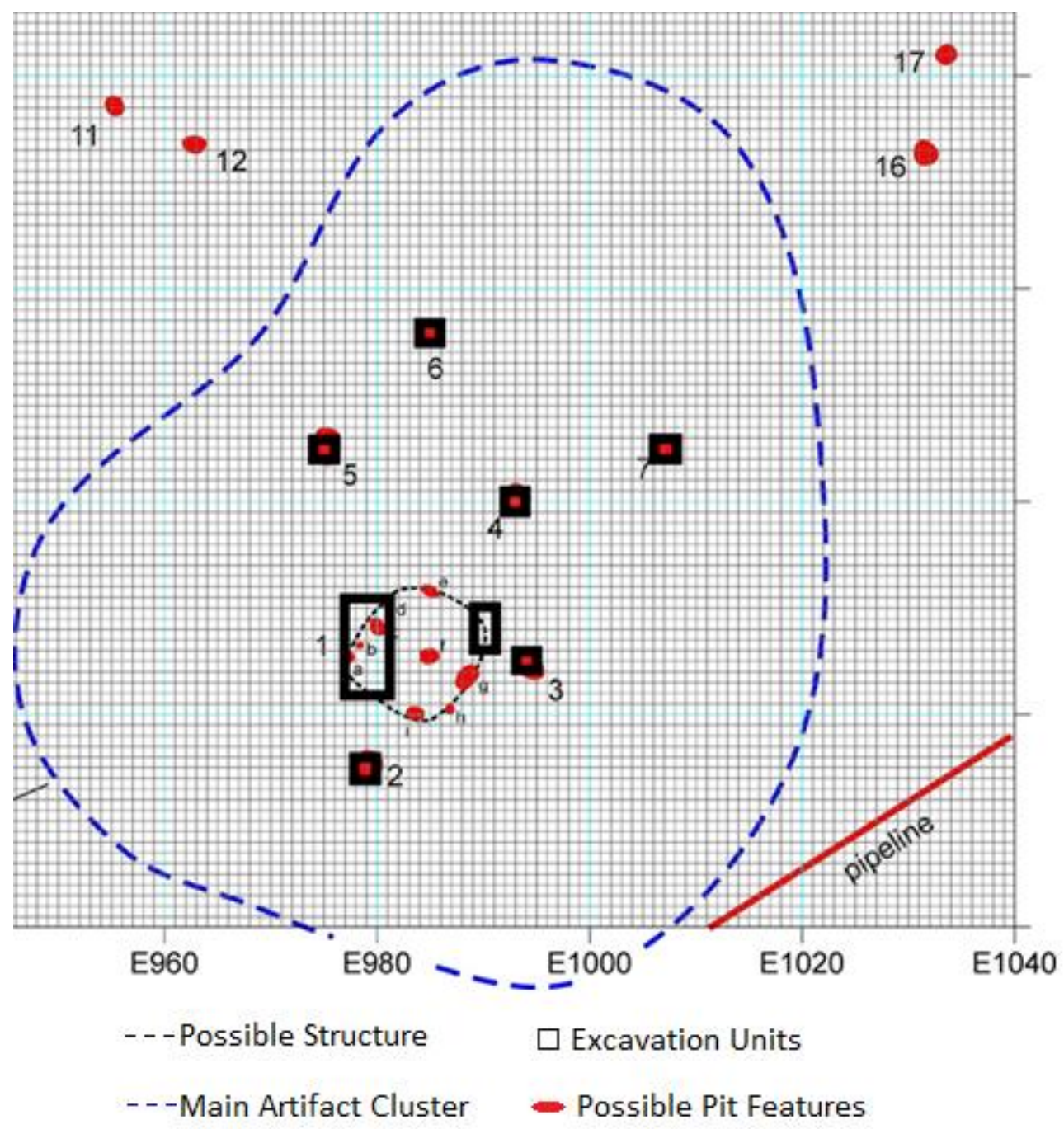

Figure 2: Geophysical survey overlaid by Miller's excavation units (Miller and Heneghan 2018)

Existing within the uplands, Spracklen would have been surrounded by old growth forests consisting predominately of oak and hickory (Miller and Heneghan 2018; Wymer 1996). 
This coincides with the presence of hickory nuts, walnuts, and raspberry seeds in the assemblage, indicating seed and nut processing. Additionally, charcoal from both oak and hickory were identified in botanical analysis, suggesting that locally available resources were utilized. Although preliminary, these botanical findings fit with the idea of Spracklen functioning as a logistical campsite for the processing of seeds and nuts located within the upland region.

Without the presence of features or a substantial ceramic assemblage, the lithic assemblage is nearly all that remains at the site. Through investigation of the lithic assemblage, we can attempt to fill in the voids and understand the function of bladelets and other lithic tools at the site. A basic understanding of tool usage at an upland campsite can aid the archaeological community in understanding the function and role of these campsites within the Hopewell community organization.

\section{Pollock Works (33GR5)}

Within proximity $(3 \mathrm{~km})$ to Spracklen, the Pollock Works is a Hopewell hilltop enclosure, occupied between 2,000 B.P and 1,800 B.P., almost entirely encompassed within a natural plateau (Figure 3) (Riordan 1995, 2010). Just north of the site flows Massie's Creek, with ancient creek channels having created a natural nine-meter cliffside to the north, east, and south. This leaves a 90-meter region to the west in which embankment walls, three to ten meters high and separated by three openings, were erected to create a barrier for the five-hectare plateau. Additionally, three to four crescent-shaped mounds were constructed to the west of the embankment wall with three small mounds between them and the wall openings, all of which have since eroded from the landscape, due in large part from agricultural and quarry activity as well as natural degradation. 


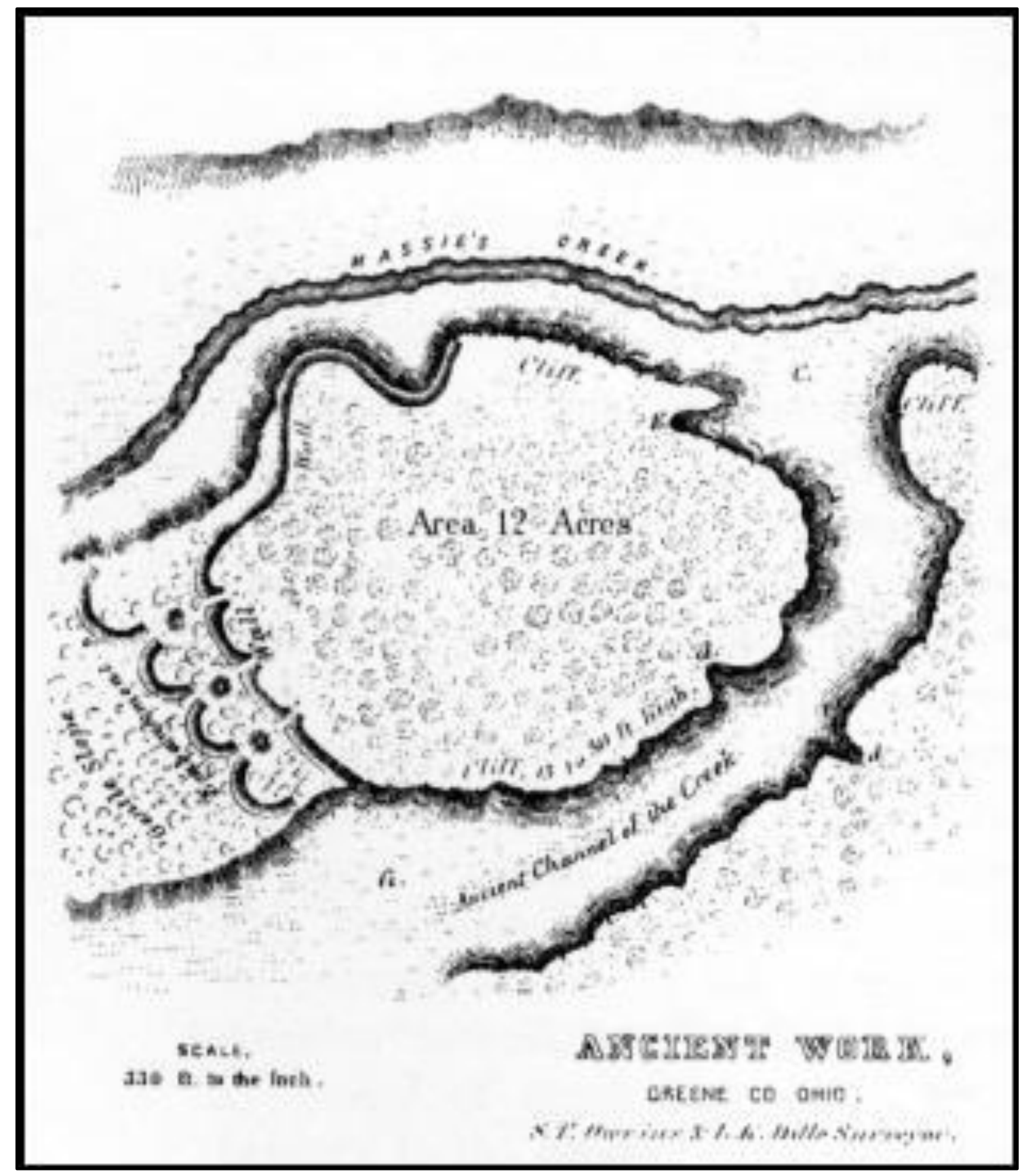

Figure 3: Pollock Works survey completed by S.T. Owens and L.K. Dille (Squier and Davis 1848)

However, excavations provided insight on the complex construction history of the site. Riordan's (1995) excavations of the embankment walls investigated the stratigraphy to 
distinguish building episodes. Separated into five building episodes, which spanned a total of 100 to 150 years, the sequence went as follows: (1) construction of the main embankment wall with one opening, (2 and 3) additions to the walls were made, increasing their height and adding the two additional openings, (4) the addition of a wooden stockade into the embankment wall, and finally (5) burning of the stockade and a capping of the walls with a layer of soil and limestone. Without the presence of the crescent-shaped walls and mounds, their order in the sequence could not be resolved. In addition to the sequencing of the site's construction, shovel tests and excavation units garnered little in the way of lithic or ceramic remnants, with Riordan (1995:83) finding "limited lithic debris, [bladelets]... a broken slate gorget, and a single fragment of... pottery" (O’Sheal 2007). However, it is through these findings and construction sequencing that an insight into the site's function has also been suggested by Riordan (1995, 2010).

Fluidity in function, much like the Fort Ancient Earthworks, occurred throughout the occupation of the Pollock Works (Riordan 1995). The lack of domestic artifacts within the hilltop enclosure, coupled with the absence of any structures, suggests a ceremonial purpose. The later construction of a stockade, however, warrants the idea of a defensive or military function to the site during the later period of its occupation. In the end, the burning of the stockade and soil capping of the embankment walls, seemingly ritual in purpose, suggest a return to the ceremonial function of the earthworks' original purpose. Nevertheless, the continued construction, without evidence of shifting cultural ideals, suggests that the Pollock Works were the product of a regional community, albeit generational, that may have centered around the earthworks. Because Pollock is close to Spracklen, I assume that the people at Spracklen were aware of the events occurring at the earthworks. 
Fort Ancient (33WA2)

Situated 40 km south of Spracklen, Fort Ancient, an Ohio Hopewell hilltop earthwork, overlooks the Little Miami River in Warren County, Ohio (Connolly 2004b; Otto 2004; Miller 2014, 2015). The earthworks, which encompass 5.7 kilometers of embankment walls, were constructed between 2,100 B.P. and 1,650 B.P., and are separated into four units: the South, Middle, and North Forts as well as the Parallel Walls to the northeast (Figure 4). These embankments range from one and a half to seven meters in height and are separated by 67 openings throughout the entire perimeter wall. Like many hilltop earthworks, Fort Ancient was believed to be a defensive fortification where people congregated during periods of stress and danger (Atwater 1820; Moorehead 1890). Today, the function of Fort Ancient is no longer believed to be defensive in purpose. Archaeologists are beginning to understand that the function of the site may have been fluid throughout its nearly 500-year occupation by the Hopewell people.

Aside from the earthen walls, the remains of structures, which Lazazzera (2004) suggested have ceremonial and domestic occupations, have been located within and surrounding Fort Ancient (Connolly 2004b; Otto 2004; Miller 2014, 2015). Lazazzera (2004) classifies these three structure types as: general domestic, specialized domestic, and specialized ceremonial. Those classified as general domestic contained an assortment of processing pits, storage pits, settlement middens, and gully trash dumps that are reminiscent of Smith's (1992) Hopewell household (Lazazzera 2004:101). Unlike the Pollock Works, which had few artifacts, Fort Ancient has an abundance of lithic (i.e. bladelets), ceramic, and faunal assemblages. It is also the diversity of both lithic and ceramic assemblages that distinguish these structures from their more specialized ceremonial counterparts. 


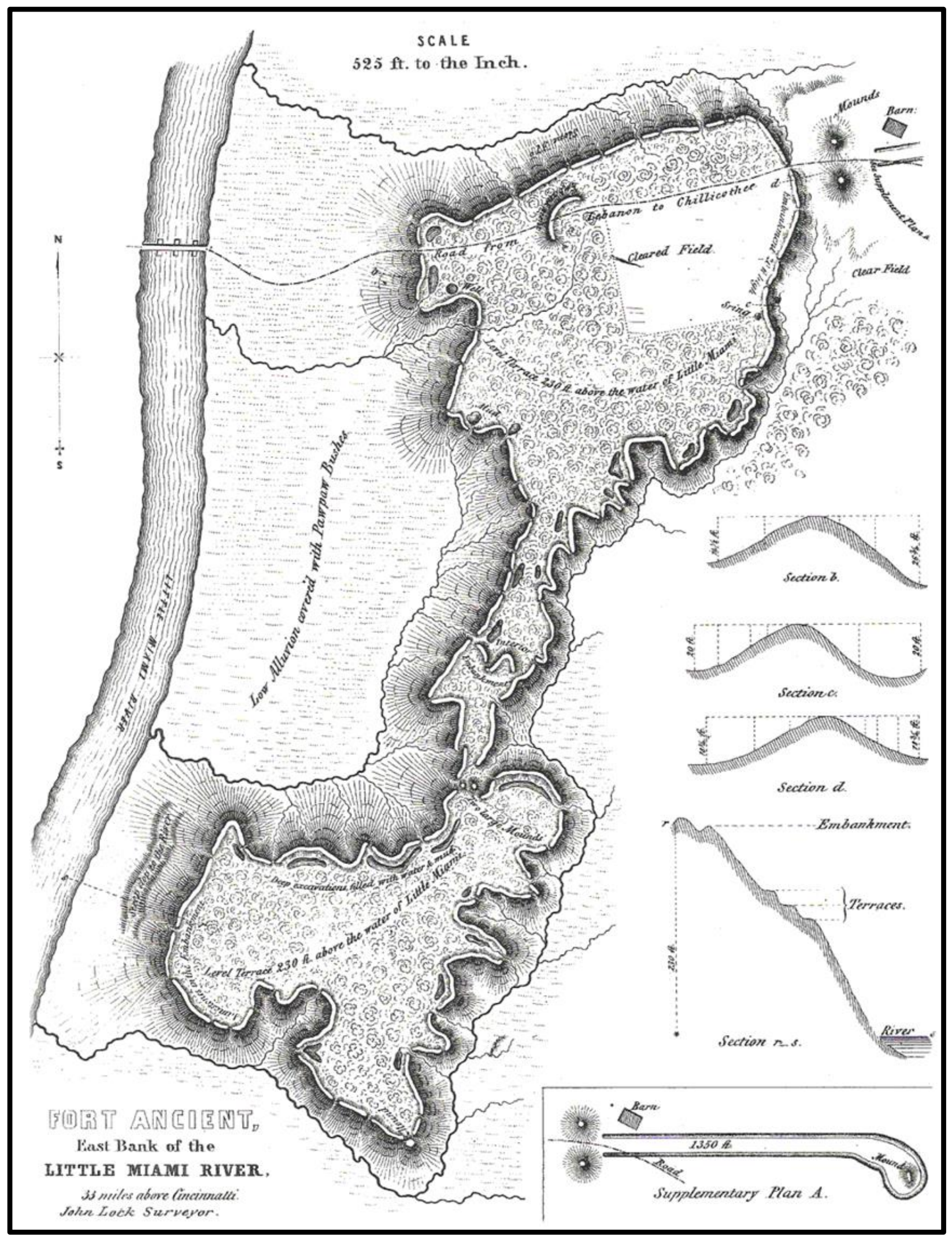

Figure 4: Fort Ancient Earthworks survey completed by John Locke (Squier and Davis 1848) 
While it has been often overlooked in supposed comprehensive investigations of the Fort Ancient site, there is as much going on outside the earthen walls as within. Artifact concentrations outside the walls, water's use as a cultural boundary, and the parallel walls noticeable in John Locke's survey compound the idea that Fort Ancient's cultural significance did not end at the earthen walls (Cowen et al. 2005; Griffin 1996). Instead, some of these artifact concentrations surrounding the parallel walls may be what remains of a domestic occupation (Connolly 1996). With centuries of looting and historic excavations, coupled with a lack of modern investigation into these regions, little can be interpreted from this northeastern portion of the site (Cowen et al. 2005). It does, nevertheless, call into question our understanding of the shifting and likely functional partitioning of all three forts and their surrounding areas..

Consistent with Prufer (1964), Connolly (2004a, 2004b) and Riordan (2004: 237) believe Fort Ancient to be a ceremonial center, "involved with the religious beliefs of a society and built as a place for community ritual and worship." The disparity, however, between the domestic structures, known as the Interior Household Cluster, within the earthworks and those ceremonial related structures provides evidence for a multi-purpose site (Connolly 2004a, 2004b; Lazazzera 2004; Riordan 2004, 2007, 2013). Additionally, Connolly (2004a:50) suggests that the presence of domestic households within the earthworks provides supplementary evidence towards the "accretive construction" of the embankment walls throughout the Hopewell timeframe. Regardless of shifting thoughts on the time, space, and function of Fort Ancient, "[t]he complexity of the constructions and the extensive evidence of human activity both inside and outside the walls indicate that [the site] was significant... for the Hopewell people" (Otto 2004:3). 
Murphy (33LI212)

Excavated between 1983 and 1986 in Licking County, Ohio, Murphy is the most extensively excavated Ohio Hopewell habitation site (Dancey 1991). Located near the Raccoon Creek, one and a half kilometers from the Alligator Mound, and three kilometers from the Newark Earthworks, the site was occupied between 100 B.C. and A.D. 225. Having been plowed for the better part of a century, much akin to Spracklen, the site's potential was recognized after surface collections yielded bladelets and bladelet cores (Cowan et al. 1981). Because of the abundance of lithic materials, Cowan and his associates generally believed that Murphy served as a bladelet production site. Nevertheless, its proximity to multiple mounds and a Licking River tributary led to the decision to excavate the site with hopes of introducing knowledge to the understanding of Hopewell life outside of their earthworks (Dancey 1991).

Very much differing from Spracklen, the Murphy site excavation uncovered 43 features including multiple hearths, pits, earth ovens, basins, and 17 postmolds. An abundance of lithics ( $\mathrm{n}>18,000)$, ceramics $(\mathrm{n}=858)$, and seeds $(\mathrm{n}=2,335)$ from the Eastern Agricultural Complex (EAC), wild berries, and nuts were identified throughout the investigation, with many being found interred within the cultural features. The lithic tool assemblage includes drills, burins, scrapers, projectile points, and projectile points crafted from both local and non-local cherts. Additionally, over 300 bladelets and 84 bladelet cores were recovered during the excavation. Yerkes (1990) microwear investigation illustrated the general use of the bladelets that were used on a variety of mediums, including mica. This general use suggests the bladelets were not involved as a part of craft specialization at Murphy.

From the distribution of pits and artifact clusters, Dancey (1991) inferred three distinct zones encompassing a structure within the site boundaries. Although a formalized floor could not 
be identified because of extensive plowing, postmolds, pits, and ovens suggest a hamlet stood at Murphy. While debitage is found throughout the site, a large quantity of materials is clustered in eastern region of the site known as the refuse zone. A clustering of earth ovens north of the structure led Dancey to identify a food processing zone. An absence of artifacts suggests an open-yard zone south of the structure. Together, these four zones constitute the Murphy site.

Radiocarbon-dating, the identification of EAC seeds, and sheer abundance of artifacts and features at Murphy allow for the argument that Murphy was a Hopewell hamlet occupied year-round (Dancey 1991). They subsisted in this location for roughly 100 years by hunting, participating in the EAC, and gathering wild berries and nuts. As a fine example of a hamlet brought forth by Prufer's (1964) model of community organization, Dancey advocates that the inhabitants communicated with other hamlets in the vicinity and congregated at nearby earthworks for communal activities.

\section{Blade Production and Use}

The production of blade cores and the blades (macroblades, microblades, and bladelets) struck from them are one such core reduction technology that is widely utilized (Brézillon 1968; Crabtree 1982; Parry 1994). Blade technologies have been argued to garner the highest efficiency among lithic tools regarding the available cutting edge produced by a mass of raw material, followed by expedient flake manufacture and core-tool technologies (Collins 1999; LeRoi-Gourhan 1943; Sheets and Muto 1972; Whittaker 1994). While blade technologies are commonplace among the Old World prehistoric cultures, its North American counterparts are restricted to nine localized industries, with the Hopewell industry broken down further with the

presence of regional variability, such as the Havana Hopewell blade and Ohio Hopewell bladelet 
(see Parry 1994). Differences among the cultures utilizing them as well as in their manufacture, form, function, and raw material makeup have been independently documented across time and space throughout North America. Nevertheless, they all consist of the blade, core, and one of two reduction methods.

\section{The Blade}

Michel Brézillon (1968) was the first to constitute a formalized definition on what makes a blade. He defined them as a flake that is at least two times as long as it is wide. However, the definition fails to cover instances where the blades have been modified, either intentionally or unintentionally, since this may affect their length to width ratio. Jay Johnson (1983) provided a more nuanced definition to what differentiates a blade from other flake technologies. He argues that blades also exhibit "a prepared broad angle platform, parallel lateral edges, and dorsal flake scars which parallel the longitudinal axis of the blade and originate from the same platform" (Johnson 1983: 50). These dorsal flake scars that are either singular or in pairs give the cross section of these blades a triangular or trapezoidal appearance (Parry 1994). With the aid of these definitions, archaeologists are better able to distinguish the standardized blade from reduction flakes that may take on a similar long and slender appearance.

Archaeologists have also subdivided blades into categories based on their form.

Microblades have been defined as being less than $30 \mathrm{~mm}$ in length (Brézillon 1968). On the other hand, blades that exceed $150 \mathrm{~mm}$ in length are often referred to as macroblades (Shafer and Hester 1983). This leaves the blades ranging between 30 and $150 \mathrm{~mm}$ to be referred to as blades or bladelets, depending on their width (Tixier 1974). These different types of blades are struck from blade cores that differ in their technological makeup. 


\section{The Blade Core}

Much can be said about the variation among differing core types, but a general differentiation will be taken to discuss two types of blade cores (Kobayashi 1970; Parry 1994). Tatsuo Kobayashi (1970), while investigating Japanese microblade production, found that there are two basic manufacturing systems among the entirety of blade industries in both the New and Old Worlds. He simply called them "Production System A" and "Production System B" (see Kobayashi 1970: 47).

System A is utilized in microblade production, where the core preform is typically a thin piece of material, such as a modified biface, flake, or shatter (Kobayashi 1970). After the platform is prepared, the blades are removed as the knapper works their way across the core. This technique is similar to burin production industries and produces shorter and thicker blades, which allow for increased force to be applied when utilized (Parry 1994). This system has been documented in four of the nine North American blade industries.

System B, which is evident in the Hopewell bladelet industry, requires the knapper to work a piece of raw material into a conical form (Kobayashi 1970; Parry 1994). Using direct and indirect percussion as well as pressure flaking, the blades are removed as the knapper works around the platform, leading to high variability in exhausted cores. Parry (1994) noted that this leads to conical, cylindrical, and tabular cores after exhaustion. Regardless of the core production method, the resulting blades prove to be vital as preforms to be further modified or for carrying out specific tasks in a variety of ways. 


\section{Summing It Up}

The technological differences in the blades and the cultural differences of the people making use of them gives rise to the notion that these industries were developed independently of one another (Parry 1994). Although they do not share a historical connection in the founding of their technological innovations, the reasoning behind their formation may lead back to similar goals. Those cultures taking part in residential mobility would benefit from an efficient utilitarian tool that could be produced from a highly portable core. The driving motivation is evident, particularly among sedentary populations, to produce large quantities of standardized blades for use as tool and tool preforms.

Going back to one of my opening statements, blade tool production has one of the highest efficiencies among tool types. This helps explain the industries who acquired materials via long distance travel or trade networks who are wishing to make the most out of what they have. Efficiency can also explain the high production of blades in sedentary populations, who found an energy and resource efficient way to produce tools that fulfilled their functional needs.

Nevertheless, it does not seem that these blades are related, but multiple cultures found a way to efficiency craft an effective and resourceful tool.

\section{Studies of the Hopewellian Bladelet}

Creating stone tools to fulfill functional needs, the Ohio Hopewell peoples of the Middle Woodland period were not so different from the cultures that preceded in time and space. However, one of those tools, both synonymous and ubiquitous with the Ohio Hopewell culture, is the prismatic bladelet (Kay and Mainfort 2014; Miller 2014, 2015; Parry 1994; Tixier 1974). Although these is slight regional variability when it comes to the size of the blades, Hopewellian 
blades and bladelets are located throughout much of the Midwest and are the most commonly recovered tool in the Hopewellian toolkit (Genheimer 1996; Kay and Mainfort 2014; Kimball 1992, Miller 2014, 2015; Odell 1994; Yerkes 1990, 1994). These tools typically range from 30$40 \mathrm{~mm}$ in length and 10-15 $\mathrm{mm}$ in width (Figure 5) and were struck using the indirect percussion method from mostly conical cores (Greber et al. 1981). Raw materials utilized to produce blades and bladelets are of very fine quality, such as Ohio Flint Ridge, Harrison County, Burlington, Cobden, and Knife River. Additionally, very few have been found to be modified from their original blade form (Odell 1985, 1987). Distinguishable from the wider blades crafted by the Havana Hopewell of Missouri and Illinois, the platforms of both blade and bladelet cores are finely prepared before the blade or bladelet can be struck in a standardized manner (Johnson 1987; Yerkes 1994). Because of this specific technique and their abundance at Ohio Hopewell sites (upwards of $75 \%$ of the tool assemblage), many lithic studies (e.g., Genheimer 1996; Kay and Mainfort 2014; Kimball 1991, 1992; Lemons and Church 1998; Miller 2014, 2015; Odell 1994; Yerkes 1990, 1994, 2009) have been focused on this particular tool.

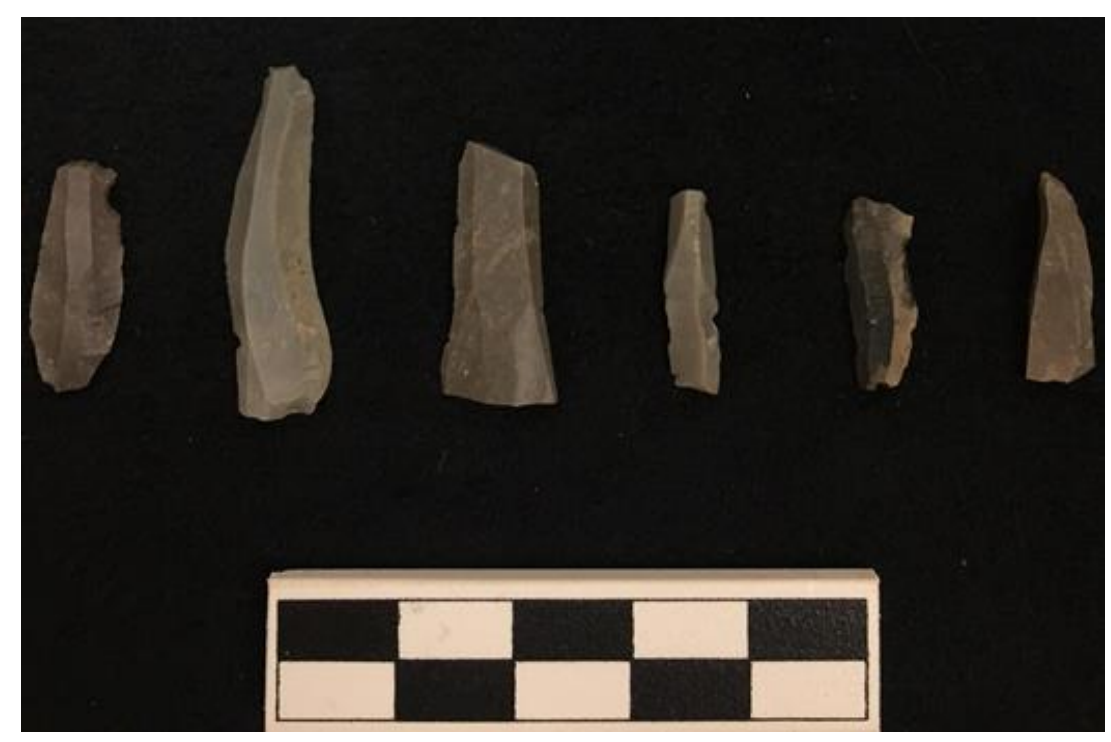

Figure 5: Sample of bladelets recovered from Spracklen 
Early studies by Struever (1964) on the Havana Hopewell blade suggested they were objects that reflected an individual's status and were utilized in both sacred and domestic facets of community life. In addition, he noted the abundance of blades, more so than any other lithic tool, associated with burials to argue that blades were buried with the dead to reiterate the individual's status. As Odell (1994) compared blade usage between domestic and mortuary contexts among the Havana Hopewell, he noticed a functional shift. Operating as generalpurpose tools with little intrinsic value in domestic settings, these same blades were restricted and concentrated to predominately the cutting and scraping of soft materials when introduced into a mortuary setting. He concludes that the blades' shift in function between contexts signifies their vital importance to the ceremonial life of the Hopewell culture.

Yerkes' (1994) investigated bladelets at the Ohio Hopewell Murphy site, a small settlement in the floodplains outside of the Newark Earthworks originally believed by Cowan and his associates (1981) to function as a center for bladelet production, but later became known as one of the more extensively excavated Ohio Hopewell habitation sites (see Dancey 1991). Thus, the microwear investigation of the tools from Murphy provides insight to the usage of bladelets in the hamlet setting. Yerkes argues that while bladelets are a part of the Hopewell Interaction Sphere, their general use in habitation sites, such as Murphy, is for the cutting of meat, plants, and hides, scraping hides, wood working, bone working, and incising stone, among other tasks. Studies from Southeastern Hopewell bladelets (Kimball 1991, 1992) reaffirm the general function of bladelets in a non-earthwork setting, namely the Garden Creek site (located in North Carolina), which included a mound, and the specialized Icehouse Bottom site (located in Tennessee). Kimball (1992) also suggests that bladelets were intentionally snapped to be used as a burin for engraving bone and antler. Many of the bladelets investigated in habitation and 
non-earthwork settings served similar functions as their biface and utilized flake counterparts (Yerkes 1994). Together, this information suggests that bladelets in the Ohio Hopewell were not associated with craft specialization.

While many of the seminal studies on Hopewell bladelets mentioned above were focused on their use in a domestic framework in floodplains surrounding earthworks (e.g., Kimball 1992; Lemons and Church 1998; Yerkes 1990, 1994), recent studies by Yerkes (2009) and Miller $(2014,2015)$ have investigated their function within the ritual economy associated with earthworks. Yerkes' (2009) investigation of Seip Mound bladelets revealed their utilitarian usage, but noted their secondary deposition as a capping event for the abandoned structures that lie beneath the mound. So, although they were being used for domestic (meat, hide, plant, bone, and wood) and crafting (mica, shell, and stone) purposes, their origin may not directly be associated with the activities that occurred at the mound.

Miller's $(20014,2015)$ studies yielded results suggesting bladelets took on differing functions depending on their locale within the earthworks, from slicing meat to scraping hides to cutting grasses and everything in between. In addition, a portion of the site associated with domestic life yielded bladelets utilized for a variety of activities in differing percentages than those associated with ceremonial portions of the site. Nevertheless, the data suggests that utilized bladelets were used for a variety of tasks, but to understand their place within the Hopewell economy the unutilized bladelets must also be taken into account. With the previous studies focusing on bladelets in floodplains and earthworks, bladelets from upland sites have not undergone similar treatment. This microwear analysis will allow for an understanding into tool use in upland settings and provide additional insight into community organization among the Ohio Hopewell. 


\section{The Study of Lithic Use-Wear and Behavioral Chain Analysis}

Late $19^{\text {th }}$ century lithic analysts, such as W. H. Holmes (1894), formally studied lithic artifacts to understand: (1) if they were created by humans, (2) the acquisition of raw materials, creation of the artifact, and how the artifact was utilized, (3) the change in form and function of artifacts throughout time and space, and (4) the history of the culture from which the artifact was crafted (Wiederhold and Pevny 2014; Yerkes and Kardulias 1993). Unfortunately, tool function is generally based upon its form and comparisons with modern-day implements (Yerkes and Kardulias 1993). Understanding the functional purpose of lithic tools is one of the driving forces behind the application of the microscopic use-wear method.

Lithic tools, including how to infer their utilization and function, have long been of interest to archaeologists. Although lithic analysts of today continue to study stone tools for use in identifying where past cultures were present in the landscape, their research has less of a chronological emphasis than the culture historians of the $19^{\text {th }}$ and early $20^{\text {th }}$ centuries. Instead, today's archaeologists are more focused on the behavioral aspects of the lithic users and cultures in their entirety. More recently, two techniques employed by archaeologists to understand the behavior of past cultures include experimental archaeology and microwear analysis. After the "New Archaeology" movement, both experimental archaeology and microwear analysis began to see widespread use within the discipline.

\section{Use-Wear Methods are Grounded in Processual Thought}

After decades of culture history and explaining the chronology of the past through unique and seemingly individual events based on artifact typologies, archaeologists began to discuss needed change in method and theory (Praetzellis 2015). Lewis Binford, Walter Taylor, and 
David Clarke were three of the first archaeologists to criticize the culture history approach and emphasize the need to understand why these cultural changes are evident in the archaeological record (O'Brien, Lyman, and Schiffer 2005). They felt that cultures should not be defined by a set of artifacts, but instead the artifacts should be viewed as reflections of total cultural systems and an emphasis placed on artifact function. It was this interest in process, both cultural and behavioral, that provided us with the name processual archaeology or New Archaeology. Methodologically, the processual archaeologists emphasized the scientific method and controlling the quality of data (Praetzellis 2015). By implementing the scientific method, controlling the quality of data and having reproducible results were realistic possibilities. One way in which archaeologists could go about this was with the introduction of experimental archaeology. Additionally, the analysis of microscopic polishes and striations has shown that differing contact materials used in a variety of motions leave different marks (Yerkes and Kardulias 1993). By closely examining the variation in these micropolishes and striations, lithic analysts improved the functional categories placed upon these lithic tools. This has allowed for the formulation of standardized techniques and the procedural thoroughness that was desired from New Archaeologists (Binford 1983; Yerkes and Kardulias 1993). Together, through the implementation of experimental archaeology and microscopic use-wear studies, lithic analysts could bolster their claims as a hard-science.

\section{Microwear Analysis}

Long before Sergei Semenov’s (1964) seminal microwear studies revolutionized the way Western archaeologists would study stone tools, Rau (1869) and Spurrell (1892) published their findings on the use-wear polish of hoes and sickle blades, respectively. Spurrell noticed, with his 
naked eye, the "corn gloss" that began to appear on the sickles after repetitive use in the field. Additionally, O. G. S. Crawford (1935) described sheen, in the form of polish exhibited on sledge flints. Their ability to detect the polishes with an unaided eye classifies these use-wear studies as being macroscopic instead of the microscopic studies of Semenov. Nevertheless, the studies proved to be two of the first accounts on the recognition of polish forming from repetitive tool usage.

Following the Russian Revolution of 1917, archaeology in the Soviet Union drew upon Marxist history and its accompanying interest in production techniques (Murray 2007). Through this newly-formed Russian archaeology, Semenov (1964) conducted experimental studies throughout the 1930s to investigate use-wear on stone tools under a low magnification binocular microscope (Murray 2007, Wiederhold and Pevny 2014; Yerkes and Kardulias 1993). His experimental archaeology approach, which is still employed by lithic analysts today, involved creating replica tools that he preceded to use on an assortment of materials in a variety of motions. Through this experimental research, he created a comparative collection of tools associated with the Paleo- and Neolithic peoples of the Eurasian region and developed a way of identifying use-wear under a microscope. However, it was not until M. W. Thompson translated Semenov's book in 1964 that Western archaeologists were able to fully take note of Semenov's achievements and begin implementing his methods into their own research and thus revolutionizing lithic analysis (Murray 2007).

After arrival into the Western world, Semenov's technique, commonly referred to as the low-power/magnification method, was used extensively by Tringham (1974) and Odell (1980, 1981a, 1981b). They utilized this approach to classify the use-wear on a microscopic scale (typically between 10x and 60x magnification) using damage on the edge of the tool and the 
striations that accompany it (Wiederhold and Pevny 2014; Yerkes and Kardulias 1993). In doing so, identification of the worked material (in the form of hardness) could be determined, along with the kinematics (e.g., cutting, slicing, drilling, sawing, etc.) associated with the material in contact with the tool.

In contrast to the low-power methods utilized by lithic analysts, Keeley (1980) began publishing data on the distinguishable polishes observable using the high-power/magnification method. This technique employs magnifications between 50x and 500x to identify use-wear micropolishes diagnostic to the material worked (e.g., wood, grass, bone, meat, hide, etc.) as well as edge damage and striations. The combination of these three observations allow for identification of how the tool was used, the area utilized on the tool, and the contact material (Wiederhold and Pevny 2014; Yerkes and Kardulias 1993). It is this identification of worked material classes, rather than hardness categories, that distinguishes the high-power method apart from the low-power technique, thus it also makes comparing data on the two methods problematic (Miller 2014). Many of the recent microwear studies conducted on lithics in the Midwest region have implemented this high-power approach (see Genheimer 1996; Kay and Mainfort 2014; Kimball 1992; Lemons and Church 1998; Miller 2014, 2015; Yerkes 1990, 1994).

\section{Behavioral Chain Analysis}

Being that the clear majority of Spracklen's assemblage is the lithic remnants left behind from the inhabitants, making use of Schiffer's (1975) behavioral chain analysis has allowed for a greater argument to be made about the site's function and its place within the Hopewell community. Behavioral chain analysis was Schiffer's response to Hill's (1970) attempt at 
breaking down differing activities occurring within a single pueblo. Schiffer (1975: 104) argues that Hill's (1970) method carries the assumption that refuse is discarded where it was utilized, while overlooking the possibility of secondary and de facto refuse. Another weakness that Schiffer (1975: 105) addresses is Hill's (1970) understanding of activity space within a pueblo is based solely on ethnographic data. Building upon the limitations and weaknesses in Hill's method, Schiffer (1975) set forth on creating a stronger model that is not limited by a lack of ethnographic comparisons and a direct knowledge of refuse practices.

Before Schiffer's (1975) method is implemented, it is required that data and knowledge is known from other sites within the region, which is applied into the analysis. After a determination of the activities that occurred at the site, a better understanding of their provenance within the site can be obtained. To come to this understanding, behavioral chain analysis modifies Hill's (1970) method by introducing behavioral chains that are made up of chain segments. Behavioral chains are the entire sequence that an artifact or site goes through from beginning to end (Schiffer 1975). For a lithic assemblage, this includes the acquisition of the raw material to its subsequent deposition as refuse. A chain segment is a specific portion of the behavioral chain that can be investigated further. For example, the production of a lithic tool and its utilization are two segments within the all-encompassing behavioral chain. By the breakdown of a behavioral chain into chain segments, Schiffer (1975: 112) argues "one can follow the cultural pathways to the archaeological record and make activity documentation more secure." As such, these chains allow for an understanding of activities at the site that do not always have direct evidence of their occurrence, which is how it provides insight into the activities that occurred at Spracklen. With a regional-wide scope, behavioral chain analysis provides insight upland site function within Hopewell community organization. 


\section{In Summary}

The Ohio Hopewell culture experienced unity through community earthworks, with people coming far and wide to gather for ceremony and trade. While Prufer's $(1965,1967)$ model discusses this community organization, which encompasses the earthworks and surrounding domestic hamlets and campsites in the floodplains, upland contexts are poorly understood and vastly understudied. However, with an increase in cultural resource management (CRM) and academic archaeology in these upland regions, sites such as Jonah's Run and Spracklen are being located and excavated. Yet, little is still known about their function and place within the Hopewell community. Coupled with an understanding of the reliance on bladelets by the Hopewell people, a lithic analysis that will encompass raw material identification, debitage analysis, and microwear analysis will allow for insight into some of these questions regarding daily life among the Hopewell, the purpose of upland dwellings, and the use of bladelets in these upland settings. 


\section{CHAPTER III: LITHIC INVESTIGATIONS AT SPRACKLEN}

In this study, I analyzed the lithic assemblage and spatial attributes from the Spracklen site using an assortment of techniques. A focus on the tools (bladelets, unifaces, bifaces, and utilized flakes) allows for the determination of their function in this domestic, upland setting. Additionally, an understanding of tool usage at Spracklen provides insight into the placement and purpose of the site. This study is split into three phases: (a) debitage analysis, (b) microwear analysis, and (c) reverse site suitability. The results from the lithic analyses are compared to tools and debitage at Fort Ancient Earthworks and Pollock Works, along with other sites in the region to investigate possible variations between ceremonial and upland sites.

\section{Materials and Methods}

\section{Materials}

After the conclusion of the 2016 excavation of the Spracklen site, the analysis of over 4,800 artifacts began. Outside of a few historic artifacts and less than ten ceramic body sherds, the collection was dominated by the lithic assemblage, with over 3,600 pieces of lithic debitage. Length, width, thickness, and weight measurements were recorded for each artifact. During this cataloging process, the lithic assemblage was also separated into tools, debitage, and cores. From here, the assemblage underwent further analysis, described below, to understand its utilization from Spracklen's inhabitants. 


\section{Chert Sourcing Methods}

While visual chert sourcing can be subjective, it also provides the most economical means of insight into the origins of the materials present at an archaeological site. The lithic comparative collection from the Midwest Archaeological Lab at Illinois State University, along with DeRegnaucourt and Georgiady's (1998) chert identification manual, aided in the sourcing of the entire lithic assemblage. For those that were unidentifiable through these means of identifcation, they were labelled as unknowns. Additionally, similar methods were employed at the Fort Ancient Earthworks (Connolly 1991, 1997) and the Pollock Works (O'Sheal 2007), allowing direct comparison between the sites.

\section{Debitage Categorization Methods}

For a comparison with the debitage collected from the Fort Ancient Earthworks (Connolly 1991, 1997), Sullivan and Rozen's (1985) debitage categorization was applied to the debitage gathered from Spracklen. This approach to debitage analysis intends to limit user functional interpretations of the debitage. Instead, a three-step dichotomous key was implemented (see Sullivan and Rozen 1985: 759) (Figure 6), allowing for a less subjective way to create four unique categories from the debitage. 


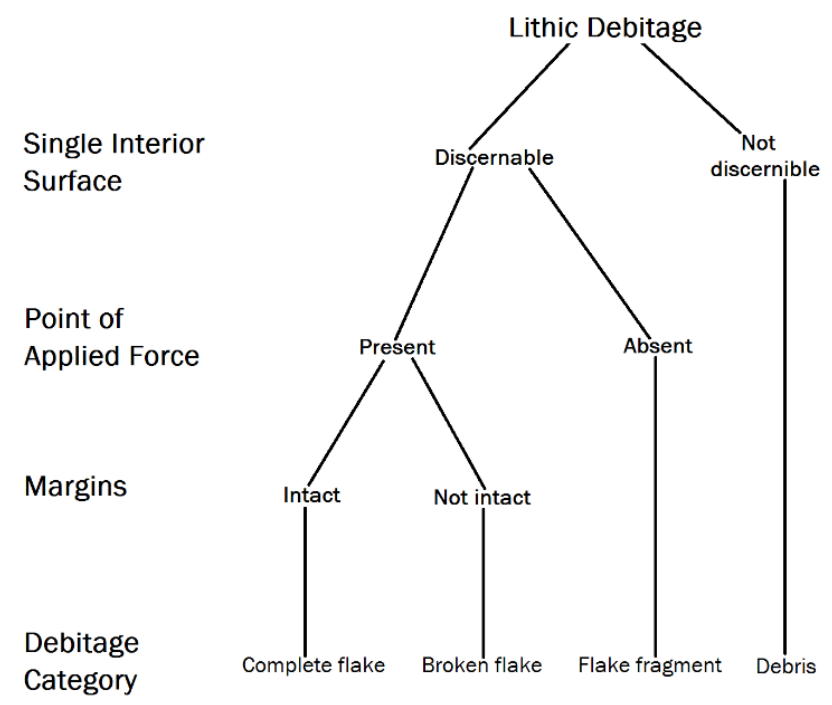

Figure 6: Dichotomous key for debitage categorization (adopted from Sullivan and Rozen 1985)

The initial dichotomous choice requires the positive identification of a single interior (Sullivan and Rozen 1985). This positive identification, exemplified by a bulb of percussion and radiating outward ripples, demonstrations that the debitage was removed using the traditional percussion method and can move on to second dichotomous choice (Speth 1972:35). If there are zero or more than one interior surfaces, then the debitage is labelled as lithic shatter or debris and identification is complete. The second step involves the identification of a point of applied force on the debitage. If the striking platform is completely or partially identifiable, then the debitage moves on to the final step. Those where no striking platform is identified are labelled as distal or medial flake fragments. The final dichotomous step separates complete flakes, as those with complete margins on either side, from ventral flake fragments. All encompassing, this three-step dichotomous test allowed for the debitage to be placed into four separate categories that suffer from less user-interpretation and can be further evaluated in other lithic analyses. 


\section{Complete Flake Analysis Methods}

The relative thicknesses $\left(\frac{\text { length }+ \text { width }}{\text { thickness }}\right)$ of the previously identified complete flakes were calculated and separated by raw-material type. From here, the median relative thickness was plotted against median thickness (proxy for flake size) for each of the identified raw-material types identified at Spracklen. With smaller sample sizes for a few of the chert types, medians applied to limit the impact of outliers. Sullivan and Rozen's (1985:765) method allowed for the characterization of debitage resulting from unintensive and intensive core reduction and tool manufacture. Contrasting both types of core reduction, debitage that is the product of tool manufacture exhibits thinner flakes, while exhibiting an increase in overall relative thickness. This data was also compiled by Connolly $(1991,1997)$ to understand how debitage was accrued at the Fort Ancient Earthworks and those findings will be compared with those from Spracklen.

\section{Microwear Analysis Methods}

Microwear analysis is the primary way for lithic analysts to uncover the function of a utilized tool (Wiederhold and Pevny 2014). For this reason, the tools identified, consisting of bladelets, unifaces, bifaces, cores and flakes, were examined using an Olympus BX51M with 50 - 500x magnification. Comparison with replica tools utilized on known mediums, allowed for the identification of micropolishes and striations on the tools. By identifying the function of the tools found at Spracklen, this study explored the activities by the former inhabitants of the site.

This process began with obtaining replica bladelets that I employed on fresh plant material (corn stalk), wood, and deer antler in two separate motions. On one side of a bladelet, I scraped for 30 minutes, utilizing the opposite side to cut the same contact material for 30 additional minutes. The comparative collection, in groups of four, was then pulsated using an 
ultrasonic cleaner for ten minutes in dish soap, before another ten-minute session in lukewarm water. This process removes the oils and residues that obscure the lithic analyst from identifying polishes on the lithics. All the while, I familiarized myself with other contact materials by studying images from Dr. Miller's comparative collection and other published microwear images and descriptions.

The comparative collection allowed for my familiarization with the how striations and micropolishes form, the microscope, and the entirety of the microwear process. As the tool comes into repeated contact with a material, its edge begins to slowly degrade. Repeating this motion over a period leaves edge damage and a flattening of the tool surface, the latter of which reflects under the light emitted from the microscope. It is this flattened surface that is diagnostic of the worked contact material. Moreover, repetitional motion creates striation on the tool that provide an analyst with information regarding tool function. Depending on the size of the artifact, surface undulations, and chert type, an exhaustive microwear analysis can range anywhere between ten minutes to over an hour, but experience is gained from repetition.

After feeling comfortable with this process, I began washing and analyzing 89 lithic artifacts that included bladelets, bladelet cores, bifaces, and flakes from Spracklen. I selected these artifacts because their morphology suggested they were the most likely implements in the assemblage to have been utilized. The remainder of the lithic artifacts consisted of exceedingly small flakes (Miller and Heneghan 2018). An Excel database was formed to record whether the artifact exhibited micropolishes, the identification of contact material (i.e. plant, wood, meat, hide, bone, etc.), the motion utilized (i.e. cutting, scraping, butchery, etc.), and any further notes (such as evidence of hafting) that were worthy of being recorded (Appendix A). Throughout the entirety of the process, images were captured in 50x, 10x, 200x, and 500x magnification and 
guidance from Dr. Miller aided in the identification process. These results will then be compared to Miller's $(2014,2015)$ inquiry into Hopewellian bladelet usage at Fort Ancient as well as other non-earthwork (Kimball 1992; Lemons and Church 1998; Yerkes 1990, 1994) and earthwork (Yerkes 2009) locales.

\section{Results and Discussions}

\section{Chert Sourcing Results}

A total of 4,090 pieces of debitage were recovered from the Spracklen site. As noted in the site description above, few of these came from features. Because of these disturbances and the site-wide investigation, the inter-site provenience of the debitage was not of great concern, and I treat the entire assemblage as one analytical unit. With the extremely small nature of some debitage, only $90 \%$ (3,679 of 4,090 pieces) of the assemblage underwent chert sourcing. The remaining $10 \%$ of the collection were flakes that were too small to be visually identified.

Similar to other Ohio Hopewell sites, the Spracklen debitage exhibited a heavy reliance on non-local cherts from Indiana and south-central Ohio (Figure 7) (Miller and Heneghan 2018). Of the 3,679 pieces of debitage examined, 2,560 (70\%) were from the Harrison County outcrops in southern Indiana. Flint Ridge $(\mathrm{n}=117,3 \%)$, Upper Mercer $(\mathrm{n}=103,3 \%)$, and Delaware $(\mathrm{n}=$ 94, $2 \%$ ) are other noteworthy non-local cherts identified within the debitage assemblage. Another $11 \%$ of the assemblage were from the locally sourced Cedarville Guelph chert $(\mathrm{n}=$ 408). A remaining 397 pieces $(11 \%)$ were not identifiable, but it is likely that they constitute both non-local and local chert types. 


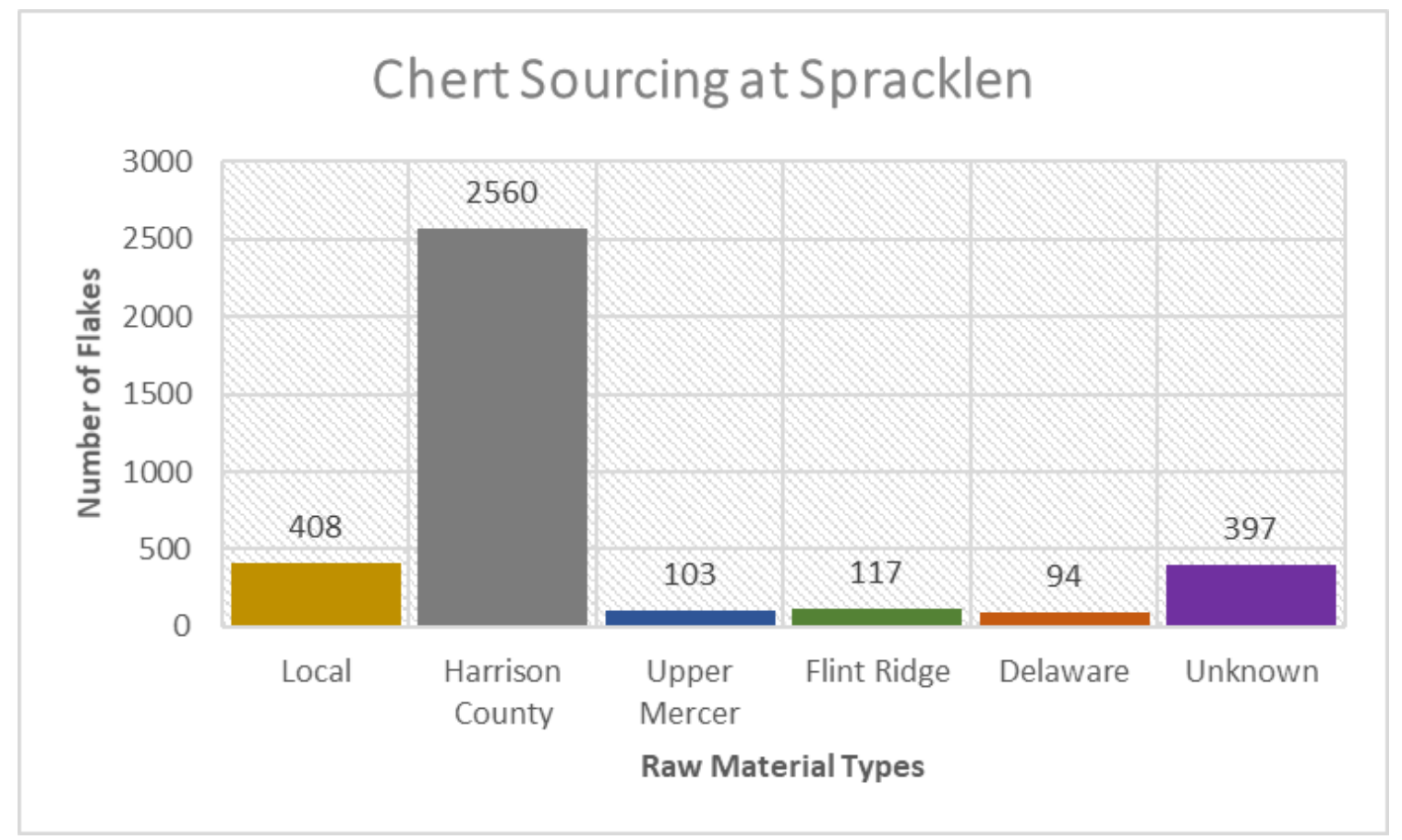

Figure 7: Chert types of debitage at Spracklen

In addition to the over 4,000 pieces of debitage, 54 bladelets were recovered at Spracklen (Figure 8). Of these bladelets, $79 \%(n=43)$ were crafted from Harrison County chert. An additional 17\% $(\mathrm{n}=9)$ are from Flint Ridge outcroppings in southern Ohio, while the remaining 4\% $(\mathrm{n}=2)$ were manufactured from Upper Mercer flint. With a mean maximum width of $10.3 \mathrm{~mm}(\mathrm{SD}=3.3 \mathrm{~mm})$ and mean maximum thickness of $3.1 \mathrm{~mm}(\mathrm{SD}=1.3 \mathrm{~mm})$, Miller and Heneghan (2018) argue that the bladelets recovered are typical of Ohio Hopewell sites (see Gerber et al. 1981). 


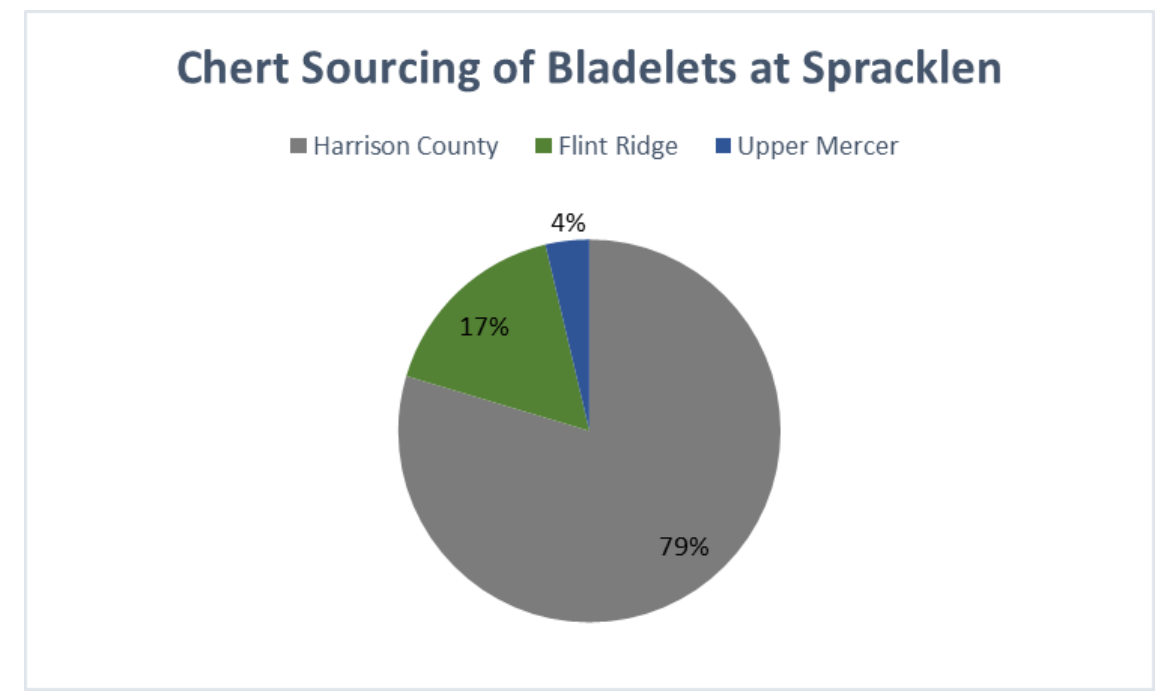

Figure 8: Chert types of bladelets at Spracklen

Evidence for bladelet manufacture is present at the site, with a recovered bladelet core rejuvenation flake (Figure 9 on left) crafted from Harrison County flint (Miller and Heneghan 2018). Additionally, nine complete and fragmentary bladelet cores (Figure 9 on right) were recovered and manufactured from non-local chert types. Six were crafted from Harrison County, two were Upper Mercer, while the remaining core was manufactured from Flint Ridge chert. The non-local origins of the bladelets and blade cores is commonly noted among Ohio Hopewell sites (Gerber et al. 1981, Miller 2015, Miller and Heneghan 2018).

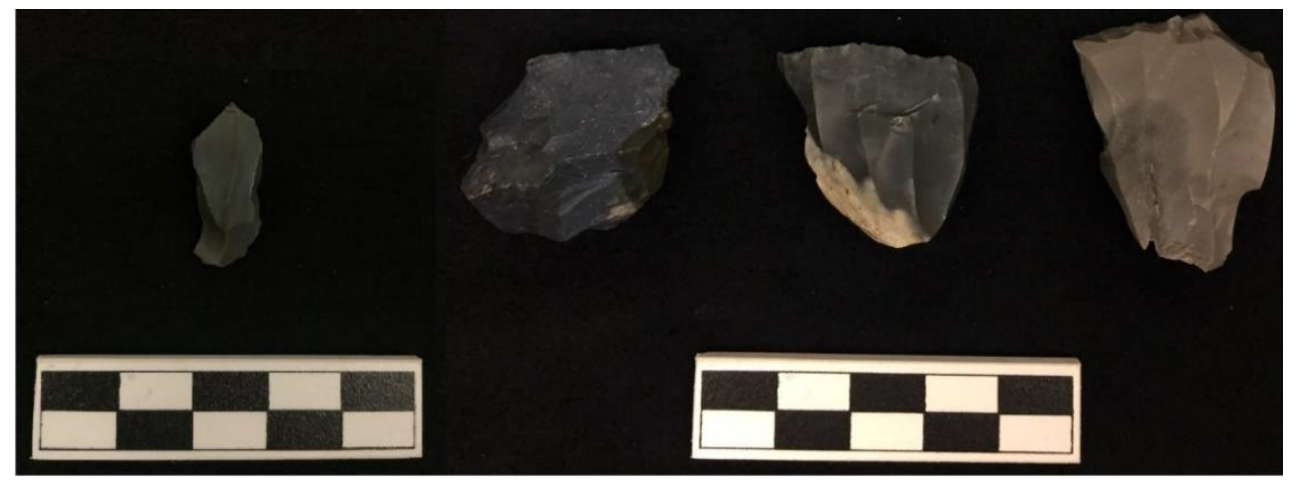

Figure 9: Bladelet core rejuvenation flake (left) and bladelet cores from Spracklen (right) 


\section{Chert Sourcing Discussion}

Hopewellian people often exchanged non-local cherts as part of the Hopewell Interaction Sphere (Caldwell 1964; Hall 1979, 1997; Yerkes 2002). Unlike trading in Mississippian chiefdoms, in which wealth was accrued by the elites within the community, Hall (1997) proposes that people within the Hopewell culture were egalitarian, and thus increased their status by the giving of goods to others. The abundance of non-local cherts and ceremonial resources as well as the accompanying community creation of earthworks and mounds would support this idea of accruing status through gift giving.

With the utilization of non-local cherts resonating throughout the Hopewell culture, the abundance of non-local cherts can often be noted throughout Hopewell sites (Pacheco 1997; Yerkes 2002). Due to the short-term episodic occupations of Spracklen, the site can provide us with an event in the archaeological record. By comparing these results to the Pollock Works (O'Sheal 2007) and Fort Ancient (Connolly 1991, 1997; Miller 2014, 2015), similarities and differences in their lithic assemblages are identified. Raw material sourcing, particularly among the Ohio Hopewell, allows for insight into trade polity and provides clues as to whether sites in the upland region may have been footprints of the same groups of people (Struever 1964; Tykot 2003).

The people of Spracklen were relying predominantly on non-local cherts (78\% of total assemblage), with Harrison County chert constituting nearly $70 \%$ of the debitage recovered. These results are similar to those found at the Fort Ancient Earthworks, where the people left behind predominately non-local cherts of the Harrison County and Flint Ridge varieties (see Connolly 1991, 1997; Miller 2014, 2015). While the reliance on these non-local cherts exists at these two sites, discrepancies exist with the greater abundance of Flint Ridge (24.7\% of total 
assemblage) exhibited at Fort Ancient (Connolly 1997). This difference is likely linked to Fort Ancient serving as a regional trading hub and ceremonial complex and allowing for the congregation of Hopewellians from various areas coming together, while Spracklen was occupied for a short period time by a small number of individuals (Connolly 2004a, 2004b; Lazazzera 2004; Prufer 1964; Riordan 2004, 2007, 2013).

Larger discrepancies are apparent between the utilized chert at Spracklen and the nearby Pollock Works (see O’Sheal 2007). Excavations at Pollock recovered only one piece of debitage classified as either Wyandotte or Harrison County, while the non-local assemblage was predominately Upper Mercer (23\% of total assemblage) and Flint Ridge (14\% of total assemblage). Several possibilities may account for these differences. These differences could be linked to analyst errors in raw material identification in one or both cases and our inability to source the unknowns in the respective assemblages. O'Sheal (2007) has a limited amount of lithics (772 total) with over $34 \%$ denoted as unknowns. It is possible that Harrison County could be in this classification or mixed with the Delaware and Upper Mercer chert types that exhibit a similar appearance. Additionally, it is possible that the occupation of the two sites occurred at different times, which would account for differences in assemblages. Lastly, with much of Pollock being unexcavated, it is possible that a cache of Harrison County chert has not been located. With such a close distance between the two sites, the expectation of similar chert materials would be expected, but these differences could indicate that the people of Spracklen were not the same people utilizing the earthworks between 2,000 and 1,800 B.P. (Riordan 1995, 2010). 


\section{Debitage Categorization Results}

Utilization of Sullivan and Rozen's (1985) categorization method limits the functional interpretations subjectively placed on debitage. The results allow for the identification of four unique categories free of these subjective interpretations. After implementation of their methods, the Spracklen assemblage consisted of $4 \%(n=136)$ debris and $65 \%(n=2,408)$ fragments. Broken flakes constitute 23\% ( $\mathrm{n}=830)$ of the flakes at Spracklen, with the remaining 8\% ( $\mathrm{n}=$ 305) being complete (Figure 10) (Miller and Heneghan 2018). Sullivan and Rozen (1985) argue that higher ratios of broken flakes and flake fragments are the result of tool manufacturing. The long-documented historical and modern agricultural plowing, however, further exacerbates fragmentation and limits the usefulness of this information (Miller and Heneghan 2018). Length, width, and thickness measurements were found for the complete flakes, and their relative thicknesses recorded.

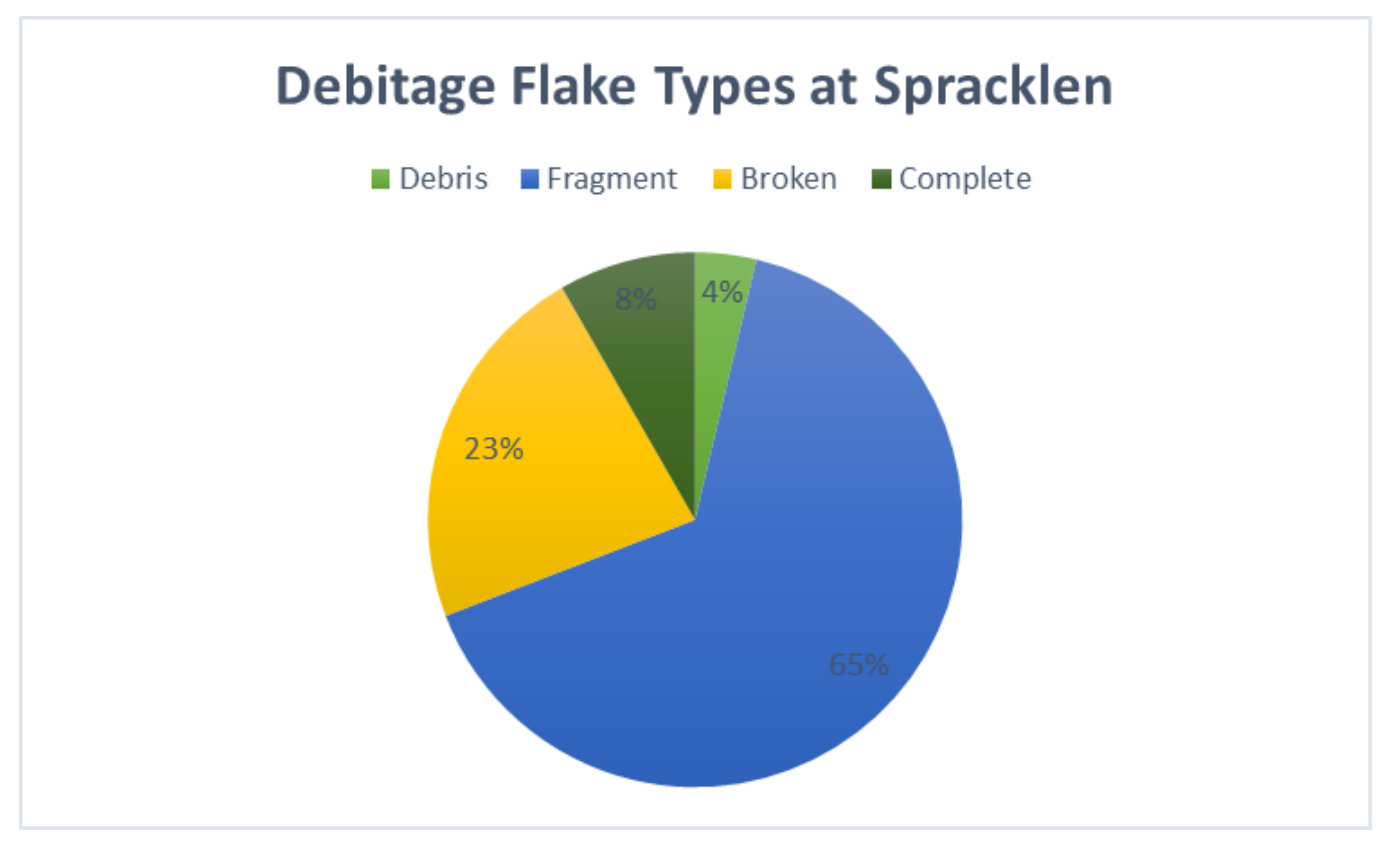

Figure 10: Debitage types at Spracklen (based on Sullivan and Rozen 1985) 
Identification of the 305 complete flakes allowed for further inquiry into the stage of production occurring at the site. (Miller and Heneghan 2018). This method, initially employed by Sullivan and Rozen (1985), allows for the identification of signatures relating to both intensive and unintesive core reduction and tool manufacture. Drawing upon their studies and those previously applied to the Fort Ancient Debitage by Connolly (1991), 1997), relative thickness values $\left(\frac{\text { length }+ \text { width }}{\text { thickness }}\right)$ were formulated for each complete flake. To account for smaller sample sizes that may have been otherwise skewed by outliers, the median values for each chert type were calculated (Table 1). This allowed for a comparison of median relative thickness against median complete thickness for the identified chert types at Spracklen (Figure 11). The same was done for median weight (Figure 12).

Table 1. Complete Flakes Recovered from Spracklen (Miller and Heneghan 2018)

\begin{tabular}{llll}
\hline Raw Material & $\mathrm{N}$ & Median Relative Thickness & Median Thickness (mm) \\
\hline Local & 57 & 7.6 & 3.6 \\
Harrison County & 200 & 10.5 & 2.2 \\
Flint Ridge & 13 & 10.8 & 1.9 \\
Upper Mercer & 3 & 9.0 & 1.3 \\
Delaware & 3 & 13.8 & 3.3 \\
Unknown & 29 & 9.0 & 2.4 \\
\hline
\end{tabular}




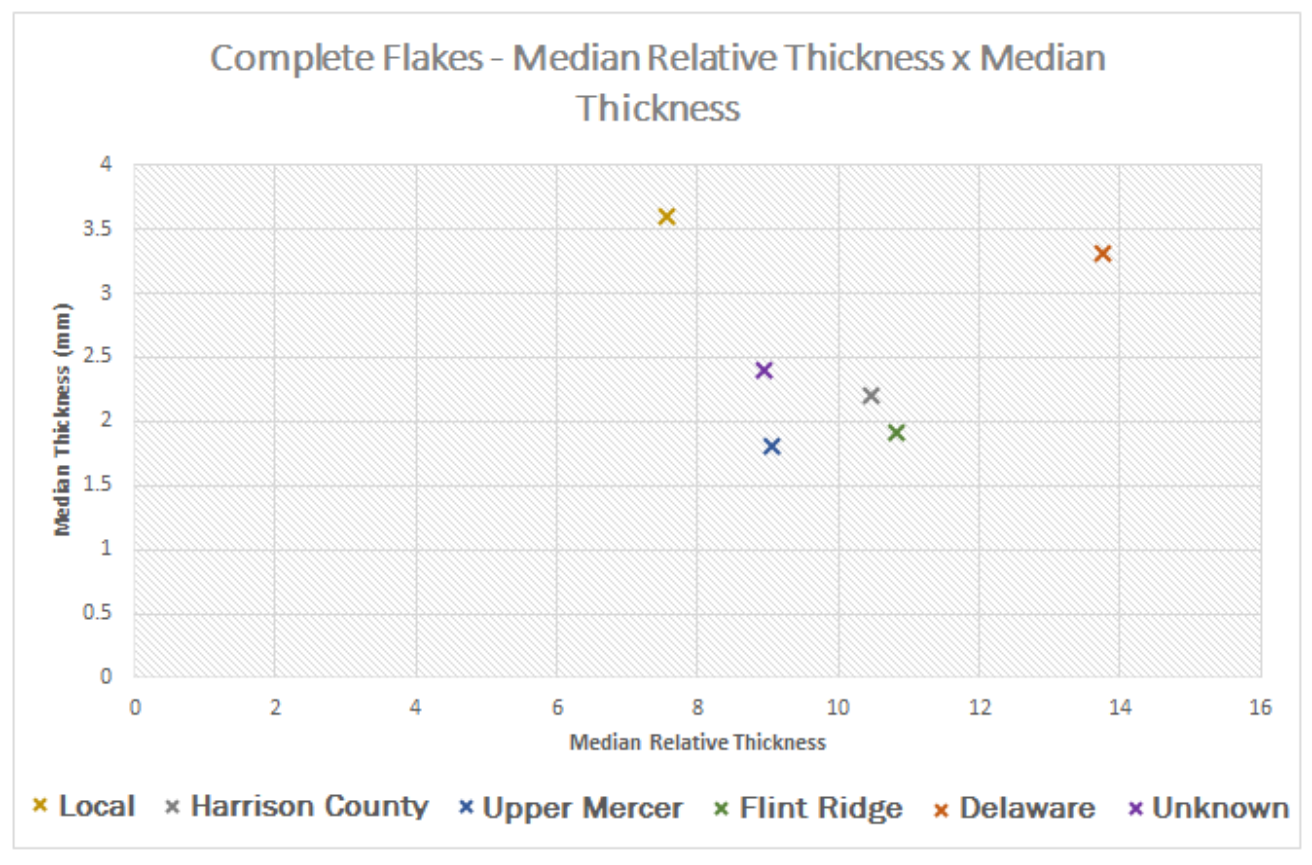

Figure 11: Plotting median relative thickness against median thickness for complete flakes recovered from Spracklen

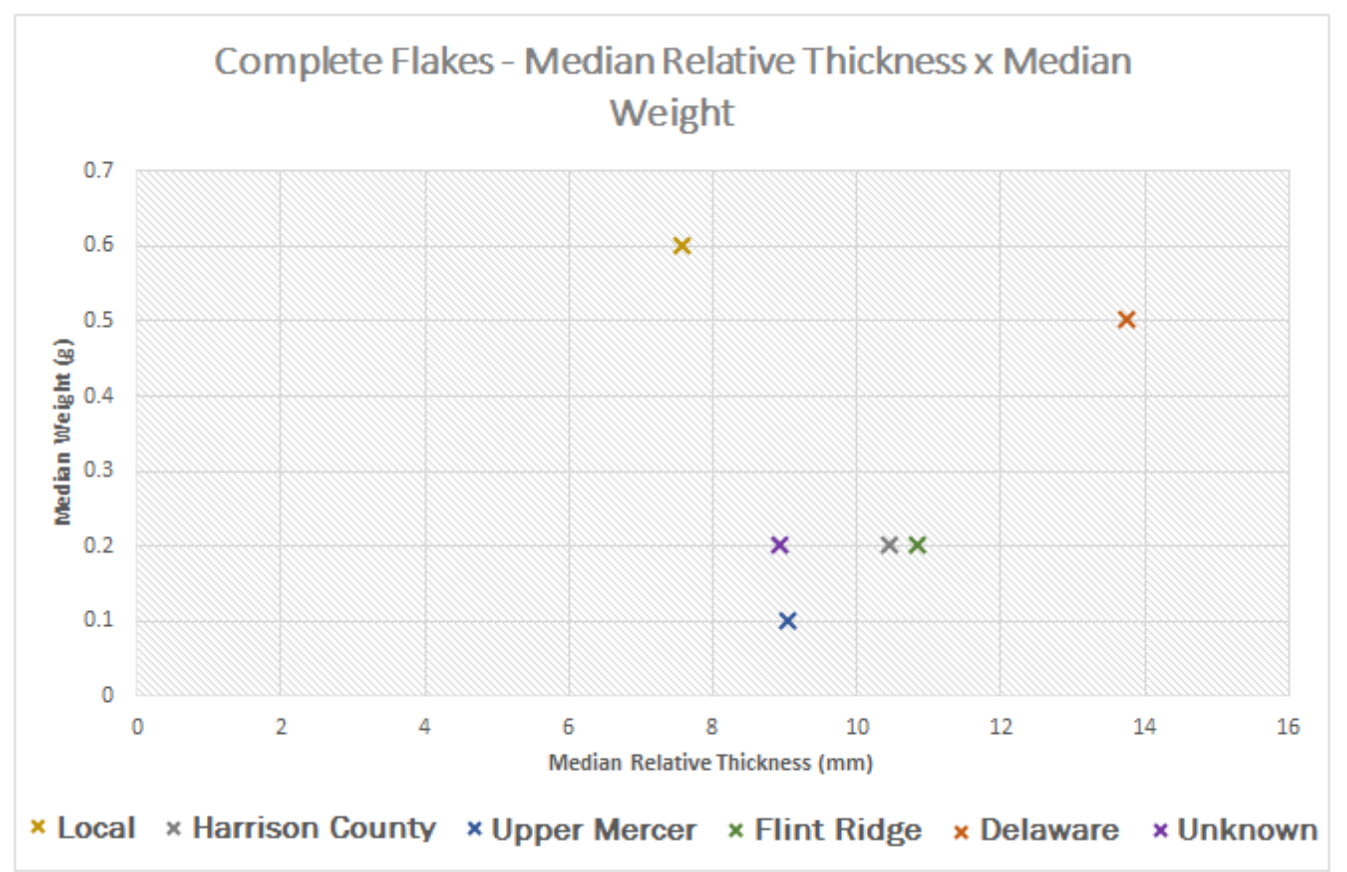

Figure 12: Plotting median relative thickness against median weight for complete flakes recovered from Spracklen 
The resulting figures shows the clumping of three out of the four non-local chert types (Upper Mercer, Harrison County, and Flint Ridge) along with the unknown flakes, which may very well be non-local in origin. The values registered by the non-local Delaware $(n=3)$, Upper Mercer $(n=3)$, and Flint Ridge $(n=13)$ flakes may be attributed to their small sample sizes and call their validity into question. Nevertheless, Harrison County $(n=200)$ is the most abundant non-local chert and was relied on most throughout the debitage categorization process.

\section{Debitage Categorization Discussion}

After the complete flakes were identified and their relative thicknesses calculated and plotted against thickness and weight, the results were compared back to the three original signatures discussed by Sullivan and Rozen (1985). Additionally, a comparison was made with the debitage analysis conducted on the Fort Ancient flakes (see Connolly 1991, 1997).

Similarities and differences between the two assemblages provided insight into the processes that occurred at Spracklen.

While both complete and broken flakes could be the result of the knapping process, only complete flakes were utilized for the following analysis. Broken flakes that could be the result of a hinge or step fracture, may very well have been broken through post-depositional processes. With a majority of the flakes exhumed from the plow zone, both modern and historical plowing likely disturbed the lithics, caused breakage, and thus altered the accurate counts of flake types. Understanding the size and shape of the debitage at a site can provide us with the ability to interpret the purpose of its removal. With the use of Sullivan and Rozen's (1985: 759 and 765) debitage type designation and plotting relative thickness by thickness to understand debitage flake removal, this was applied to the complete flakes at Spracken. 


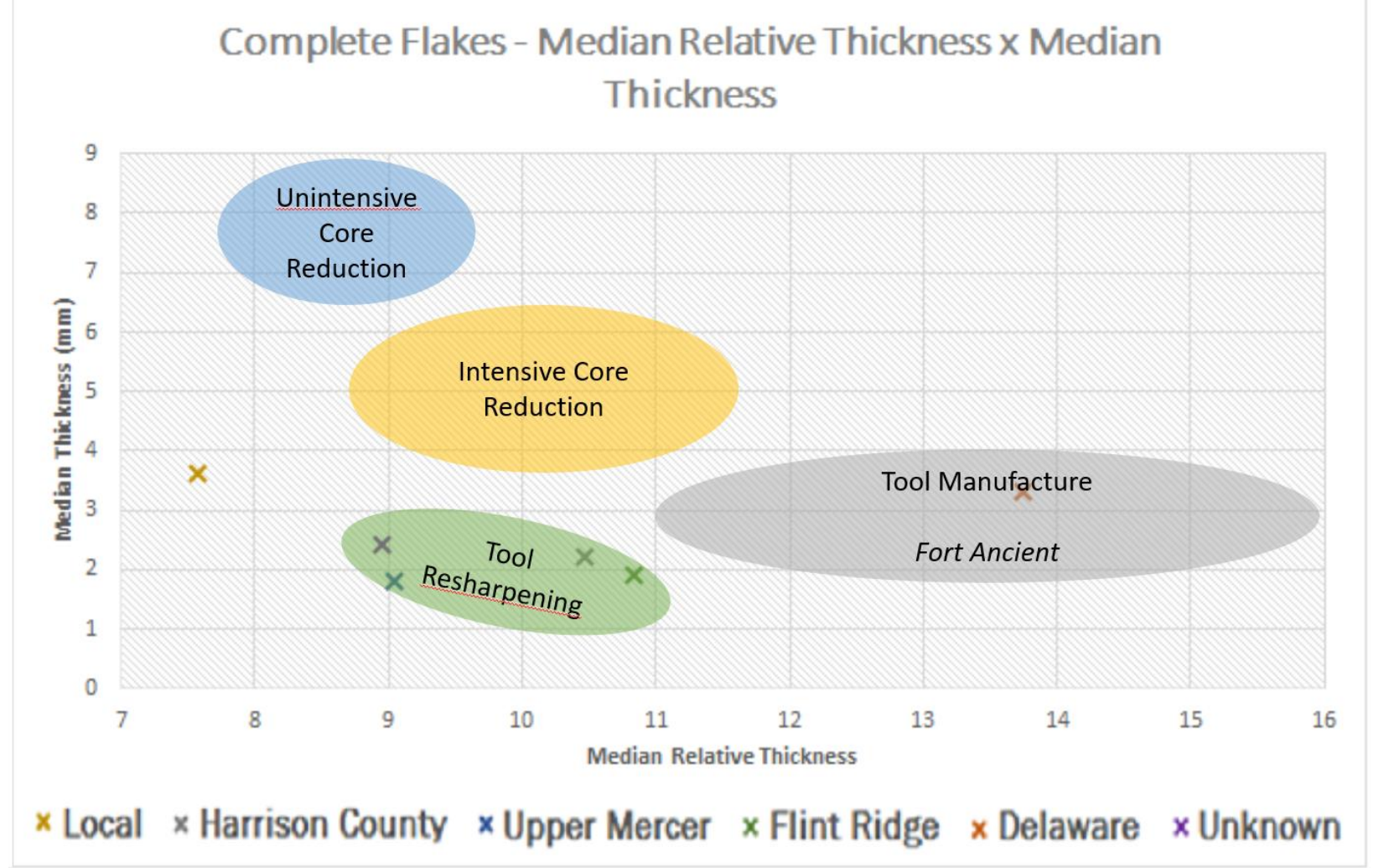

Figure 13: Comparison of Spracklen debitage with Sullivan and Rozen's (1985) classification signatures and Connolly's (1991, 1997) Fort Ancient findings

The resulting values from Spracklen do not fall within the existing reduction signatures (core reduction or tool manufacture) identified by Sullivan and Rozen (1985) and reiterated by Connolly's $(1991,1997)$ findings when comparing median relative thickness to the size proxies (thickness and weight) (Miller and Heneghan 2018) (Figure 13). Although Spracklen's complete flakes fall outside of the identified signatures, this provides evidence for a third signature, previously unidentified by Sullivan and Rozen (1985). This third signature, tool resharpening, is later in a tool's life than either of the previously identified signatures (Miller and Heneghan 2018). 
According to Sullivan and Rozen's (1985) findings, core reduction results in low relative thickness values, while also having an increasing large overall flake size (identified through flake thickness and weight). In comparison with the recovered debitage from Fort Ancient (Connolly 1991, 1997), Spracklen's assemblage has considerably smaller relative thicknesses values while having very similar thickness and weight values. When median weight is substituted for median thickness, the same patterns were found (Connolly 1991).

When these data are combined, Spracklen's assemblage is dominated by small, thin flakes. These results contradict Sullivan and Rozen's (1985) findings because their chosen size proxies do not account for differences in the length or width of the flakes (Miller and Heneghan 2018). While recovered flakes from Spracklen had similar thickness values to those from Fort Ancient, the difference arises in the lower relative thickness values. These findings suggest that the lower relative thickness values are the result of shorter and/or narrower flakes.

Unlike the flakes at Fort Ancient that are the result of tool manufacture, Spracklen's thin flakes that are also short and/or narrow would be the byproduct of tool resharpening. Miller and Heneghan (2018) argue that these results suggest that the lithic strategy, particularly associated with the non-local cherts, involved the resharpening of finished, previously utilized tools. With the lack of non-local chert bifaces at Spracklen and the tool resharpening signature, they deduce that these tools were neither initially crafted nor disposed of at the site. Being that the site is ephemeral and lacking an architectural signature, the people utilized the crafted tools and what remains is debitage related to the resharpening events, while the tools were transported away from the site. With the function of Fort Ancient being widely accepted as a ceremonial center with evidence of craft specialization, a debitage assemblage dominated by the tool manufacturing signature would be expected. With these deductions, tool resharpening would 
provide evidence for a short-term occupation site, such as Spracklen, where supplies were limited.

\section{Microwear Analysis Results}

After an extensive microwear investigation of 86 artifacts (i.e. bladelets, blade cores, bifaces, and retouched flakes), prehistoric utilization was noted on just over $23 \%(\mathrm{n}=20)$ of the sample (Table 2). Part of the reason the total percentage of utilized artifacts is low is because not one of the nine bladelet cores nor 14 bifaces exhibited use-wear. However, while the total utilization percentage is low, the analysis of solely the bladelets yielded a utilization percentage over $38 \%(n=18)$ of the 47 bladelets. This utilization percentage falls in line with other Hopewellian bladelet studies (see Miller 2014, 2015; Yerkes 1990, 1994) ranging between roughly 20 and 50\%, with some ceremonial contexts (e.g. Moorehead Circle within Fort Ancient) reaching upwards of $85 \%$ utilization.

Table 2. Spracklen Lithic Utilization

\begin{tabular}{lllll}
\hline Tool Type & Yes & No & Total & $\%$ Utilized \\
\hline Bladelets & 18 & 29 & 47 & 38.30 \\
Bladelet Cores & 0 & 9 & 9 & 0.00 \\
Flakes & 2 & 14 & 16 & 12.50 \\
Bifaces & 0 & 14 & 14 & 0.00 \\
Total & 20 & 66 & 86 & 23.26 \\
\hline
\end{tabular}

Materials relating to the butchery process, such as meat, fresh hide, and bone, were evident among the lithic assemblage at Spracklen (Figure 14). Meat was the most commonly worked material, with 12 of the 18 (67\%) utilized bladelets exhibiting the dull and greasy altered surfaces developed after extended period of contact (Figure 15). Three of these bladelets 
displayed evidence for contact with more than one material, although the polish could have developed throughout the butchery process. For example, one bladelet (\#55.2) exhibits meat and bone polishes coinciding with one another, with the bone polish superimposing the meat polish (Figure 24). This suggests that bones or tendons were nicked throughout the butchery process or carried out after the bladelet was used for butchering the meat. Another bladelet (\#306) displays evidence of use on both meat and fresh hide (Figure 26). What is of most interest here is how a portion of the bladelet was utilized for meat butchery, while another section scraped fresh hide. Nevertheless, the presence of both polishes points towards the bladelet having been used on both tasks during a short period of time.

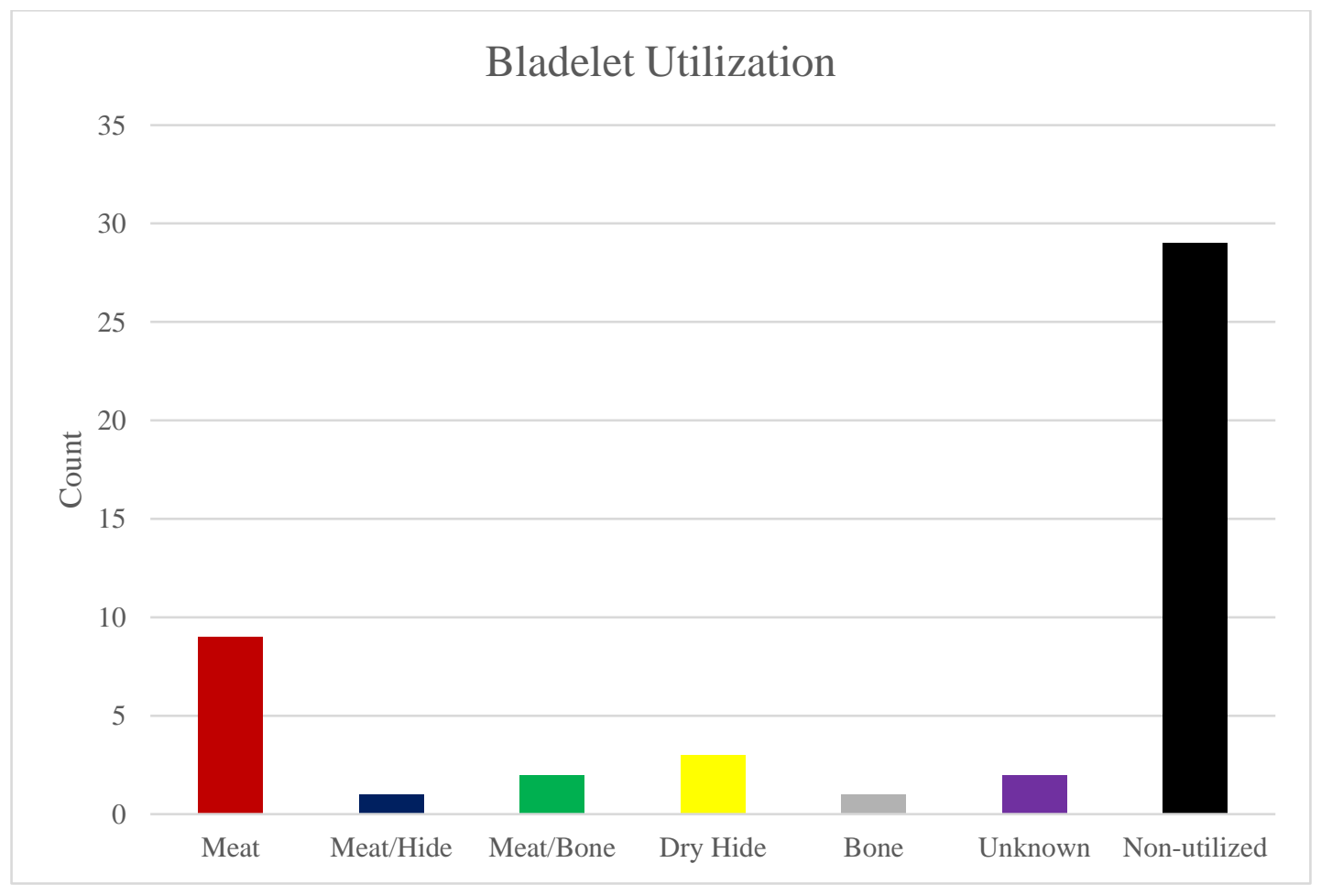

Figure 14: Summarization of bladelet use-wear on various contact materials 

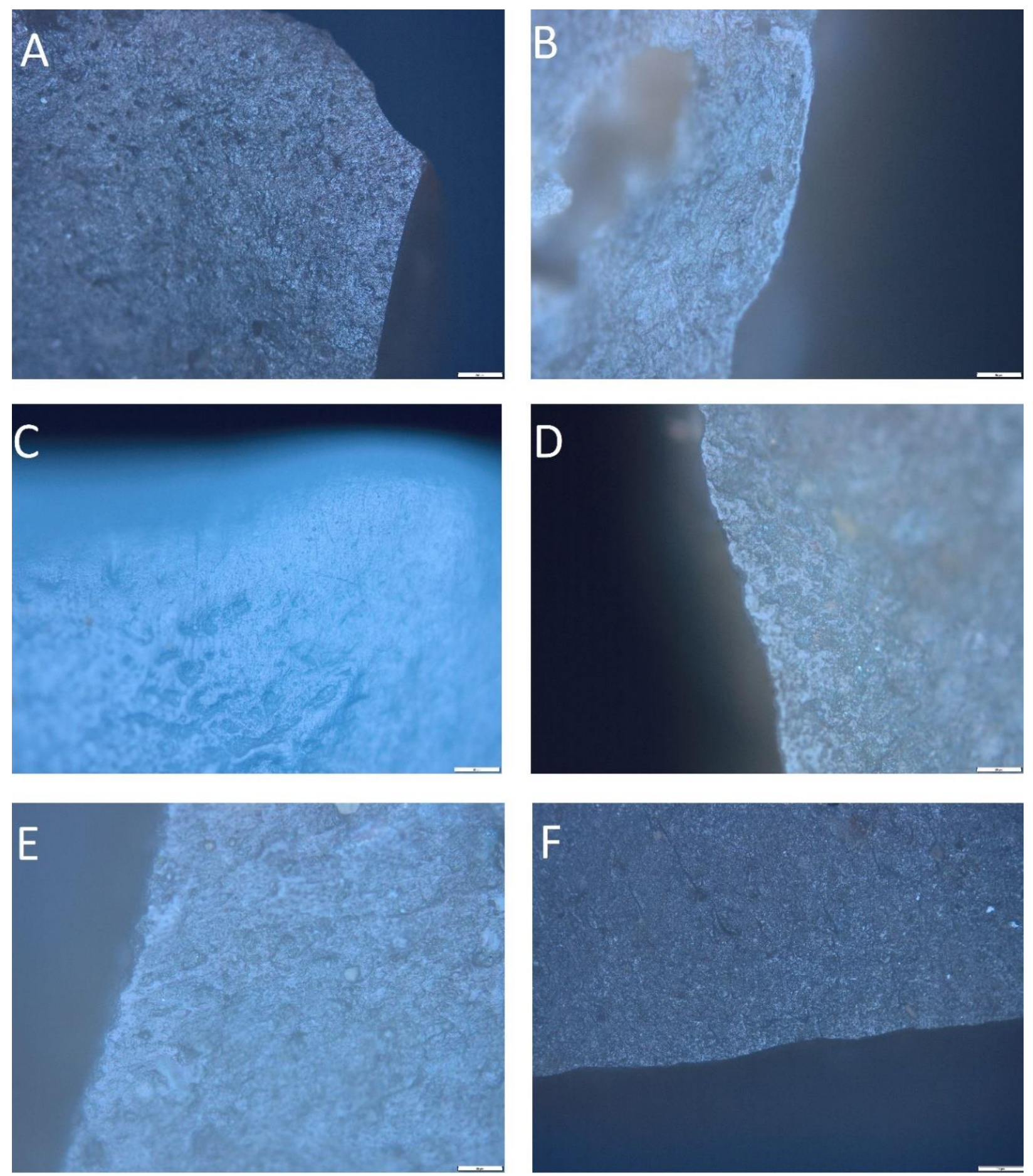

Figure 15: Examples of microwear traces from Spracklen lithics

a) Meat cutting (magnified 50x) b) Bone cutting/incising (magnified 200x)

c) Dry hide scraping (magnified 200x) d) Dry hide cutting (magnified 200x)

e) Fresh hide scraping (magnified 200x) f) General/Unknown (magnified 50x) 
Outside of the meat butchery, some bladelets displayed evidence of dry hide processing. The bladelets utilized on dry hide revealed two different motions. Extensive rounding on the edge of artifact \#12.2 is in line with extensive dry hide scraping that would have taken place long after the completion of the butchery process and drying of the hide (Figure 19). Evidence from polish working itself back from the edge and on one side of the tool provides evidence for a scraping motion, while the other bladelet exhibited motions developed from cutting, evident by the striations that run more parallel to the tool's edge. As dry hide cutting and scraping would occur after the hide has been left to cure, it provides insight into additional activities occurring outside of just butchery.

Strikingly, one of the meat/bone bladelets (\#824) was worked into a burin, and thus a bone polish (bright with many pits) was evident near the sharp edge (Figure 30). The name burin is derived from the French term for graver, which implies its function as a tool used for chiseling and engraving (Barton et al. 1996). However, functional studies (see Becker and Wendorf 1993; Finlayson and Betts 1990; Knecht 1988) conducted throughout the 1980s and 19990s has exemplified their use as cutting, scraping, and hafting tools among other uses. Nevertheless, this burin was reworked from a bladelet to score or engrave onto bone using the distal tip. In addition, one edge of the tool was used during the meat butchery process, while also providing evidence for hafting across its dorsal surface.

This burin, along with one meat bladelet and five other tools (three bladelets and two retouched flakes) without evidence of use, provides indication for hafting (Figure 16). Hafting polish is observed by the extreme flat and bright polish that appears near the middle of the bladelet and away from any cutting edges, caused by contact with the haft or microflakes that rub against the tool inside of the haft. Odell (1994) suggests the functional purpose of hafting 
bladelets is to allow for a greater exertion of leverage into harder contact materials. While some may not classify butchery as having harder materials, a haft would certainly allow for extended periods of use, by exerting less force behind each cut. In addition, hafting would allow for the usage of smaller bladelets that would be challenging to hold otherwise.
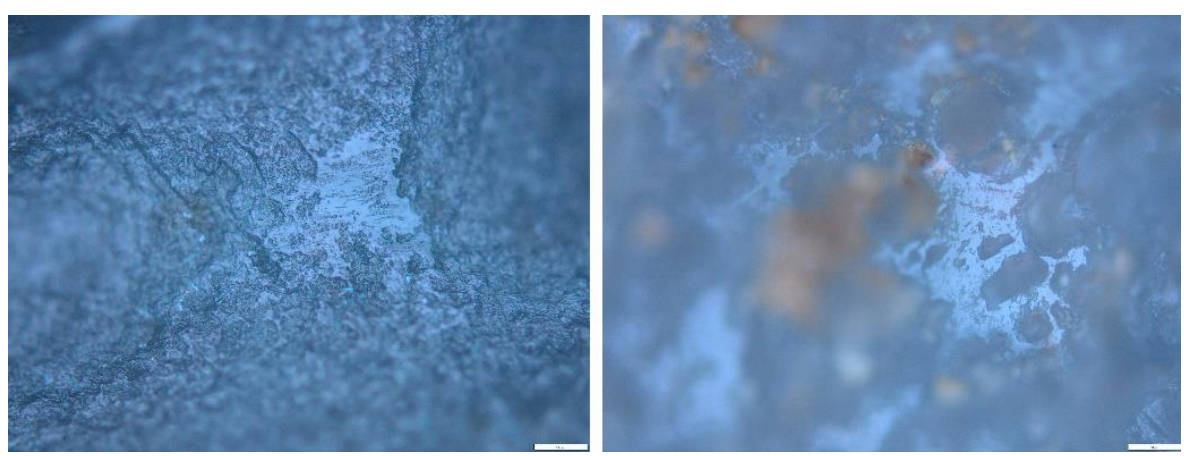

Figure 16: Hafting microwear traces on Spracklen lithics (magnified 200x)

The utilization of flakes at Spracklen is less evident, with only two artifacts exhibiting use-wear, while another two non-utilized flakes were hafted (Figure 17). Isolated bone polish exhibited on one flake (\#1190) suggests limited use or incidental contact with a bone during transportation (Figure 39). The second flake (\#1191) exhibits a broken or snapped edge illustrating the scraping of fresh hide with striations perpendicular to the flake edge (Figure 40). The remaining 12 flakes showed no evidence of use wear nor hafting. 


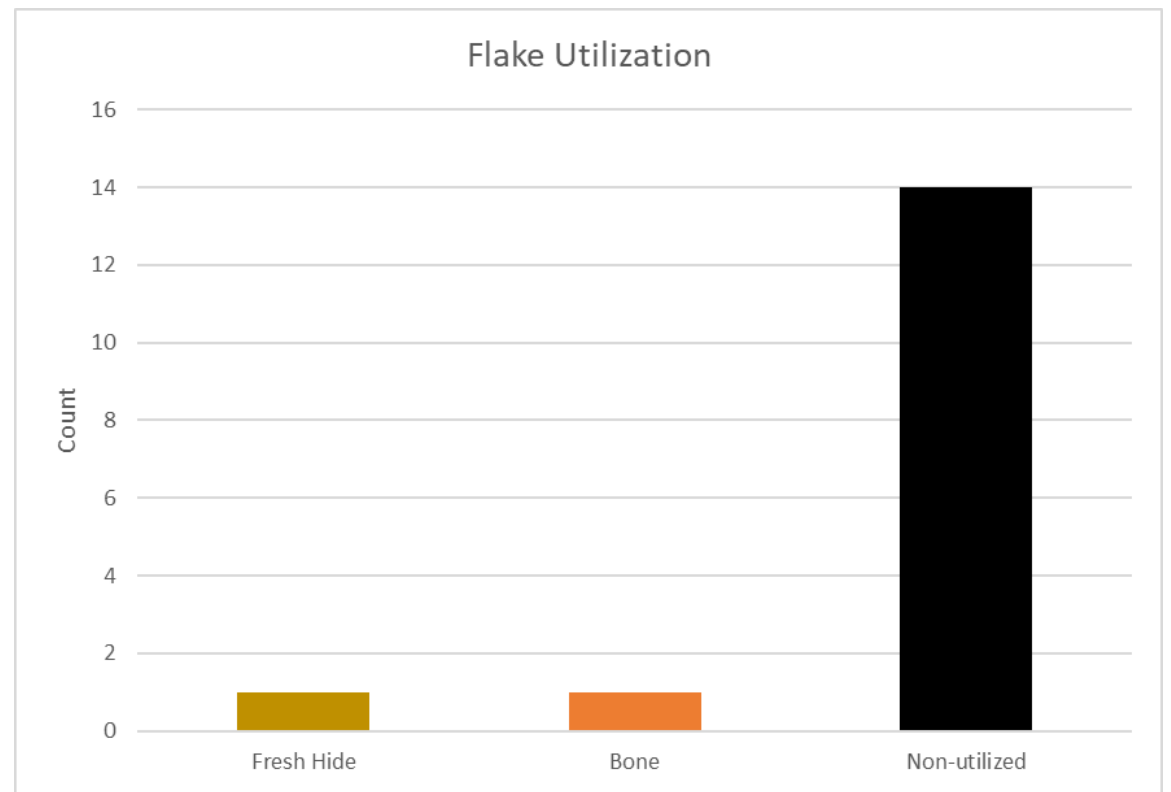

Figure 17: Summarization of flake use-wear on various contact materials

To summarize these results, the microwear analysis yielded a use-wear rate of just $23 \%$, with nearly $36 \%$ of the bladelets providing evidence for use. Outside of the two unknown and undeveloped polishes, the remaining utilized assemblage were formed throughout the butchery process or thereafter on dry hides. Additionally, six of these bladelets, and eight tools total, exhibit polishes characteristic of hafting. However, a majority of these bladelets were fragmented, possibly leading to an inflation of utilized and unutilized counts.

\section{Microwear Analysis Discussion}

Because of its ability to qualitatively describe the use evident on Spracklen's lithic assemblage, microwear analysis provides a glimpse into the activities performed by the lithic users at this location. However, polish is not always distinguishable, identifiable, nor evident on each artifact. Combine this with the fact that a majority of the bladelets were fragmented and may not be representative of the assemblage that was transported away from the site, and it is 
easy to see that quantitative microwear results are less reliable. Grace (1990) argues that microwear analysis is limited in its ability to distinguish material types, identify postdepositional changes, and represent low usage rates among the assemblage. Much of these limitations are drawn back to the qualitative nature of the process.

The 14 recovered and analyzed bifaces provide a good example of one limitation with the microwear process. While some of these bifaces were fragmented, neither them nor the completed bifaces exhibited signs of use. While it would be ill-advised to classify the bifaces as utilized based on their formalized and finished appearance, the lack of use-wear does not discount the possibility that these were utilized tools. Drawing back upon the discussion from the debitage analysis, a tool resharpening signature was identified from the debitage assemblage. The process of resharpening rids the biface's edge of its polish and thus leads to an unutilized classification. Therefore, the question as to if the bifaces were utilized becomes unobtainable through the microwear process.

In addition to the limitations garnered through tool resharpening, fragmented tools, such as the majority of those analyzed at Spracklen, make it impossible to produce reliable quantitative data. Being that refitting was not undertaken in this project, it is uncertain how many of the fragmented tools are representative of a single entity. As a product of this fragmentation, the qualitative portion of the data is unreliable. This also leads many questions unanswered as many of the tools exhibiting use or hafting were broken. While the fragmentation of the lithics cannot be solely attributed to post-depositional process nor usage, it makes the analysis no less challenging. Yet, the identification of use and hafting is still advantageous as these polishes are the byproducts of the site and can aid in the understanding of the site's function. 
Understanding the functional purpose of lithic tools is one of the driving forces behind the application of the microscopic use-wear method. Even after the successful identification of a polish, some archaeologists are skeptical on the application of the method, due to its subjective nature and overreliance on experimentally utilized tools for comparison (Van Gijn 2014). These archaeologists feel that the results gathered by users of this method have very little value outside of the lithic analysts who employ them, leading to repeated attempts of quantifying use-wear. Through this quantification, they feel that the methods will be more standardized, involve a higher level of scientific objectivity, and reduce the time needed to infer on the use-wear. However, a standardized quantification process has not been rigorously tested and employed by microwear analysts. On the positive, the qualitative nature of this analysis allows for the users to better understand formational processes through experimental reconstructions, a more nuanced appreciation for lithic taphonomy, and is not detrimental or intrusive to the artifacts themselves. Though this limits the positive identification of lithics that were used for short periods of time or utilized on materials unknown to the analyst.

Nevertheless, Grace (1990:9) affirms the usefulness of microwear analysis when applied to explicit questions at a site level, which is exactly what is being undertaken with Spracklen. The microwear process allows for the identification in the range of activities undertaken at the site. As such, Spracklen's utilized assemblage suggests that the site was a hunting camp, evident from the bladelets used for the cutting of meat and bones, along with the scraping and cutting of fresh hides. However, bladelet utilization on dry hides and the reworked bladelet utilized as a burin on bone would have occurred after the butchery process. While this does not discount the hunting camp function of Spracklen, it suggests that it was occupied after the duration of the hunt or during a multi-day hunting trip where the procured hides were left to dry as further 
resources were gathered. It may also be possible that the dry hide working and burin usage are evidence of down-time activities that occurred before or after the butchery process, with the dry hides being brought to Spracklen. Regardless, Spracklen's microwear signature points towards a specialized camp where butchery and hide processing was taking place, thus providing the foundational groundwork for bladelet usage outside of earthworks and the traditional domestic settings in the floodplains.

\section{How This Fits}

Previously conducted microwear studies on Hopewell bladelets, outlined in Chapter 4, come from earthworks (see Miller 2014, 2015; Yerkes 2009) and non-earthwork floodplain settings (see Kimball 1992; Lemons and Church 1998; Yerkes 1990, 1994). Spracklen, therefore, is the first upland site to undergo a comparative microwear analysis with other Ohio Hopewell contexts. This information, while not all-encompassing of upland sites, allows for the initial inquiry into the bladelets at these sites. Hopefully, this kind of analysis can be repeated at other upland sites to develop a more complete picture of activities at non-earthwork sites.

Where the assemblage differs from previously investigated assemblages is its influx of hafted bladelets. While cases (see Odell 1994) have been made for both lateral and end-hafts on bladelets, they have mostly been attributed to the Havana Hopewell culture. Being that a majority of them were broken width-wise, these bladelets were likely utilized in end-hafts. However, because of the unknown combination of post-depositional and breakage during usage, it is not possible to ascribe the breakage to the type of hafts being utilized at Spracklen. As additional upland sites are studied, the question of bladelet hafting could be more investigated further. It may be possible that the upland nature of the site led to an increased awareness of the 
conservation of lithic raw materials. In turn, hafting would allow for the utilization of smaller bladelets that would be difficult use with a handhold.

When comparing with these sites, Spracklen's bladelets were utilized far more for butchery-related activities than anything else. Being that Spracklen does not have evidence for long-term occupation and is far from domestic sites and earthworks, the reason for the differences is not likely attributed to a functional difference in bladelets themselves nor how they were perceived by their Hopewell users. It is worth noting that the butchery and hide working nature of Spracklen's assemblage is likely the product of it being a hunting campsite and less so the product of specialized bladelets, such as the mortuary bladelets originally suggested by Streuver (1964). Bladelets that could be transported as a single core before being struck off from the flintknapper when needed, provide a quickly crafted, easily modified and transported, and efficient tool. Therefore, their purpose at Spracklen goes in line with the utilitarian purpose for these tools often noted throughout many of the sites not associated with ceremonial contexts. 


\section{CHAPTER IV: FUTURE RESEARCH AND CONCLUSIONS}

A holistic understanding of community organization must involve investigation of all regions within and surrounding Hopewell earthworks. Located over four kilometers from the closest earthworks, Spracklen's archaeological footprint was heavily impacted by historical agricultural plowing. This chapter illustrates how, through the utilization of GIS, archaeologists pinpoint regions that share the same or similar spatial and geographical characteristics as their site in question. Using the spatial characteristics of the site, a reverse site suitability was run on ArcMap 10 to identify these regions exhibiting similar characteristics. The identification of these regions allows archaeologists to conduct surface surveys in hopes of locating sites with features for future excavation, such as the intact remnants of a structure or pits. Finally, conclusions deduced from the literature review and lithic analysis are discussed.

\section{Searching the Uplands: Using GIS to Identify Sites}

\section{A Brief Insight into GIS's Archaeological Application}

Just as processual archaeology introduced the emphasis on the scientific method and control of data, computational advances through the 1960s and 1970s allowed for the introduction of Geographic Information Systems (Praetzellis 2015). Collaboration with GIS experts and implementation of their methods allows for the enhancement of archaeological inquires through place (Guttman 2002; Harris 2002). For example, GIS analyses can visually analyze, interpret and display Spatial patterning of artifacts, sites, and the general movements of people. These inquiries provide insight into the intra-site distribution of artifacts, burials, and structures. 
In addition to the site-focused studies, region-wide spatial analyses utilize the power of GIS to interpret community organization and spatial awareness through studies like mound construction of the Adena (2,500 B.P.) within the Hocking River valley (Waldron and Abrams 1999). As an ongoing topic of interest among the archaeological community, early community organization often arose alongside the emergence of cultivated seeds, which is evident among the Adena culture. In addition to becoming less nomadic and living in semi-permanent structures, known as hamlets, these people were characterized by small burial mounds located on ridgetops overlooking their domestic structures.

The application of GIS in viewshed analysis, allowed for the determination of which areas of the landscape were visible from the burial mounds (Waldron and Abrams 1999). A completed analysis of the data showed that each of the 42 mounds, in the region of focus, were in sight of at least one other mound. This allowed for the interpretation that the Adena people who constructed a mound would be visibly aware of adjacent mounds in the vicinity, giving rise to a sense of territory and regional connectivity among one another. Additionally, ethnographic evidence observed in tribal societies today, and in the recent past, suggests they could have used these mounds to communicate between one another, and thus furthering a sense of regional community.

At an even larger scale, Constantinidis (2009) utilized GIS to identify archaeological sites by making use of known sites to interpret their spatial patterns and allowing for the identification of areas in which unknown archaeological sites have a high probability of occurring. When used in coordination with archaeological excavation, these methods can allow for the identification of greater variability in the archaeological record as well as their documentation for potential recognition on the country's historic preservation lists. With archaeological sites being finite and 
of major cultural significance, it is important for archaeologists to ensure their conservation. This can be done in multiple ways including, identifying known sites, understanding their spatial patterns to interpret where other sites may be located, and documenting the potential threats that could negatively affect the integrity of a site.

\section{Reverse Site Suitability}

With known site characteristics, spatial and archaeological data is extrapolated and implemented into the region of inquiry to identify locations that exhibit these same characteristics (Constantinidis 2009; Hopkins 1977; Malczewski 2004). This form of spatial patterning is known as reverse site suitability and has been utilized throughout the archaeological, urban development, and geography disciplines among many more. With the extrapolation of the proximity to important locales and a variety of other environmental conditions, GIS can identify the regions that exhibit these characteristics (Constantinidis 2007). With a site such as Spracklen, which has been severely impacted by historical and modern agricultural plowing, much of the site has been destroyed. Because of this disturbance, as well as the lack of archaeological investigations into the upland region outside of rockshelters, the identification of regions exhibiting the same or similar environmental and spatial characteristics should be identified for future excavation and inquiry. A reverse site suitability discovers the rarity or commonality associated with the spatial and environmental characteristics of Spracklen, while also identifying if any known sites fall within these defined locales. 


\section{Materials and Methods}

Ohio Archaeological Inventory (OAI) forms, containing the UTM coordinates of Middle Woodland archaeological sites, were obtained from Ohio History Connection. After selecting the located sites in Greene County, their UTM coordinates were transferred into an Excel sheet and imported into ArcMap 10 in the form of an attribute table. This data included 22 different locations, two of which were the Bull and Pollock Works, three are sites associated with Spracklen, and the remaining 17 are unexcavated Hopewell sites identified by surface remains. This data, originally in NAD27, was then reprojected into Ohio State Plane South. Additionally, Greene County waterways, waterbodies, and an outline of the county itself were acquired from TIGER (U.S. Census Bureau 2014) and reprojected into the same geographic coordinate system (GCS). Two digital elevation maps (DEM) for the region were downloaded from the USGS National Map (U.S. Geological Survey 2017) and reprojected as GCSs. After all datasets, shape files, and rasters were imported into ArcMap 10, the processing extent was adjusted to Greene County.

The first step was performing a mosaic to stitch the DEM data into one raster and a hillshade was created from this data. Next, a spatial join was performed on all 22 sites to find their distances from the closest water source. Using the DEM data acquired, elevation, slope, and aspect values were extracted for each of the 22 different sites. This allowed for the investigation of Spracklen's elevations, slopes, aspects, and distances to water. Spracklen is over 700 meters away from the closest water source, over 320 meters above mean sea level, with less than a $1.3 \%$ change in slope, and south (S), southwest (SW), and southeast (SE) aspects. With this data in hand, it was then possible to perform a reverse site suitability on Spracklen's attributes. 
A buffer was created by inputting the waterways shape file and having an output within 700 meters from a waterway. This shape file was then converted to a raster, before being reclassified to display the regions over 700 meters from a waterway. Additionally, elevations were reclassified to highlight regions over 320 meters above mean seas level. A reclassification was also performed on slope to identify regions below $1.3 \%$ change in slope as well as aspect for all S, SW, and SE directions. Regions with the presence of these characteristics were given a value of one, while all other regions were given a value of zero. Considering how flat the region was and the short-term occupancy, aspect may not have played a crucial role in selecting where to settle.

Because of this, the raster calculator function was employed on two different instances. The first was used to add slope, distance to water, elevation, and aspect. The second raster calculator analysis excluded aspect. Both output rasters were again analyzed using the raster calculator to display only regions exhibiting the highest values. This means that the first raster displayed regions that exhibited the same elevation, slope, distance to water, and aspect, while the second raster excluded this aspect data. Finally, a map was created to display the regions exhibiting similar characteristics to Spracklen.

\section{Reverse Site Suitability Results}

Regions resembling the characteristics of the Spracklen sites are restricted to the eastern side of Greene County (Figure 18). When aspect is not considered (shown in orange), nearly 66.4 $\mathrm{km}^{2}$ of land exhibits Spracklen's characteristics. This is reduced to just over $25.5 \mathrm{~km}^{2}$ when aspect is accounted for (shown in red). While this may seem like a large region, they account for $6.2 \%$ and $2.4 \%$, respectively, of the total $1077.4 \mathrm{~km}^{2}$ of Greene County. In addition, many of 
these areas have likely been disturbed by construction and agriculture leading archaeologists to focus in on the very few regions that have been undisturbed. This drastically reduces the regions that would need to be further investigated in hopes of finding additional Hopewell presence in the region. Future research would account for these already disturbed areas, by utilizing land cover data, to focus further into undisturbed regions. Drastically reducing the area needed to be surveyed, this would make a thorough and complete investigation a realistic possibility.

\section{Discussion and Future Considerations}

Higher elevations, along with flatter land, are likely part of the reason why the Hopewell settled in the area, building two separate earthworks nearby. Outside of Spracklen and the two nearby sites, none of the other known Hopewell sites are in areas identified by the reverse site suitability. This is because many of these 17 sites were located near a waterway in the floodplains. The Hopewell benefitted from living near a waterway for travel, trade, access to drinkable water, and subsistence in the form of fishing. However, the regions at higher elevation and further away from water are prime locations for old growth oak and hickory forests that supply abundant amounts of nuts that could be processed and stored for long periods of time. Additionally, the microwear analysis suggests that the site functions as a hunting camp. Therefore, upland sites, such as Spracklen, would potentially be in these regions.

With the identified regions accounting for a considerable portion of the county and the small archaeological footprint of Spracklen, it is not outside the realm of possibility that there are a considerable number of sites that resemble it. These upland sites should be located, adding additional data and inquiry into what has been understood at Spracklen. If we hope to gain a better understanding of logistical mobility and Ohio Hopewellian community organization in its 


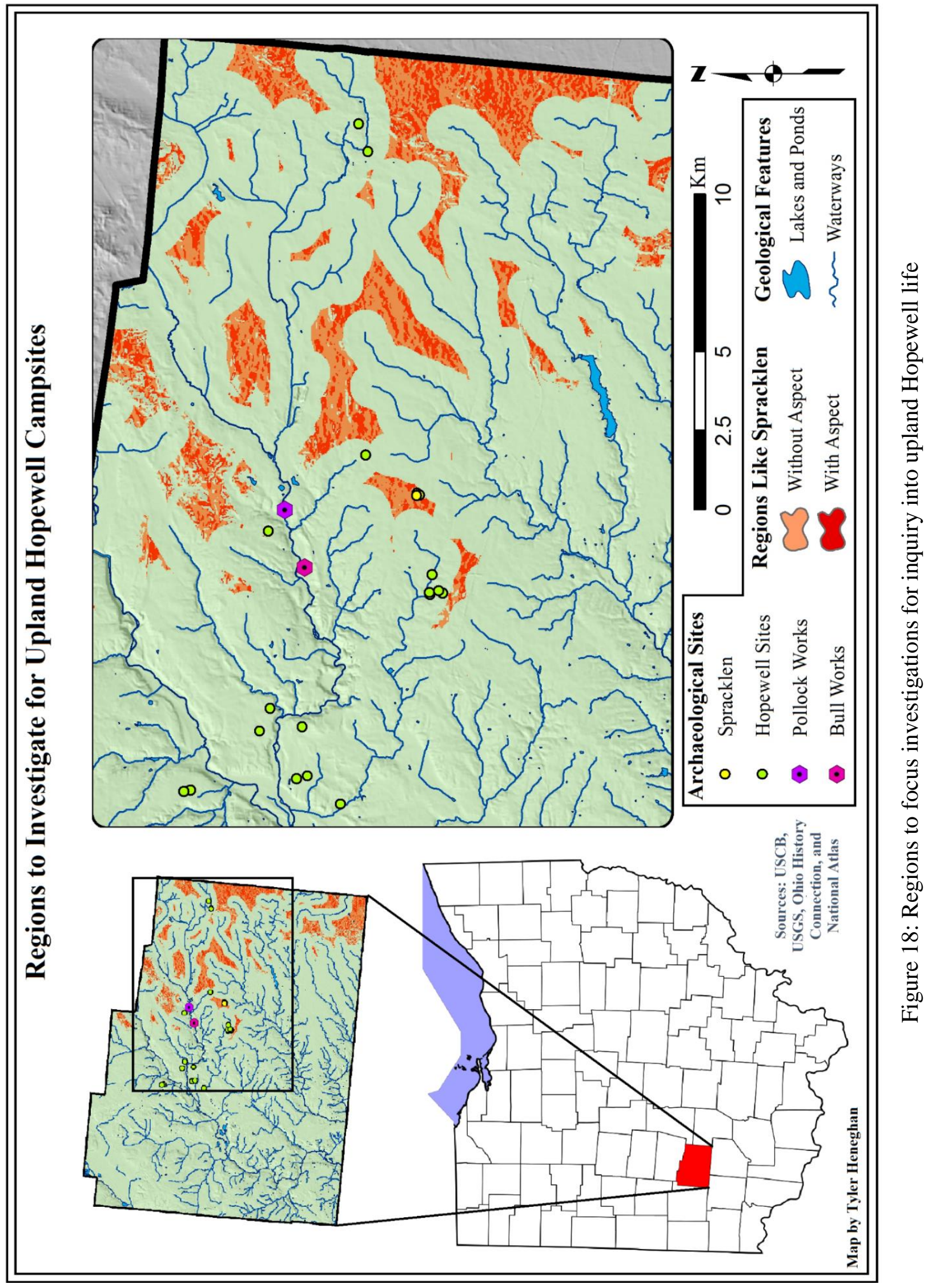


entirety, these sites need to be identified and excavated. The first step to this process is to identify regions where archaeologists should focus their efforts. Now that the reverse site suitability has been completed and the regions of interest have been identified, Hopewell archaeologists now have a better idea of where upland sites like Spracklen might be located. Not to mention, this information could help locate new sites that would aid in the understanding of the Hopewell culture. At the end of the day, ArcMap 10 made this possible through a process that can be applied to the entirety of the Hopewellian region.

\section{How Spracklen Fits within Hopewell Community Organization}

New Insights into Upland Life

Throughout the three-part examination of the lithic scatter that encompasses Spracklen, an understanding of the site's function and place within the Hopewell community begins to take shape. The raw material identification exhibited a reliance on non-local cherts, such as Harrison County (70\% of total assemblage), which is a pattern found throughout the Ohio Hopewell culture. A reliance on non-local cherts, coupled with the presence of bladelets crafted from these non-local materials, provided the initial evidence for the Hopewell occupation of the site. However, radiocarbon dates equating to the Late Prehistoric period suggests that the region was occupied on more than one occasion through time.

The debitage analysis suggests that Spracklen was a short-term occupation site. There was extensive evidence of resharpening suggesting that the inhabitants were making efficient use of their tools and raw materials. All the while, they were recycling through resharpening to ensure that their lithic materials were not exhausted before making the trip back to their places of permanent occupation. As bladelets are rarely resharpened, and limited evidence of core 
reduction or biface production is noted among the lithic debitage, I argue that much of the lithic tools utilized at Spracklen were not initially produced there. A lack of abundant biface remains suggests that these tools were then transported away from the site after utilization and resharpening. While their use-wear polishes cannot be examined, the remaining tools and retouched flakes underwent microscopic use-wear analysis to uncover what was occurring at Spracklen.

The analysis yielded results in line with meat butchery and subsequent hide working at the site. An overwhelming majority of the bladelets and flakes exhibiting use-wear were employed in this manner, with a reworked bladelet fashioned into a burin being used for the engraving of bone. While the function of bladelets was so striking, little can be said about the 14 bifaces that were analyzed. It is possible that they were never utilized or breakage and resharpening led to the remove of polish that would have provided the answers. Contrary to much of the literature on Hopewell bladelets, hafting was evident among multiple bladelets, the bladelet-burin, and two flakes. This provides additional evidence to the over-exhaustion of the lithic assemblage at the site, as hafting allows for increased leverage and for the use of smaller bladelets.

In summary, the raw-materials, debitage, tool utilization, and with use of behavioral chain analysis, new insights into Hopwellian life in the uplands were ascertained. The chain begins with the sourcing of raw materials, before moving to the production of the tools with remains of bladelet cores evident at the site. Sharpening events were documented, highlighting the continued consumption of lithic tools throughout the occupation of Spracklen. Finally, microwear investigations provided evidence of butchering. All of this information suggests that Spracklen functioned as a hunting and butchery camp. Additionally, botanical results (Miller and 
Heneghan 2018) provided evidence for the presence of wild berries, suggesting that the gathering of berries may have taken place during the occupation at Spracklen.

The site's seemingly isolated location in relation to earthworks, and in conjunction with its reoccupied nature, points towards the importance of its location for the procurement of meat and other faunal resources. While this does not indicate the site is rare, it does demonstrate that the location provided enough in the way of resources to constitute initial occupation and possibly reoccupation. Furthermore, the abundant disposal of bladelets and bladelet cores, coupled with hafting and bladelets utilized on a snapped edge, suggests that Spracklen's inhabitants made the most of the resources at their disposal.

When all this information is brought together, I argue that Spracklen functions as a shortterm hunting camp revisited on multiple occasions by the Hopewell. It is likely that the proximity to both the Bull Works and Pollock Works ties into the site's occupation, and the inhabitants of Spracklen may have known about the Hopewell presence at these nearby earthworks. Spracklen conveys new insights into Hopwellian life outside of the earthworks, but unfortunately, agricultural plowing has left the inability to answer questions relating to a formalized layout, architecture, and artifact concentrations. This is where further investigations of identified lithic scatters would prove beneficial to harnessing a more nuanced understanding of the function of these sites. Nevertheless, Spracklen now provides a foundational knowledge for future investigations and excavations.

\section{How This Fits into What We Know}

Contrary to Fort Ancient and many other well-excavated earthworks, Spracklen's assemblage is restricted to predominately bladelets and a few bifaces. Fort Ancient's assemblage, 
in contrast, was wide-ranging from finely crafted scrapers, projectile points, drills, and others. Activities relating to craft specialization, ceremony, and trade are documented throughout Fort Ancient and are more-encompassing than the butchery-related activities observed at Spracklen (Connolly 2004b; Lazazzera 2004; Otto 2004; Miller 2014, 2015). Moreover, the resharpening signature differentiates Spracklen from the tool manufacturing signatures noted by Connolly (1991, 1997). With the significance of Fort Ancient, it is likely that the people at Spracklen were aware of the goings in the ceremonial center, possibly even having obtained non-local cherts through trade.

Interestingly, the lithic assemblage from the much closer Pollock Works is less like the lithics at Spracklen than Fort Ancient, which has a heavier reliance on the local chert assemblage and more restricted non-local chert assemblage (O'Sheal 2007). These differences could be significant or due to excavations at Pollock having been directed at sequencing the earthworks' construction and less so on material culture (Riordan 1995, 2010). Although thorough investigations have not been undertaken in the floodplains surrounding the earthworks, it is possible that hamlets, similar to Murphy, dotted the landscape around Pollock. Whether or not the people of Spracklen had a direct link to the earthworks is not certain, but its proximity to the site constitutes a likely awareness of the region.

Murphy, being the most extensively excavated hamlet site, allowed for a better understanding of everyday Hopewell life, much like the occupation at Spracklen. Even after extensive historical plowing, features were prominent throughout the site, with Dancey (1991) identifying four distinct zones, including postmolds of a domestic structure. It is this formalized layout of the site, coupled with Yerkes (1990) microwear analysis illustrating the general use of the bladelet, that allows for a distinction with Spracklen. Nevertheless, Murphy represents the 
type of year-round domestic hamlet where the occupants of Spracklen would reside when not participating in ceremonial community or out gathering subsistence goods in the far-reaching uplands.

Small, specialized, and logistical campsites are mentioned throughout discussions of the Hopewell community organization model and are typically considered as such, because of the presence of a substantial non-local chert assemblage and bladelet production (Coughlin and Seeman 1997; Dancey and Pacheco 1997; Pacheco 2010; Pacheco and Dancey 2006; Prufer 1967). However, there are significant differences between specialized campsites and the noted observations at Spracklen. First and foremost, specialized campsites are typically within proximity to an earthworks, much closer than the four kilometers distance between Spracklen and the Pollock Works. With Spracklen serving as a hunting camp, this contradicts the ceremonially-focused purpose of these specialized campsites. While the usage of bladelets for one particular purpose would seem on the surface to indicate a specialization to the site, hunting and butchery are more so subsistence practices than ceremonial in nature. Jonah's Run (33WA82) may represent a logistical campsite in the uplands that is similar in function to Spracklen. The site is comparable with its lack of architectural features and generalized layout with a scattering of bladelets and other lithic tools and debitage (Brose and White 1979). However, without further investigation into its artifact assemblage, it would be difficult to speak to their similarities or differences.

I must reiterate that Spracklen's activities and location are likely common, but to date provide the most detailed insights into non-rockshelter sites in the uplands. That is not to say it is the first to do so, and offers more reason to examine previously excavated sites, like Jonah's Run, to allow for a more nuanced comparison of the two upland sites. It might be that Spracklen 
is more hunting-focused than others, or comparisons may shed light on the purpose and reasoning for visiting the uplands for subsistence. Once a comparison can be undertaken, not much more can be obtained from Spracklen's data and thus, the focus must shift towards gathering additional data to obtain a holistic understanding of the Hopewell.

\section{Anthropological Importance and Where We Go from Here}

Without a greater breadth of knowledge surrounding all locales encompassing the Ohio Hopewell, it is impossible ascertain a holistic understanding of the culture. Through this investigation of the happenings occurring at Spracklen, the community organization model initially recognized by Prufer $(1965,1967)$ and elaborated on further by Dancey and Pacheco (Dancey and Pacheco 1997; Pacheco and Dancey 2006) is understood in greater depth. Lithic scatter, ranging from debitage to exhausted cores and tools, suggests that activities were being carried out at Spracklen or in the nearby vicinity. Similar evidence of Hopewell life in the uplands is neither rare or undocumented, with sites such as Jonahs's Run (33WA82), 33GR924 (a Middle Woodland artifact scatter at the base of an upland slope), and the Bailey site (33WA797) exhibiting a lack of structural features much like Spracklen (see Dancey and Pacheco 1997; Pacheco and Dancey 2006; Klinge et al. 2008; Klinge and Schwartz 2011).

Outside of the increased artifact density exhibited at Spracklen and their similarities in relation to their Hopewell environment, little can be compared between the sites. This inability to properly associate the four sites is because, unlike the investigation that the lithic scatter has underwent here, thorough investigations were not undertaken elsewhere. A lack of inquiry into these sites is what plagues our understanding and hopefully is remedied by the Spracklen examination. This investigation hopes to have garnered a renewed interest into the workings of 
the Hopewell outside of their earthworks and provides just as, if not more, crucial information into their everyday lives.

Now more than ever, there is justified reason to relocate the assemblages of previously excavated lithic scatters and identify those that remain interred and unknown to the archaeological community. Because while Spracklen provides us with a look into Hopewell life in the uplands, it is but a glimpse of what these people were doing in their time spent away from the floodplains. Making use of GIS and spatial data from Spracklen enables archaeologists the opportunity to continue this all-encompassing analysis of Ohio Hopewell community organization. 


\section{REFERENCES CITED}

Abrams, Elliot M.

2009 Hopewell Archaeology: A View from the Northern Woodlands. Journal of Archaeological Research 17:169-204.

Ambrose, Stanley H.

2001 Paleolithic technology and human evolution. Science 291:1748-1753.

Atwater, Caleb

1820 Description of the Antiquities Discovered in the State of Ohio and Other Western

States. Transactions and Collections of the American Antiquarian Society 1:105-267.

Barton, C. Michael, Deborah I. Olszewski, and Nancy R. Coinman

1996 Beyond the Graver: Reconsidering Burin Function. Journal of Field Archaeology, 23(1):111-125.

Becker, Mark, and Fred Wendorf

1993 A Microwear Study of a Late Pleistocene Quadan Assemblage from Southern Egypt. Journal of Field Archaeology 20: 389-398.

Bernardini, Wesley

2004 Hopewell geometric earthworks: a case study in the referential and experiential meaning of monuments. Journal of Anthropological Archaeology 23:331-356.

Binford, Lewis R.

1980 Willow Smoke and Dog's Tails: Hunter-Gatherer Settlement Systems and

Archaeological Site Formation. American Antiquity 45:4-20.

1982 The Archaeology of Place. Journal of Anthropological Archaeology 1:5-31. 
1983 Working at Archaeology, Academic Press, New York.

Brézillon, M. N.

1968 La Dénomination des Objets de Pierre Taillée. Gallia Préhistoire, supplement 4.

Centre National de la Recherche Scientifique, Paris.

Brose, David S., and Nancy M. White

1979 Archaeological Investigations of Prehistoric Occupation in Caesar Creek Lake:

Clinton, Greene, and Warren Counties, Ohio. Cleveland Museum of Natural History,

Cleveland.

Burks, Jarrod

2016. Magnetic Gradient and Magnetic Susceptibility Survey Results from Site 33Gr1585, a Hopewell Occupation Site in the Upper Little Miami River Valley. OVAI Project 2016-07. Manuscript in Possession of the Author.

Burks, Jarrod, and Robert A. Cook

2011 Beyond Squier and Davis: Rediscovering Ohio's Earthworks using Geophysical Remote Sensing. American Antiquity 76(4):667-689.

Caldwell, Joseph R.

1964 Interaction Spheres in Prehistory. In Hopewellian Studies, edited by J. R. Caldwell and R. L. Hall, pp. 133-143. Illinois State Museum Scientific Papers 12. Springfield. Collins, Michael B.

1999 Clovis Blade Technology. University of Texas Press, Austin. 
Connolly, Robert P.

1991 Prehistoric Site Structure at the Fort Ancient State Memorial: New Evidence from Lithic Analysis. Unpublished Master's thesis, Department of Anthropology, University of Cincinnati, Cincinnati.

1996 Prehistoric Land Modification at the Fort Ancient Hilltop Enclosure: A Model of Formal and Accretive Development. In A View from the Core: A Synthesis of Ohio Hopewell Archaeology, edited by P. J. Pacheco, pp. 258-273. Ohio Archaeological Council, Columbus.

1997 The Evidence for Habitation at the Fort Ancient Earthworks, Warren County, Ohio.

In Ohio Hopewell Community Organization, edited by W. S. Dancey and P. J.

Pacheco, pp. 251-281. The Kent State University Press, Kent.

2004a The Evolution of Fort Ancient Embankment Wall Form. In The Fort Ancient

Earthworks: Prehistoric Lifeways of the Hopewell Culture in Southwestern Ohio, edited by R. P. Connolly and B. T. Lepper, pp. 35-50. Ohio Historical Society, Columbus.

2004b Time, Space, and Function at Fort Ancient. In The Fort Ancient Earthworks:

Prehistoric Lifeways of the Hopewell Culture in Southwestern Ohio, edited by R. P.

Connolly and B. T. Lepper, pp. 217-222. Ohio Historical Society, Columbus.

Constantinidis, Dora

2009 GIS for managing the analysis and protection of archaeological remains in the Willandra Lakes World Heritage Area. Archaeology in Oceania 44(2):112-118. 
Coughlin, Sean, Mark F. Seeman

1997 Hopewell Settlements at the Liberty Earthworks, Ross County, Ohio. In Ohio Hopewell Community Organization, edited by W. S. Dancey and P. J. Pacheco, pp. 231-250. Kent State University Press, Kent.

Cowan, Frank L., Ted S. Sunderhaus, and Robert A. Genheimer 2004 Earthwork Peripheries: Probing the Margins of the Fort Ancient Site. In The Fort Ancient Earthworks: Prehistoric Lifeways of the Hopewell Culture in Southwestern Ohio, edited by R. P. Connolly and B. T. Lepper, pp. 107-124. Ohio Historical Society, Columbus.

Cowan, C. Wesley, Bruce W. Aument, L. J. Kemplay, and L. R. Piotrowski 1981 Variation in Hopewell Settlement Patterns and Lithic Industries in the Vicinity of the Newark Earthworks: Some Preliminary Observations. Paper presented at the $25^{\text {th }}$ Annual Meeting of the Midwestern Archaeological Conference, Madison.

Crabtree, Don E.

1982 An Introduction to Flintworking (Second Edition). Occasional Papers of the Idaho State University Museum 28. Pocatello.

Crawford, O. G. S.

1935 A primitive threshing machine. Antiquity 9:335-339.

Dancey, William S.

1991 A Middle Woodland Settlement in Central Ohio: A Preliminary Report on the Murphy Site (33LI212). Pennsylvania Archaeologist 61(2):37-72.

Dancey, William S., and Paul J. Pacheco (editors)

1997 Ohio Hopewell Community Organization. Kent State University Press, Kent. 
Finlayson, Bill, and Alison Betts

1990 A Functional Analysis of Chipped Stone Artefacts from the Late Neolithic Site of Gabal Na'ja, Eastern Jordan. Paleorient 16(2): 13-30.

Genheimer, Robert A.

1996 Bladelets Are Tools Too: The Predominance of Bladelets among Formal Tools at Ohio Hopewell Sites. In A View from the Core: A Synthesis of Ohio Hopewell Archaeology, edited by P. J. Pacheco, pp. 92-107. Ohio Archaeological Council, Columbus.

Grace, Roger

1990 The Limitations and Applications of Use Wear Analysis. In The Interpretive Possibilities of Microwear Analysis, edited by B. Graslund, H. Knutsson, K. Knutsson, and J. Taffinder, pp. 9-14. AUN 14: Societas Archaeologica Upsaliensis, Uppsala. Greber, N'omi, Richard Davis, and Ann DuFresne 1981 The Micro Component of the Ohio Hopewell Lithic Technology: Bladelets. Annals of the New York Academy of Sciences 376:489-528.

Griffin, James B.

1996 The Hopewell Housing Shortage in Ohio, A.D. 1-350. In A View from the Core: A Synthesis of Ohio Hopewell Archaeology, edited by P. J. Pacheco, pp. 4-15. Ohio Archaeological Council, Columbus.

Guttman, Myron P.

2002 Preface. In Past Time, Past Place: GIS for History, edited by A. K. Knowles, pp. vii-X. ESRI, Redlands, CA. 
Hall, Robert L.

1979 In Search of the Ideology of the Adena-Hopewell Climax. In Hopewell Archaeology: the Chillicothe Conference, edited by D. S. Brose and N. Greber, pp. 258-265. Kent State University Press, Kent, OH.

1997 An Archaeology of the Soul: North American Indian Belief and Ritual. University of Illinois Press, Urbana and Chicago.

Harris, Trevor M.

2002 GIS in Archaeology. In Past Time, Past Place: GIS for History, edited by A. K. Knowles, pp. 131-144. ESRI, Redlands, CA.

Hill, James N.

1970 Prehistoric social organization in the American Southwest, theory and method. In Reconstructing Prehistoric Pueblo Societies, edited by W. A. Longacre, pp. 11-58. University of New Mexico Press, Albuquerque.

Holmes, W. H.

1894 Natural history of flaked stone implements. In Memoirs of the International Congress of Anthropology, edited by C. S. Wake, pp. 120-139. Schulte, Chicago. Hopkins, Lewis D.

1977 Methods for Generating Land Suitability Maps: A Comparative Evaluation. Journal of the American Institute of Planners 43(4):386-400.

Johnson, Jay K.

1983 Poverty Point Period Blade Technology in Yazoo Basin, Mississippi. Lithic Technology 12(3): 49-56. 
Kay, Marvin, and Robert C. Mainfort Jr.

2014 Functional analysis of prismatic blades and bladelets from Pinson Mounds, Tennessee. Journal of Archaeological Science 50:63-83.

Keeley, Lawrence H.

1980 Experimental Determination of Stone Tool Uses: A Microwear Analysis. University of Chicago Press, Chicago.

Kimball, Larry R.

1991 The Function of Hopewell Blades from the Icehouse Bottom and Garden Sites.

Paper presented at the $56^{\text {th }}$ Annual Meeting of the Society of American Archaeology, New Orleans.

1992 The Function of Hopewell Blades from the Southeast. Frank H. McClung Museum Notes No. 12. University of Tennessee, Knoxville.

Klinge, David F., and Kevin Schwartz

2011 Phase II Site Evaluations of 33GR924, 33GR1421, and 33GR1422 at the Wright-

Patterson Air Force Base, Greene County, Ohio. Report Submitted to Wight-Patterson Air Force Base: Environmental Quality Section. Copies available from the State Historic Preservation Office-Ohio History Connection.

Klinge, David F., Kevin Schwartz, and Erica Schneider

2008 Additional Phase II Archaeological Evaluative Testing of Nine Sites for the Proposed Rockies Express Pipeline-East (REX-East) Project, Butler, Warren, Clinton, Fayette, and Pickaway Counties, Ohio. Copies available from the State Historic Preservation Office-Ohio History Connection. 
Knecht, Heidi

1988 Upper Paleolithic Burins: Type, Form, and Function. BAR International Series 434. Oxford: B.A.R.

Kobayashi, Tatsuo

1970 Microblade Industries in the Japanese Archipelago. Artic Anthropology 7(2): 38-58.

Kozarek, Sue E.

1997 Determining Sedentism in the Archaeological Record. In Ohio Hopewell

Community Organization, edited by W. S. Dancey and P. J. Pacheco, pp. 131-152.

Kent State University Press, Kent.

Lazazzera, Adrienne J.

2004 Hopewell Household Variation at the Fort Ancient Site. In The Fort Ancient

Earthworks: Prehistoric Lifeways of the Hopewell Culture in Southwestern Ohio, edited by R. P. Connolly and B. T. Lepper, pp. 35-50. Ohio Historical Society, Columbus.

Lemons, Reno, and Flora Church

1998 A Use-Wear Analysis of Hopewell Bladelets from Paint Creek Lake Site \#5, Ross County, Ohio. North American Archaeologist 19:269-277.

Lepper, Bradley T.

1996 The Newark Earthworks and the geometric enclosures of the Scioto Valley:

Connections and conjectures. In A View from the Core: A Synthesis of Ohio Hopewell Archaeology, edited by P.J. Pacheco, pp. 304-314. The Ohio Archaeological Council, Columbus. 
2004 The Newark Earthworks: Monumental Geometry and Astronomy at a Hopewellian Pilgrimage Center. In Hero, Hawk, and Open Hand: American Indian Art of the Ancient Midwest and South, edited by R. F. Townsend, pp. 73-82. Yale University Press, New Haven.

2005 Ohio Archaeology: A Visual Chronicle of Ohio's Ancient American Indian Cultures, Orange Frazer Press, Wilmington.

LeRoi-Gourhan, André

1943. Evolution et techniques. I: L'homme et la matiere. edited by A. Michel, Paris. MacLean, John P

1879 The Mound Builders, Robert Clark \& Company, Cincinnati.

Malczewski, Jacek

2004 GIS-based land-use suitability analysis: a critical overview. Progress in Planning 62(1):1-2.

Miller, G. Logan

2014 Ohio Hopewell Ceremonial Bladelet Use at the Moorehead Circle, Fort Ancient. Midcontinental Journal of Archaeology 39(1):83-102.

2015 Ritual economy and craft production in small-scale societies: Evidence from microwear analysis of Hopewell bladelets. Journal of Anthropological Archaeology 39:124-138.

Miller, G. Logan and Tyler R. E. Heneghan 2018 Spracklen (33GR1585): New Insights into Short Term Middle Woodland sites in the Uplands. Journal of Ohio Archaeology (in press). 
Moore, Mark W.

2011 The design space of stone flaking: implications for cognitive evolution. World Archaeology 43(4):702-715.

Moore, Mark W., and Yinika Perston

2016 Experimental Insights into the Cognitive Significance of Early Stone Tools. PLoS ONE 11(7):1-37.

Moorehead, Warren K.

1890 Fort Ancient, the Great Prehistoric Earth-work of Warren County, Ohio: With an Account of Its Mounds and Graves, Robert Clarke \& Company, Cincinnati.

Murray, Tim

2007 Milestones in the Twentieth Century and Beyond. In Milestones in Archaeology: A Chronological Encyclopedia, pp. 326-600. ABC-CLIO, Incorporated, Santa Barbara. O’Brien, Michael J., R. Lee Lyman, and Michael B. Schiffer 2005 Archaeology as a Process: Processualism and its Progeny, University of Utah Press, Salt Lake City.

Odell, George H.

1980 Toward a more behavioral approach to archaeological lithic concentrations. American Antiquity 45:404-431.

1981a The mechanics of use-breakage of stone tools: some testable hypotheses. Journal of Field Archaeology 8:197-209.

1981b The morphological express at function junction: searching for meaning in lithic tool types. Journal of Anthropological Research 37:319-342. 
1994 The Role of Stone Bladelets in Middle Woodland Society. American Antiquity 59:102-120.

O’Sheal, Tiffany B.

2007 A lithic analysis of the Pollock Works: an investigation of chert usage of the Ohio Hopewell at the Pollack Works. Unpublished Master's thesis, Department of Anthropology, Ball State University, Muncie.

Otto, Martha Potter

2004 A Brief History of Archaeological Investigations at Fort Ancient, Warren County, Ohio. In The Fort Ancient Earthworks: Prehistoric Lifeways of the Hopewell Culture in Southwestern Ohio, edited by R. P. Connolly and B. T. Lepper, pp. 3-13. Ohio Historical Society, Columbus.

Parry, William J.

1994 Prismatic Blade Technologies in North America. In The Organization of North American Prehistoric Chipped Stone Technologies, edited by P. J. Carr, pp. 87-98. International Monographs in Prehistory, Ann Arbor.

Pacheco, Paul J.

1988 Ohio Middle Woodland Settlement Variability in the Upper Licking River Drainage. Journal of the Steward Anthropological Society 18:87-117. 1997 Ohio Middle Woodland Intracommunity Settlement Variability: A Case Study from the Licking Valley. In Ohio Hopewell Community Organization, edited by W. S. Dancey and P. J. Pacheco, pp. 41-84. Kent State University Press, Kent. 
2010 Why Move? Ohio Hopewell Sedentism Revisited. In Hopewell Settlement Patterns, Subsistence, and Symbolic Landscapes, edited by A. M. Byers and D. Wymer, pp. 3755. University Press of Florida, Gainesville.

Pacheco, Paul J., and William S. Dancey

2006 Integrating Mortuary and Settlement Data on Ohio Hopewell Society. In Recreating Hopewell, edited by D.K. Charles and J.E. Buikstra, pp. 3-25. University Press of Florida, Gainesville.

Praetzellis, Adrian

2015 How Theory Works. In Archaeological Theory in a Nutshell, pp. 9-28. Left Coast Press, Inc., Walnut Creek.

Prufer, Olaf $\mathrm{H}$.

1964 The Hopewell Complex in Ohio. In Hopewellian Studies, edited by J. Caldwell and R. Hall, pp. 37-83. Illinois State Museum Scientific Papers Vol. 12. Illinois State Museum, Springfield.

1965 The McGraw Site: A Study in Hopewellian Dynamics. Scientific Publications, n.s.

Vol. 4, No. 1. Cleveland Museum of Natural History, Cleveland.

1967 The Scioto Valley Archaeological Survey. In Studies in Ohio Archaeology, edited

by O. H. Prufer and D. McKenzie, pp. 267-328. Kent State University, Kent.

Rafferty, Janet

1985 The Archaeological Record on Sedentariness: Recognition, Development, and Implications. In Advances in Archaeological Methods and Theory, Vol. 8. edited by M. B. Schiffer, pp. 113-156. Academic Press, New York. 
Rau, Charles

1869 A deposit of agricultural flint implements in southern Illinois. In Annual Report of the Smithsonian Institution, 1868, Washington, DC, 401-407.

Riordan, Robert V.

1995 A Construction Sequence for a Middle Woodland Hilltop Enclosure.

Midcontinental Journal of Archaeology 20(1): 62-104.

2004 Fort Ancient and Southwest Ohio. In The Fort Ancient Earthworks: Prehistoric

Lifeways of the Hopewell Culture in Southwestern Ohio, edited by R. P. Connolly and

B. T. Lepper, pp. 223-239. Ohio Historical Society, Columbus.

2007 Report on the Excavations of the Moorehead Circle at Fort Ancient, 2006. In

Reports in Anthropology 9, Wright State University Laboratory of Anthropology,

Dayton.

2010 Enclosed by Stone. In Hopewell Settlement Patterns, Subsistence, and Symbolic

Landscapes, edited by A. M. Byers and D. Wymer, pp. 215-229. University Press of

Florida, Gainesville.

2013 Report on the Excavations of the Moorehead Circle at Fort Ancient, 2012. In

Reports in Anthropology 14, Wright State University Laboratory of Anthropology,

Dayton.

Schiffer, Michael B.

1975 Behavioral Chain Analysis: Activities, Organization, and the Use of Space.

Fieldiana. Anthropology 65: 103-119. 
Seeman, Mark F.

1996 The Ohio Hopewell Core and Its Many Margins: Deconstructing Upland and Hinterland Relations. In A View from the Core: A Synthesis of Ohio Hopewell Archaeology, edited by P.J. Pacheco, pp. 304-314. The Ohio Archaeological Council, Columbus.

Semenov, Sergei A.

1964 Prehistoric Technology, translated by M. W. Thompson, Barnes and Noble, New York.

Shafer Harry J. and Thomas R. Hester

1983 Ancient Maya Chert Workshops in Northern Belize, Central America. American Antiquity 48: 519-543.

Sheets, Payson D. and Guy R. Muto

1972. Pressure blades and total cutting edge: an experiment in lithic technology. Science 175: 632-634.

Smith, Bruce D.

1992 Rivers of Change: Essays on Early Agriculture in Eastern North America. Smithsonian Institution Press, Washington, D.C.

Spurrell, Flaxman

1892 Notes on early sickles. Archaeological Journal 49:53-59.

Squier, Ephraim G., and Edwin H. Davis

1848 Ancient Monuments of the Mississippi Valley. Contributions to Knowledge, vol. 1. Smithsonian Institution Press, Washington, D.C. 
Streuver, Stuart

1964 The Hopewell Interaction Sphere in Riverine-Western Great Lakes Culture History. In Hopewellian Studies, edited by J. R. Caldwell and R. L. Hall, pp. 85-106. Illinois State Museum, Scientific Papers 12, Springfield.

Sullivan, Alan P. III, and Kenneth C. Rozen

1985 Debitage Analysis and Archaeological Interpretation. American Antiquity 50(4):755-779.

Tixier, Jacques

1974 Glossary for the description of stone tools, with special reference to the Epipaleolithic of the Maghreb. In Newsletter of Lithic Technology, edited by M. H. Newcomer, Special Publication, vol. 1

Tringham, Ruth, Glenn Cooper, George Odell, Barbara Voytek, and Anne Whitman 1974 Experimentation in the formation of edge damage: a new approach to lithic analysis. Journal of Field Archaeology 1:171-196.

U.S. Census Bureau

2014 TIGER/Line Shapefiles. Topographically Integrated Geographic Encoding and Referencing Web Page, accessed November 11, 2017 at https://www.census.gov/geo/maps-data/data/tiger-line.html.

U.S. Geological Survey

2017 The National Map. 3DEP products and services: The National Map, 3D Elevation Program Web Page, accessed November 13, 2017 at https://nationalmap.gov/3DEP/3dep_prodserv.html. 
Waldron, John, and Elliot M. Abrams

1999 Adena Burial Mounds and Inter-Hamlet Visibility: A GIS Approach.

Midcontinental Journal of Archaeology 24(1):97-111.

Whittlesey, Charles

1850 Descriptions of Ancient Works in Ohio. Contributions to Knowledge 3, Article 7.

Smithsonian Institution Press, Washington, D.C.

Wiederhold, James E., and Charlotte Donald Pevny

2014 Fundamentals in practice: a holistic approach to microwear analysis at the Debra L.

Friedkin site, Texas. Journal of Archaeological Science 48:104-119.

Yerkes, Richard W.

1990 Using Microwear Analysis to Investigate Domestic Activities and Craft

Specialization at the Murphy Site, a Small Hopewell Settlement in Licking County,

Ohio. In The Interpretive Possibilities of Microwear Analysis, edited by B. Gräslund,

H. Knutson, K. Knutson, and J. Taffinder, pp. 167- 176. Societas Archaeologica

Upsaliensis, Aun 14, Uppsala, Sweden.

1994 A Consideration of the Function of Ohio Hopewell Bladelets. Lithic Technology

19:109-127.

2002 Hopewell Tribes: A Study of Middle Woodland Social Organization in the Ohio

Valley. In The Archaeology of Tribal Societies, edited by W.A. Parkinson, pp. 227-

245. International Monographs in Prehistory, Archaeological Series, Ann Arbor.

2009 Microwear Analysis of a Sample of 100 Chipped Stone Artifacts from the

1971-1977 Ohio Historical Society Excavations at the Seip Earthworks.

Mid-Continental Journal of Archaeology 34:109-12. 
Yerkes, Richard W., and P. Nick Kardulias

1993 Recent developments in the analysis of lithic artifacts. Journal of Archaeological Research 1(2):89-119. 


\section{APPENDIX A: BLADELET MICROWEAR IMAGERY}

Table 3. Bladelets that Underwent Microwear Analysis

\begin{tabular}{|c|c|c|c|c|}
\hline Artifact & Location & Material & Motion & Notes \\
\hline 12.2 & Surface & Dry Hide & Scraping & Rounding from hide polish \\
\hline 12.3 & Surface & Meat & Butchery & Light usage \\
\hline 16.2 & Surface & Bone & Unknown & One spot \\
\hline 20.2 & Surface & N/A & N/A & \\
\hline 39.6 & Surface & Meat & Unknown & \\
\hline 40.3 & Surface & N/A & N/A & \\
\hline 41.2 & Surface & Dry Hide & Cutting & \\
\hline 55.2 & Surface & Meat and Bone & Butchery & Incidental bone / tendon \\
\hline 58.1 & Surface & Meat & Butchery & Extensive edge damage \\
\hline 305 & 1.1 & N/A & N/A & \\
\hline 306 & 1.1 & Meat and Fresh Hide & Butchery and Scraping & Meat butchery and scraping hide \\
\hline 690 & 2.1 & N/A & N/A & \\
\hline 691 & 2.1 & N/A & N/A & \\
\hline 692 & 2.1 & Meat & Butchery & \\
\hline 693 & 2.1 & Meat & Butchery & \\
\hline 694 & 2.1 & N/A & N/A & \\
\hline 695 & 2.1 & N/A & N/A & Hafted \\
\hline 696 & 2.1 & N/A & N/A & \\
\hline 824 & 3A. 1 & Meat and Bone & Burin and Butchery & Hafted / Used as burin \\
\hline 1195 & 3.1 & N/A & N/A & \\
\hline 1196 & 3.1 & N/A & N/A & \\
\hline 1197 & 3.1 & N/A & N/A & \\
\hline 1198 & 3.1 & N/A & N/A & \\
\hline 1199 & 3.1 & N/A & N/A & \\
\hline 1390 & 4.1 & Meat & Butchery & \\
\hline 1391 & 4.1 & Meat & Unknown & \\
\hline 1392 & 4.1 & N/A & N/A & \\
\hline 1778 & 4.2 & N/A & N/A & \\
\hline 2616 & 6.1 & N/A & N/A & \\
\hline 2617 & 6.1 & N/A & N/A & \\
\hline 2618 & 6.1 & N/A & N/A & \\
\hline 2619 & 6.1 & N/A & N/A & \\
\hline 2620 & 6.1 & N/A & N/A & Hafted \\
\hline 2621 & 6.1 & Dry Hide & Scraping & One spot on broken edge \\
\hline 2622 & 6.1 & N/A & N/A & Hafted \\
\hline 3591 & 8.1 & Unkown & Unknown & One Spot \\
\hline 3593 & 8.1 & N/A & N/A & \\
\hline 3594 & 8.1 & N/A & N/A & \\
\hline 3595 & 8.1 & N/A & N/A & \\
\hline 3596 & 8.1 & N/A & N/A & \\
\hline 3883 & 9.1 & Meat & Butchery & \\
\hline 3884 & 9.1 & Meat & Butchery & Hafted \\
\hline 3885 & 9.1 & N/A & N/A & \\
\hline 4194 & 12.1 & Unknown & Unknown & \\
\hline 4519 & 13.1 & N/A & N/A & \\
\hline 4520 & 13.1 & N/A & N/A & \\
\hline 4666 & Surface & N/A & N/A & \\
\hline
\end{tabular}



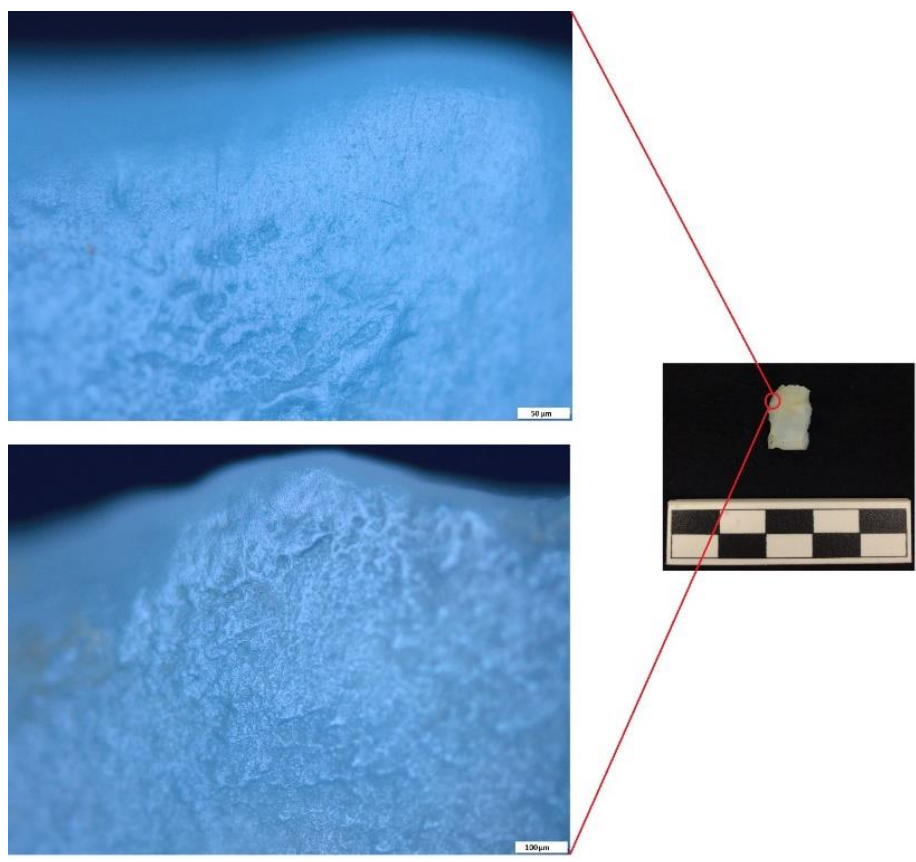

Figure 19: Dry hide scraping microwear traces on a flake (\#12.2) confined to the dorsal (top: 200x) and ventral (bottom: 100x) edges

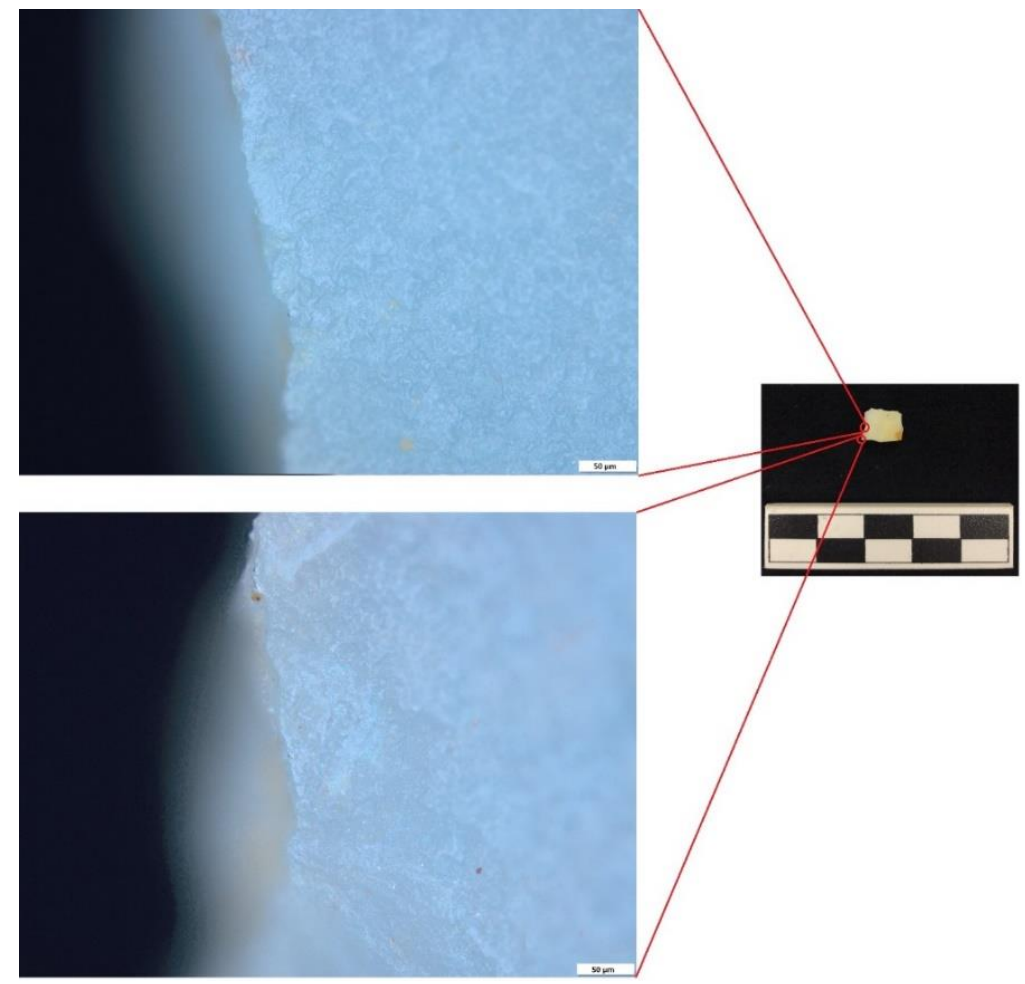

Figure 20: Meat microwear traces on a flake (\#12.3) confined to the ventral edge (200x) 


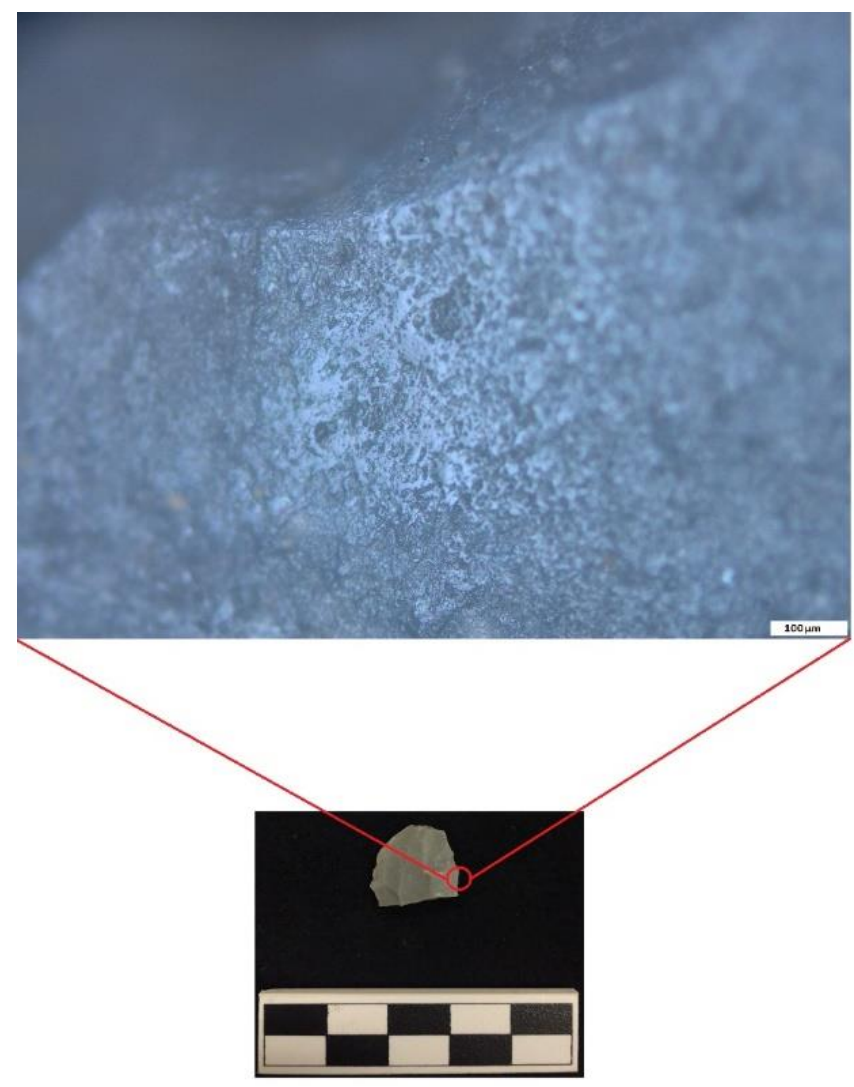

Figure 21: Bone microwear traces on a flake (\#16.2) confined to the dorsal edge (100x)

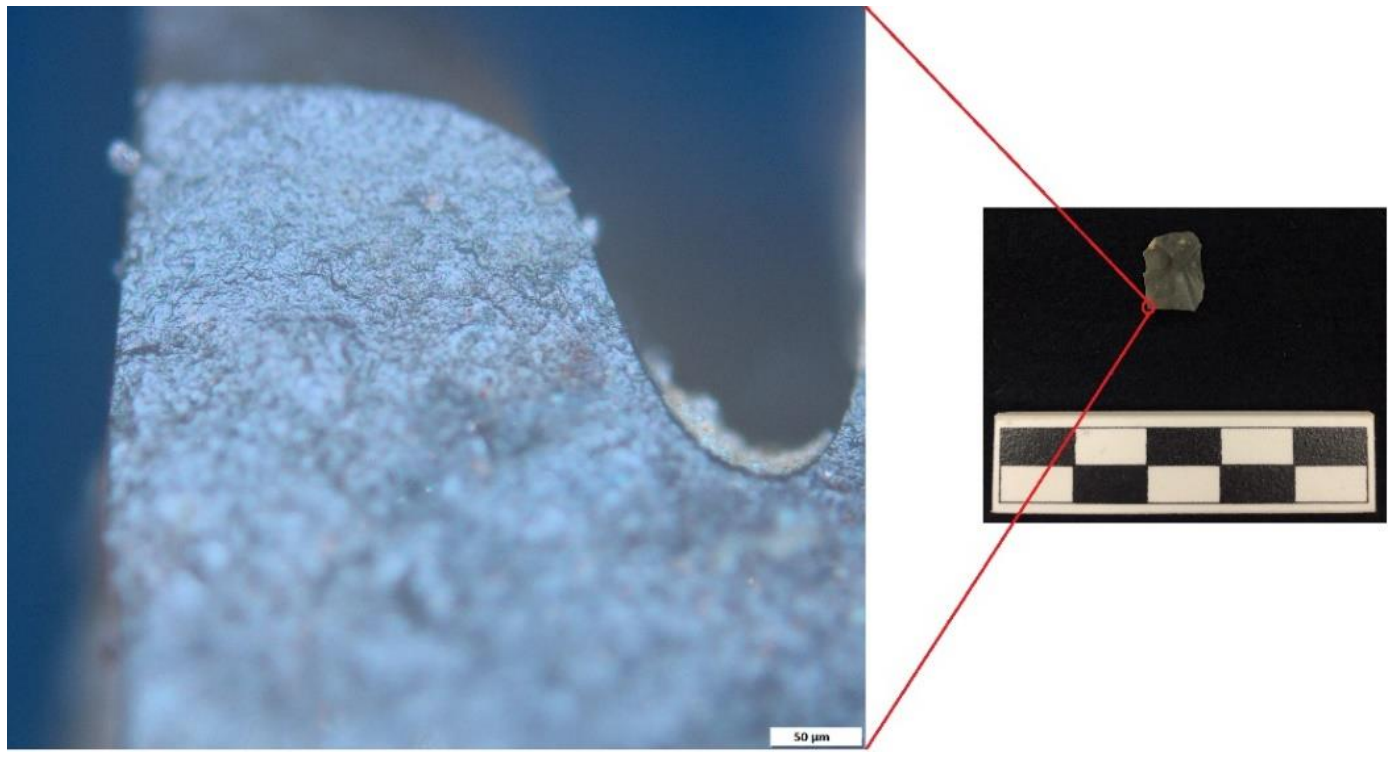

Figure 22: Meat microwear trace on a bladelet (\#39.6) confined to the dorsal edge (200x) near the broken edge 


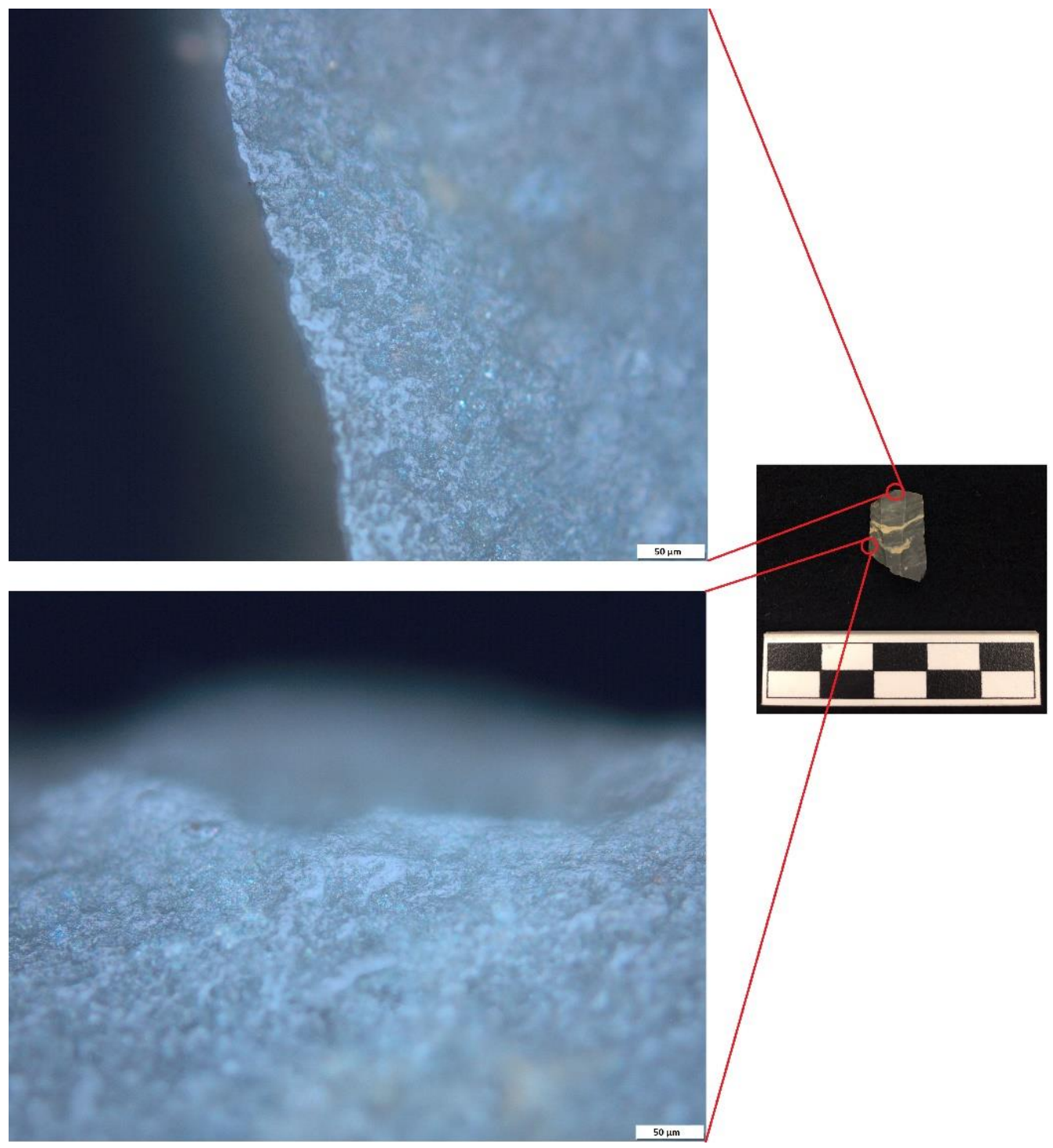

Figure 23: Dry hide cutting microwear traces on a bladelet (\#41.2) confined to the ventral edge (top: 200x) and dorsal surface (bottom: 200x) 


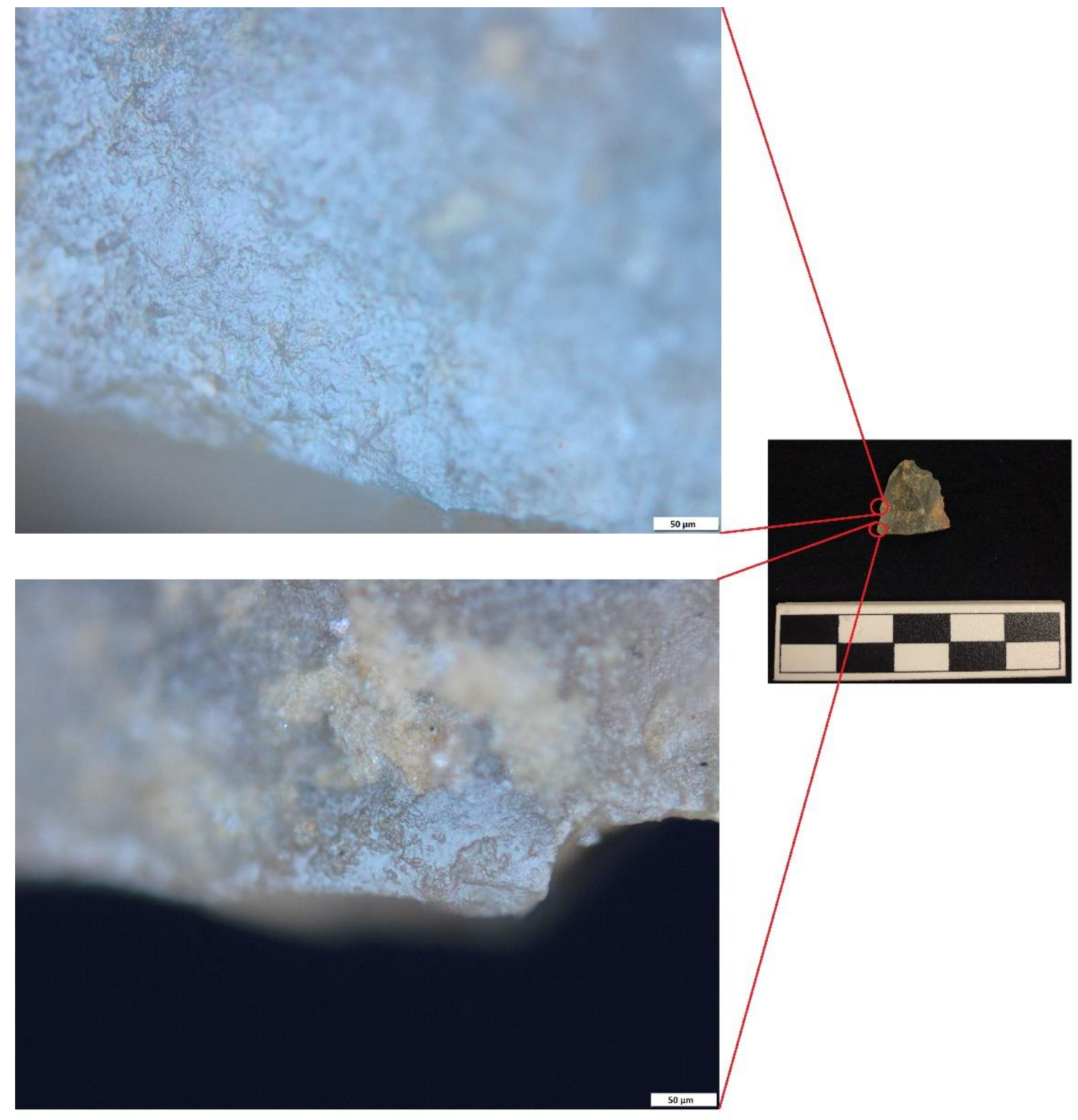

Figure 24: Meat butchery microwear trace on a bladelet (\#55.2) confined to the dorsal edge (top: 200x) and bone microwear trace confined to one spot on the dorsal surface (bottom: 200x) 


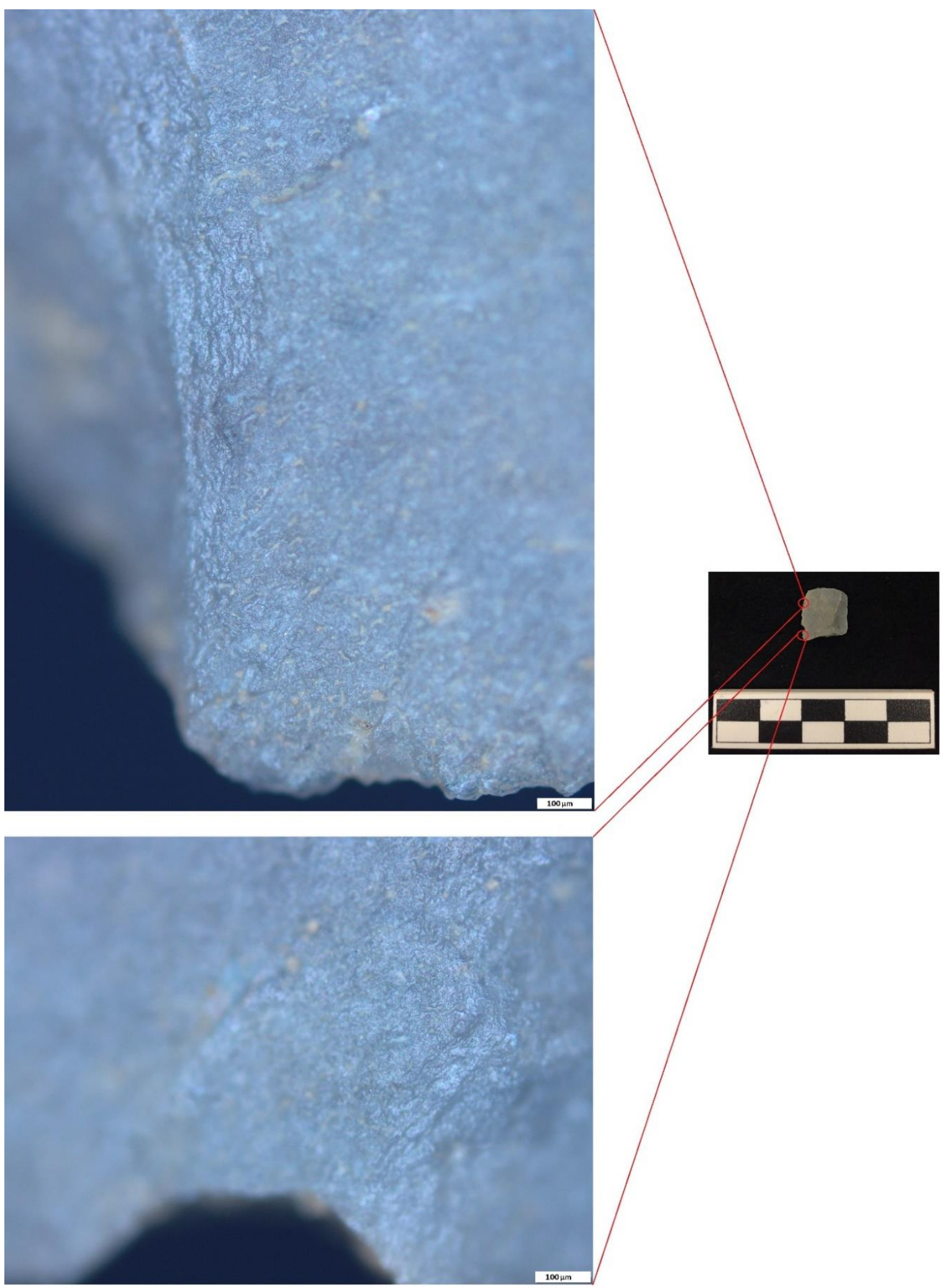

Figure 25: Meat butchery microwear traces on a bladelet (\#58.1) confined to the dorsal edge (100x) that exhibits extensive edge damage 

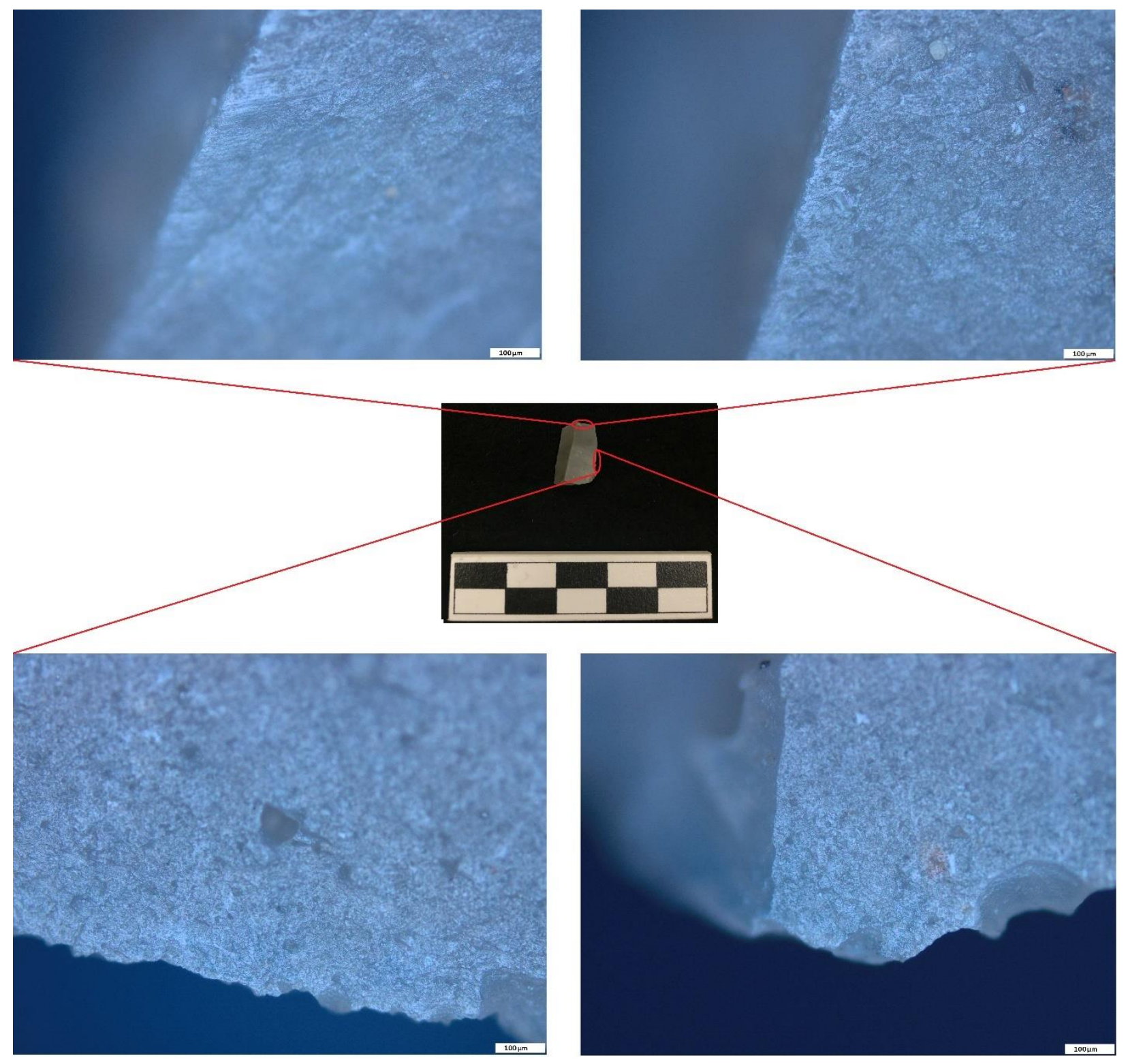

Figure 26: Fresh hide scraping microwear traces on a bladelet (\#306) confined to the snapped ventral edge (top: 100x) and meat butcher microwear traces confined to the dorsal edge (bottom: $100 x)$ 


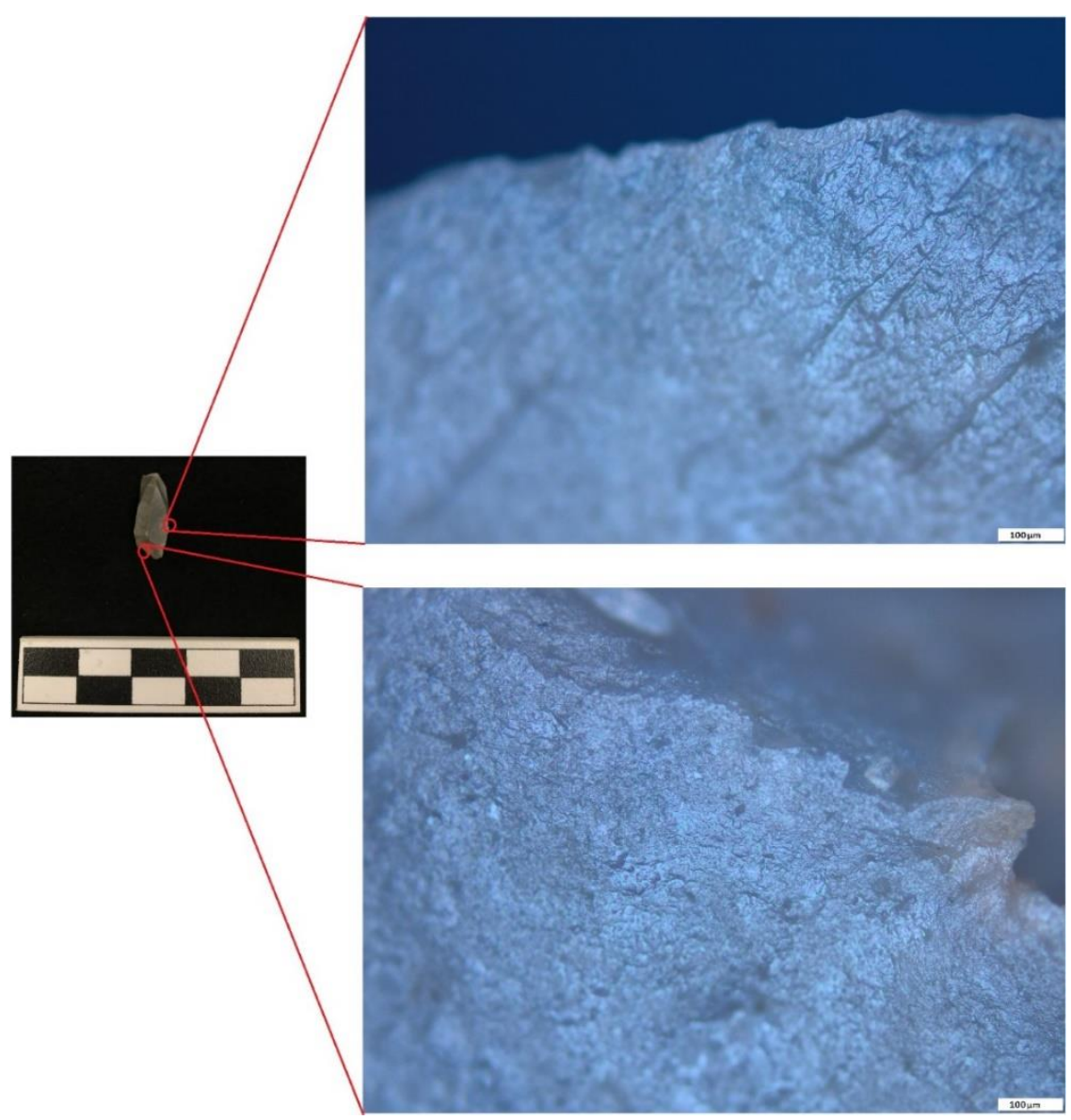

Figure 27: Meat butchery microwear traces on a bladelet (\#692) confined to the ventral edge $(100 x)$

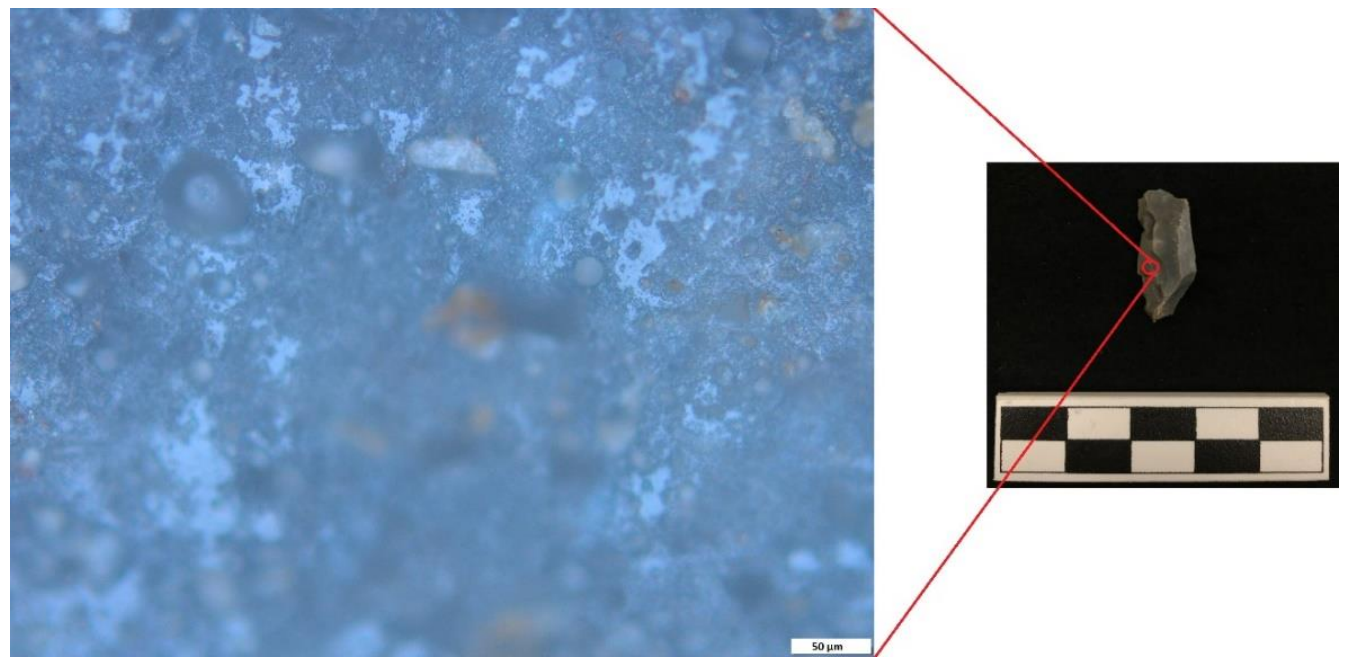

Figure 28: Hafting microwear trace on a bladelet (\#695) confined to the dorsal surface (200x) 


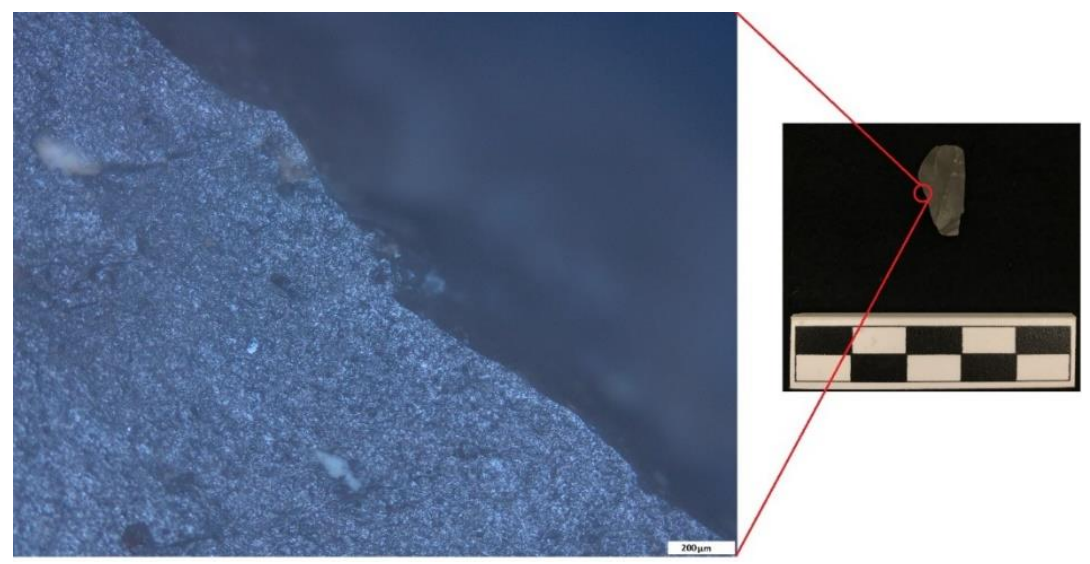

Figure 29: Meat butchery microwear traces on a bladelet (\#693) on the ventral edge (50x)

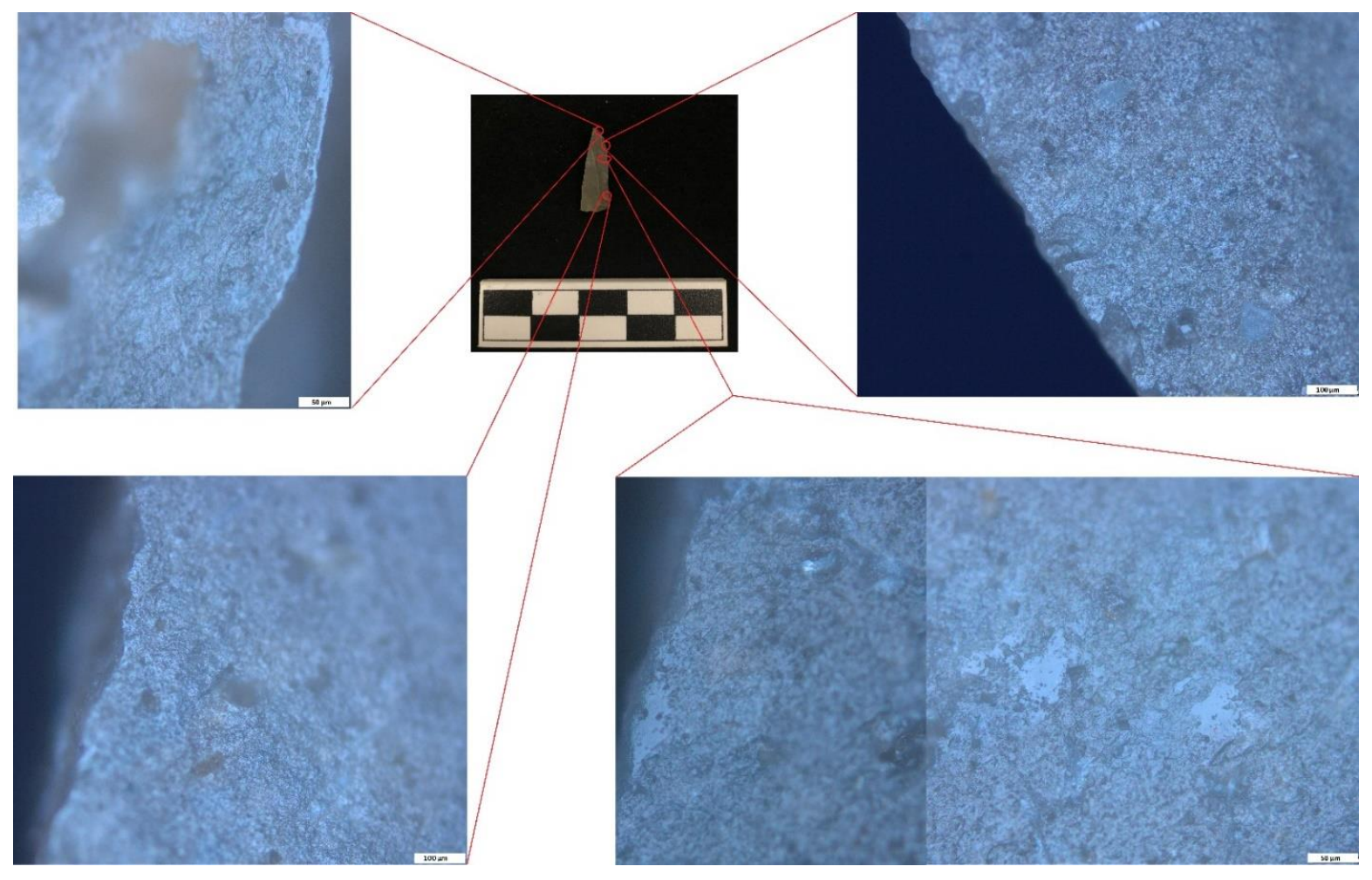

Figure 30: Bone incising microwear trace on a bladelet/burin (\#824) confined to the dorsal tip edge (top left: 200x) with meat butchery microwear traces on the dorsal edge (top right and bottom left: 100x) and hafting microwear traces along the dorsal edge towards the dorsal ridge (200x) 


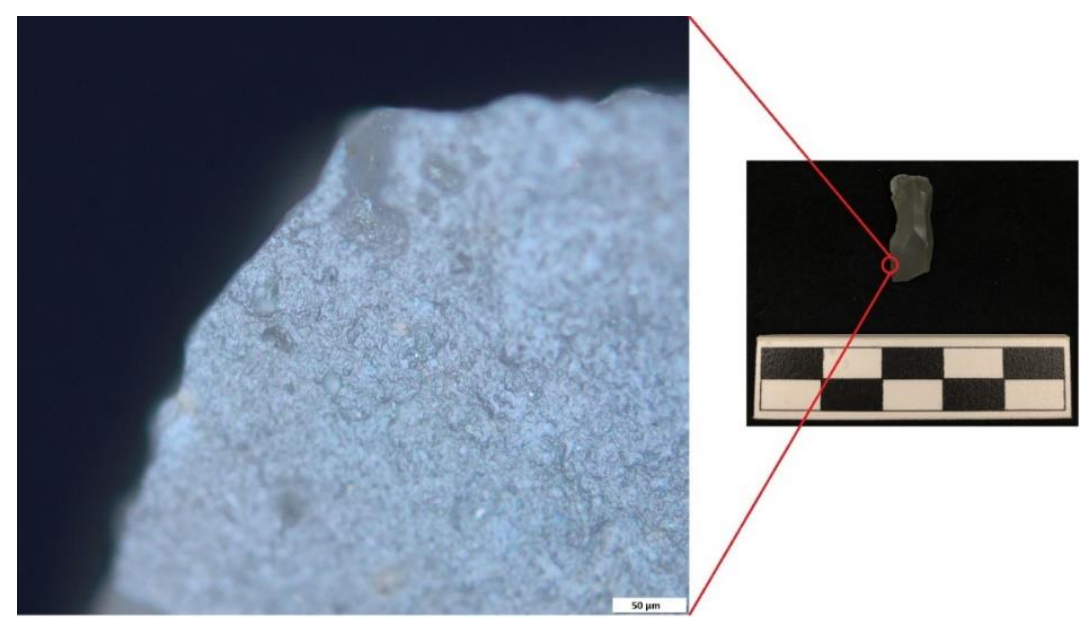

Figure 31: Meat butchery microwear traces on a bladelet (\#1390) confined to the dorsal edge (200x), which exhibits some edge damage

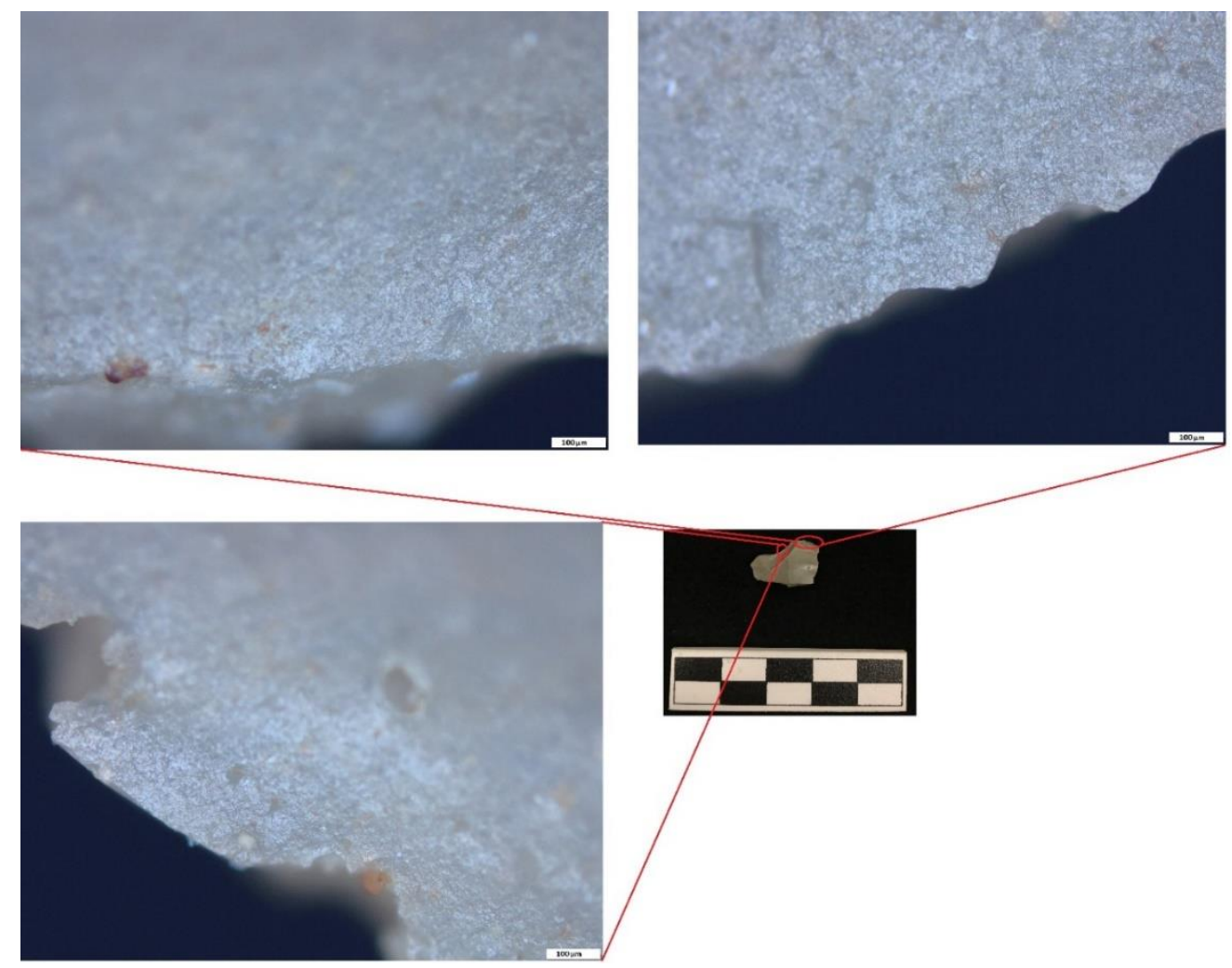

Figure 32: Meat microwear traces on a bladelet (\#1391) confined to the ventral edge (100x) that exhibits extensive edge damage 


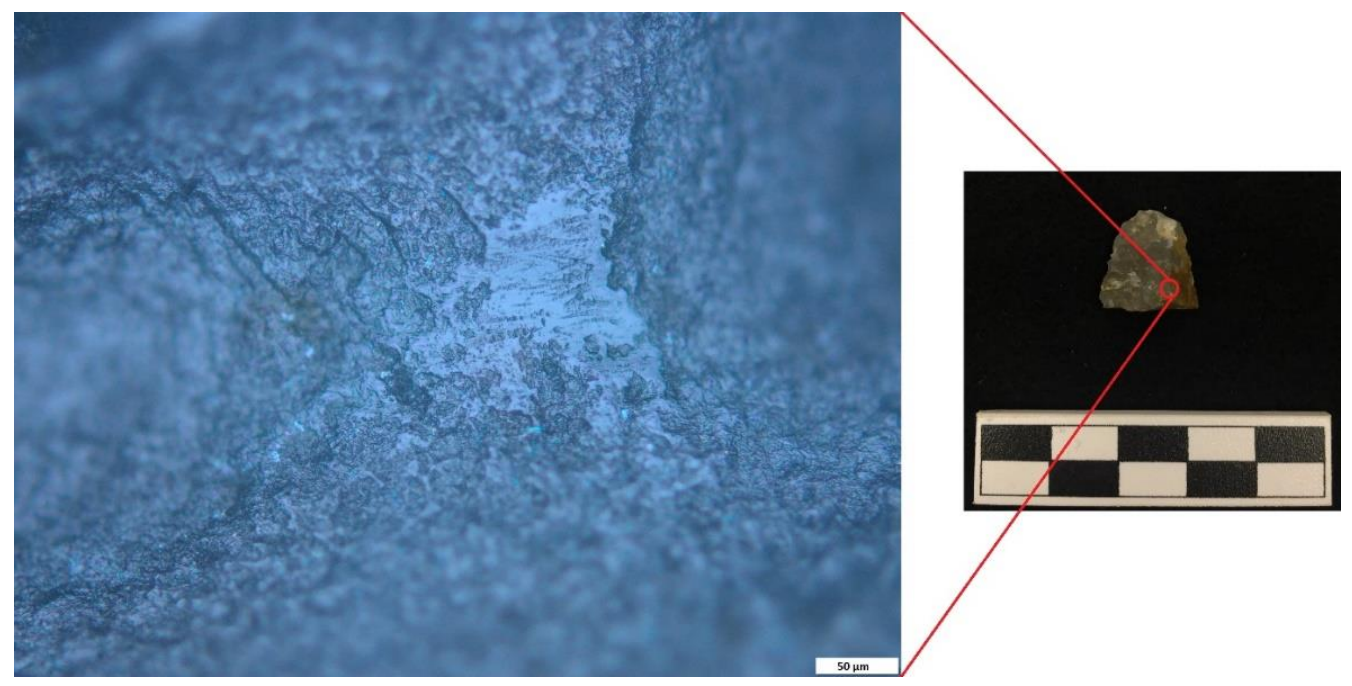

Figure 33: Hafting microwear trace on a bladelet (\#2620) confined to the ridge of the dorsal surface $(200 x)$

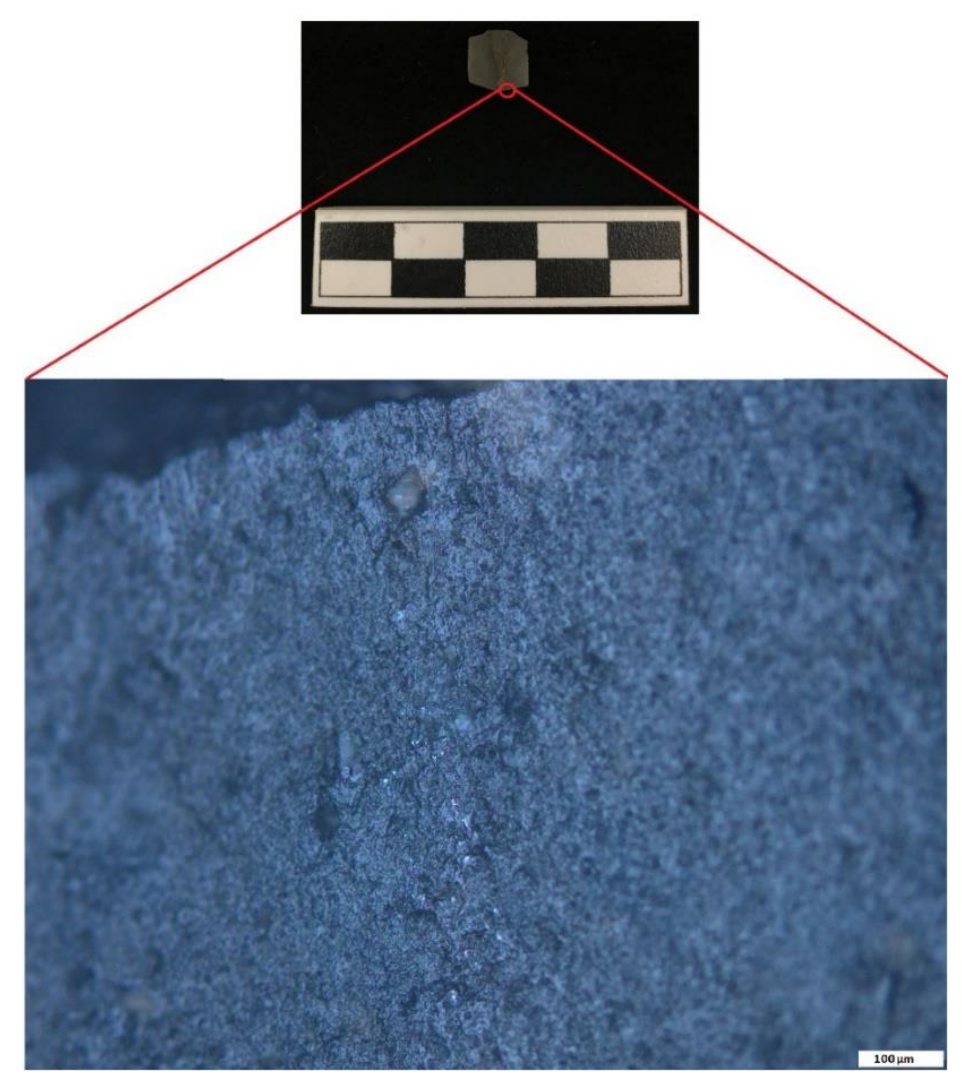

Figure 34: Dry hide scraping microwear trace on a bladelet (\#2621) confined to the snapped ventral edge (200x) 


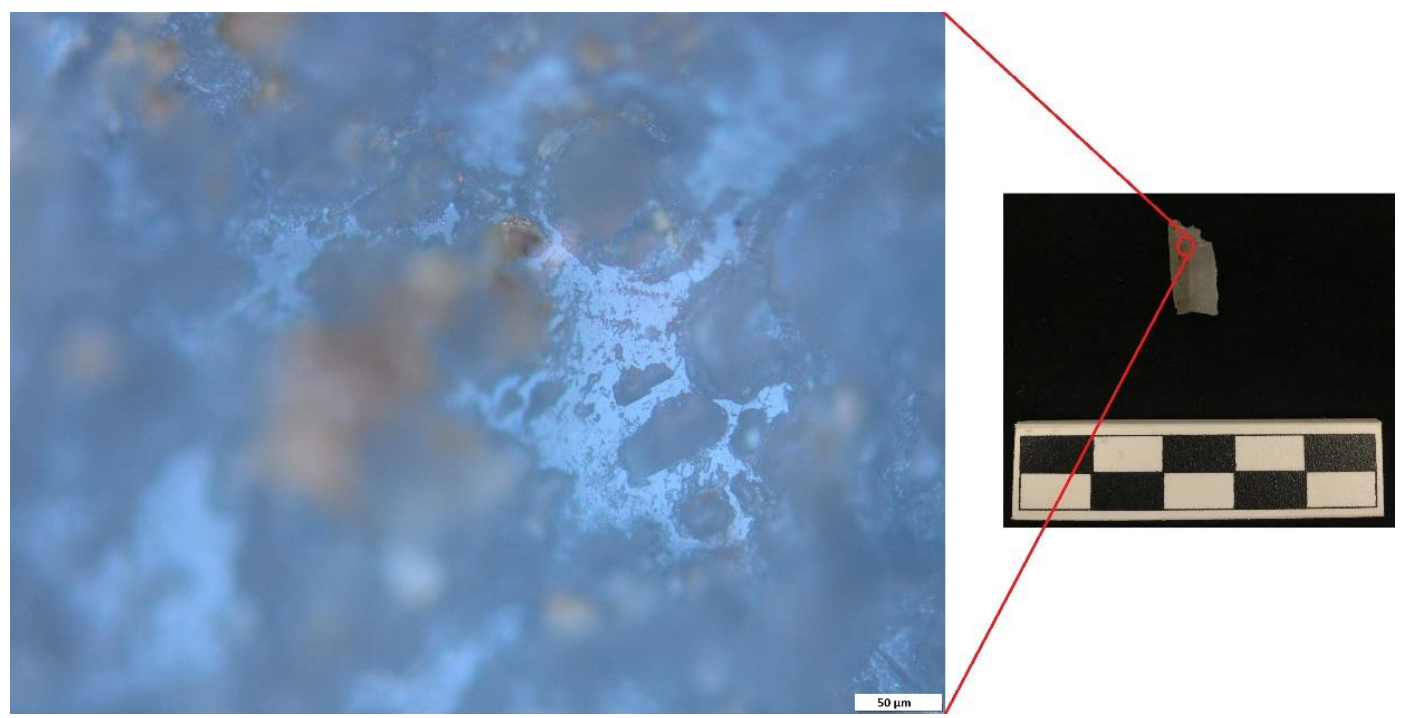

Figure 35: Hafting microwear trace on a bladelet (\#2622) confined to the dorsal surface (200x)

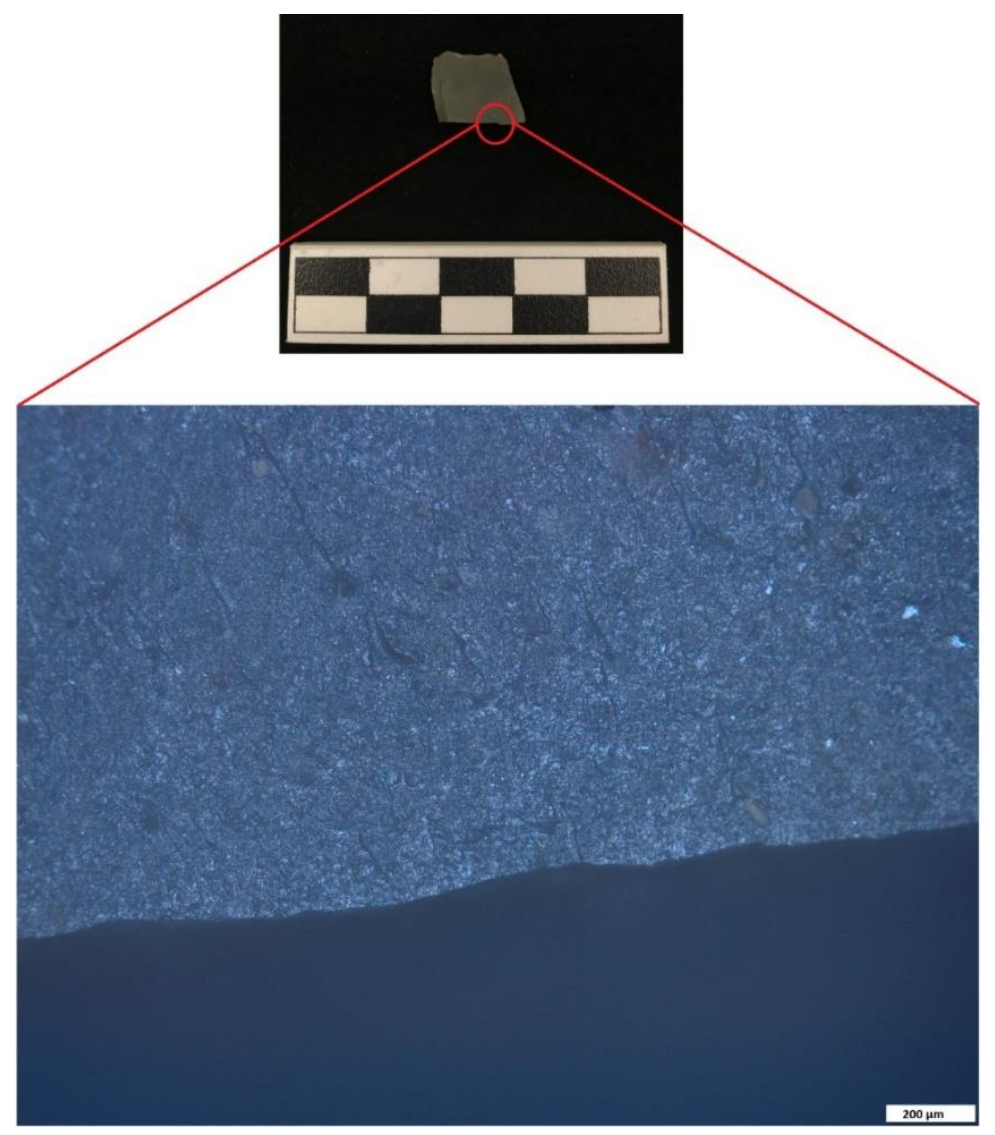

Figure 36: General microwear trace on a bladelet (\#3591) confined to the snapped ventral edge (200x) and classified as unknown 


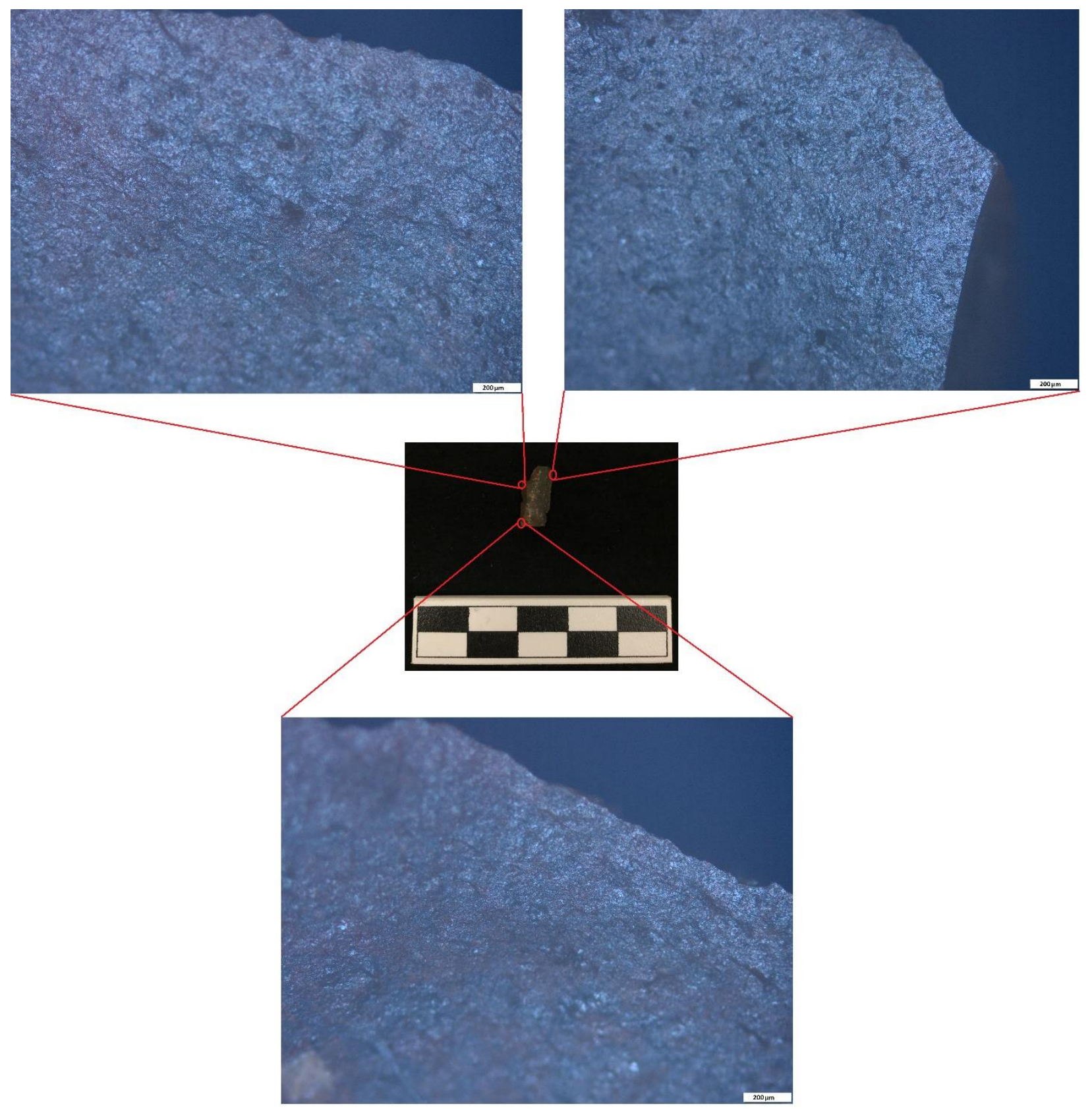

Figure 37: Meat butchery microwear traces on a bladelet (\#3883) confined to the ventral edges (50x) 


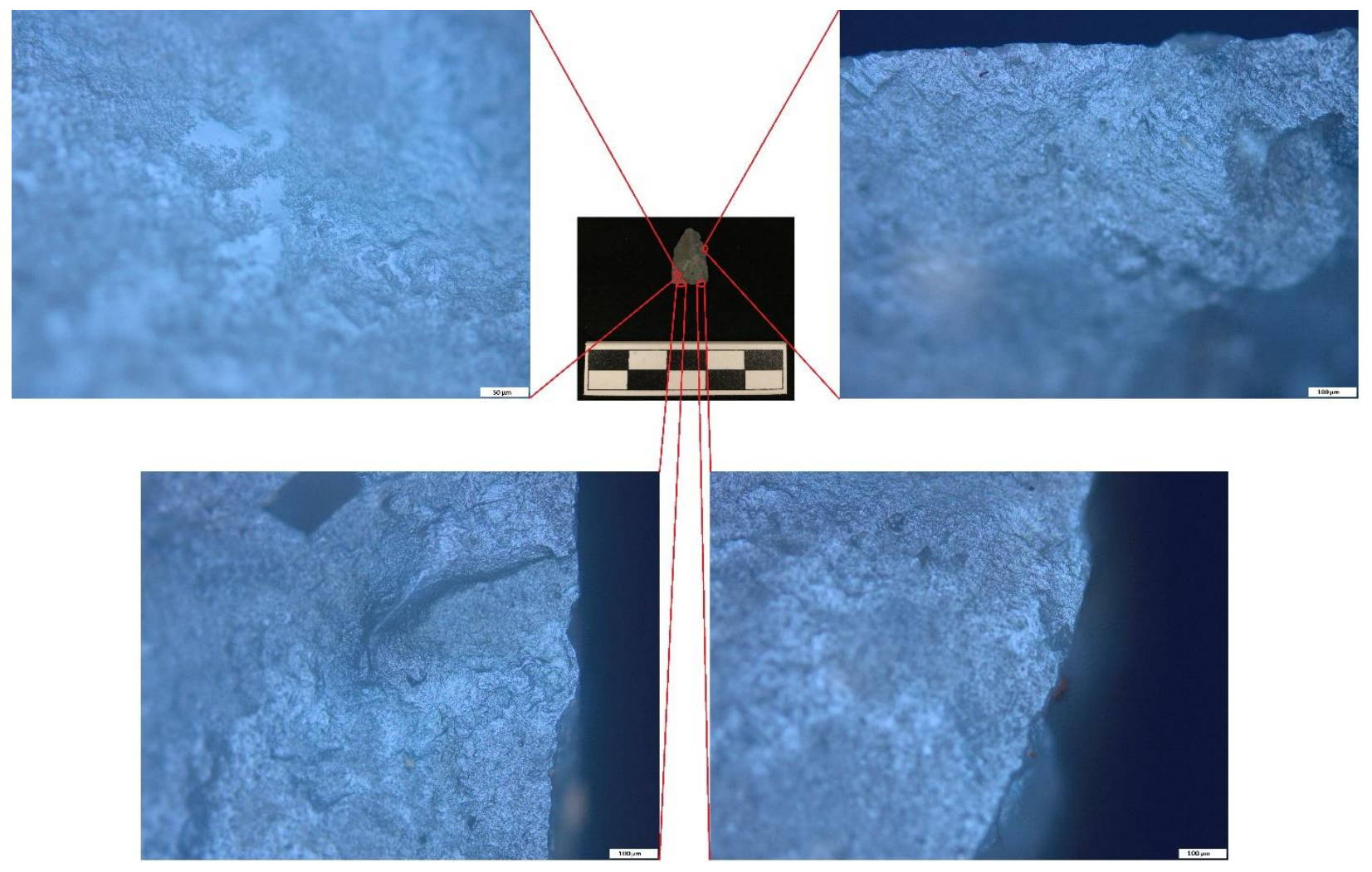

Figure 38: Hafting microwear trace on a bladelet (\#3884) on the dorsal surface (top left: 200x) with meat butchery microwear traces on the dorsal edge (right: 100x) and snapped dorsal edge (bottom: 100x) 


\section{APPENDIX B: FLAKE MICROWEAR IMAGERY}

Table 4. Flakes that Underwent Microwear Analysis

\begin{tabular}{llllll}
\hline Artifact & Location & Arifact Type & Material & Motion & Notes \\
\hline 16.7 & Surface & Flake & N/A & N/A & \\
388 & 2.1 & Retouched Flake & N/A & N/A & \\
689 & 2.1 & Bladelet Core Rejuvenation Flake & N/A & N/A & \\
1188 & 3.1 & Retouched Flake & N/A & N/A & \\
1189 & 3.1 & Retouched Flake & N/A & N/A & \\
1190 & 3.1 & Retouched Flake & Bone & Unknown & One spot \\
1191 & 3.1 & Retouched Flake & Fresh hide & Scraping & A few spots on the broken edge \\
1192 & 3.1 & Retouched Flake & N/A & N/A & \\
1393 & 4.1 & Retouched Flake & N/A & N/A & \\
2613 & 6.1 & Blade-Related Flake & N/A & N/A & \\
2614 & 6.1 & Blade-Related Flake & N/A & N/A & \\
2615 & 6.1 & Blade-Related Flake & N/A & N/A & \\
3171 & 7.1 & Retouched Flake & N/A & N/A & Hafted \\
3173 & 7.1 & Retouched Flake & N/A & N/A & Hafted \\
4195 & 12.1 & Retouched Flake & N/A & N/A & \\
4288 & 12.1 & Retouched Flake & & & \\
\hline
\end{tabular}

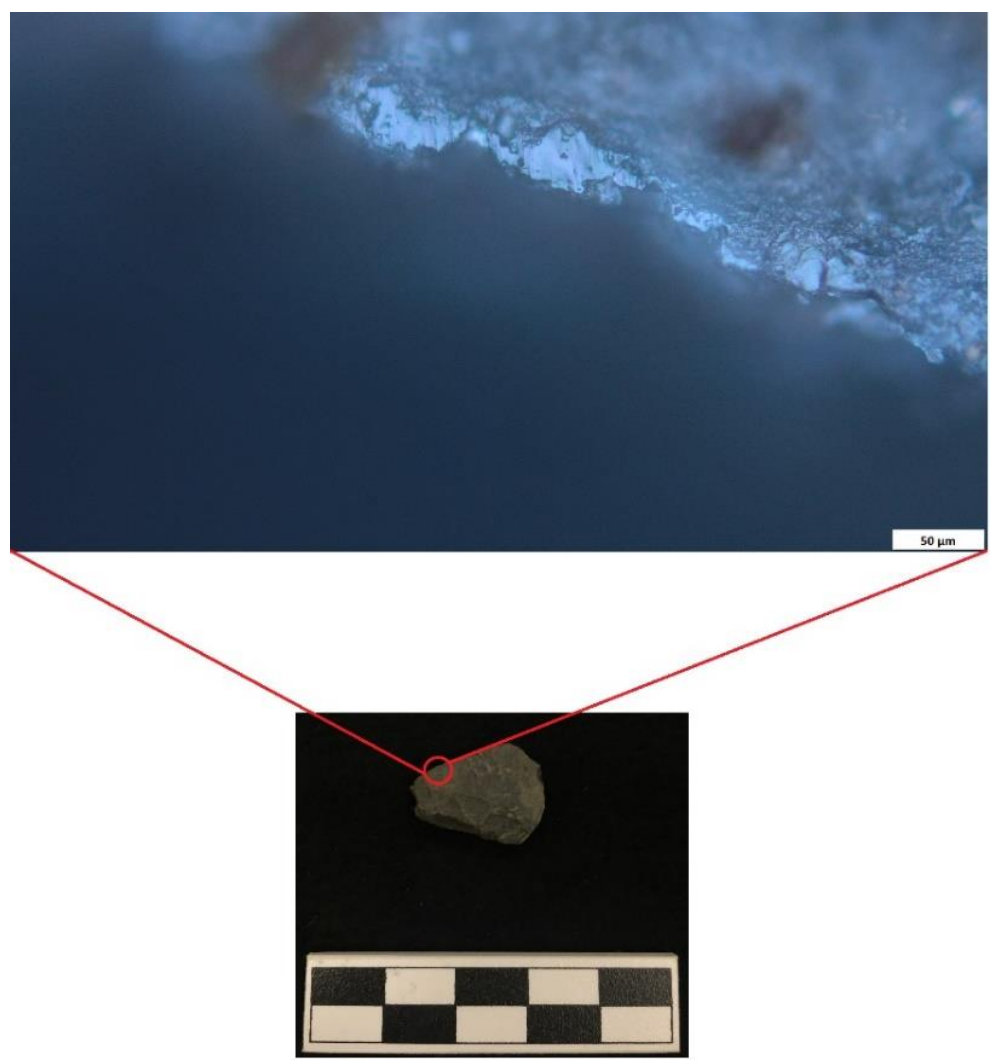

Figure 39: Bone microwear trace on a retouched flake (\#1190) confined to the ventral edge $(200 x)$ 


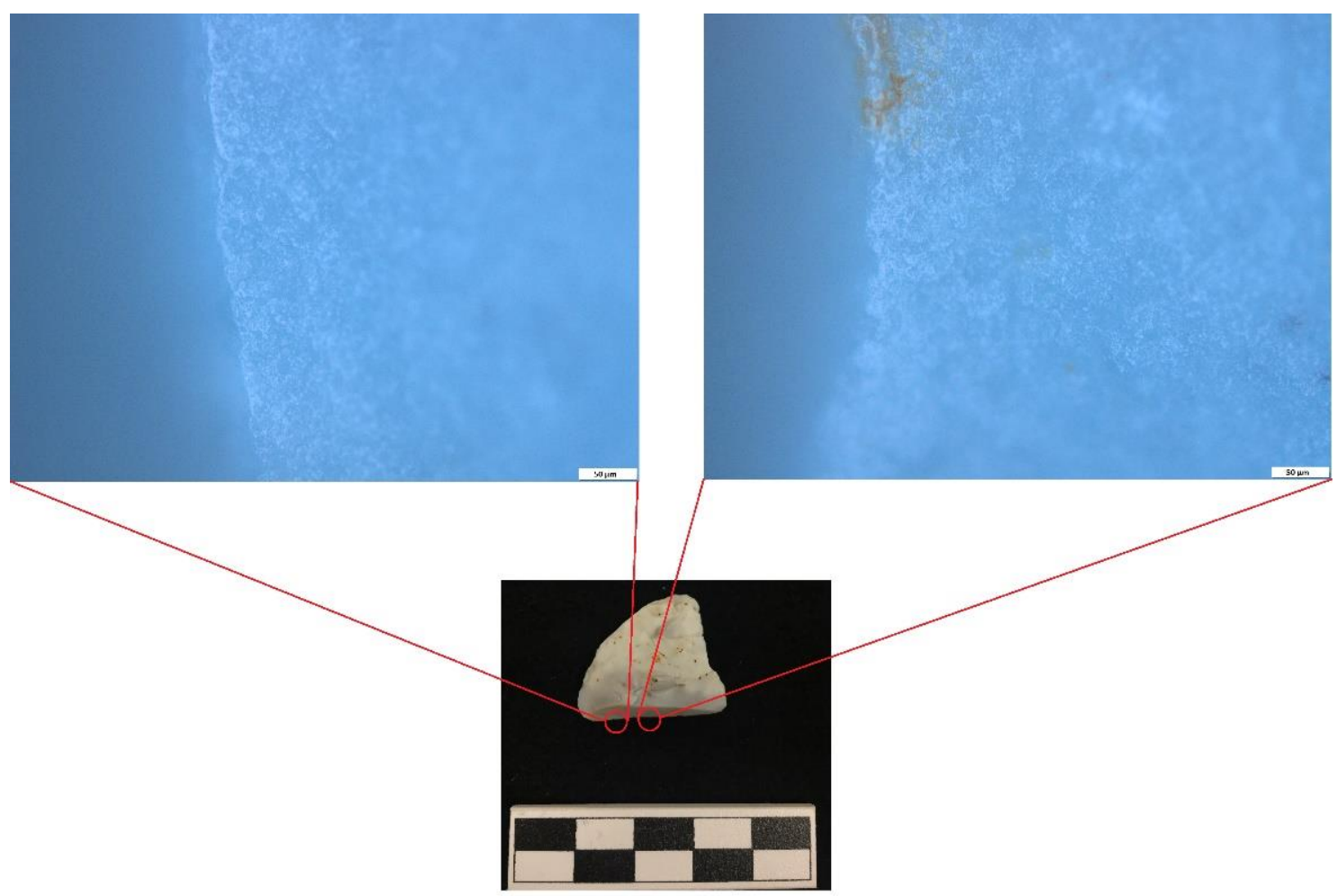

Figure 40: Fresh hide scraping microwear traces on a retouched flake (\#1191) confined to the broken dorsal edge (200x)

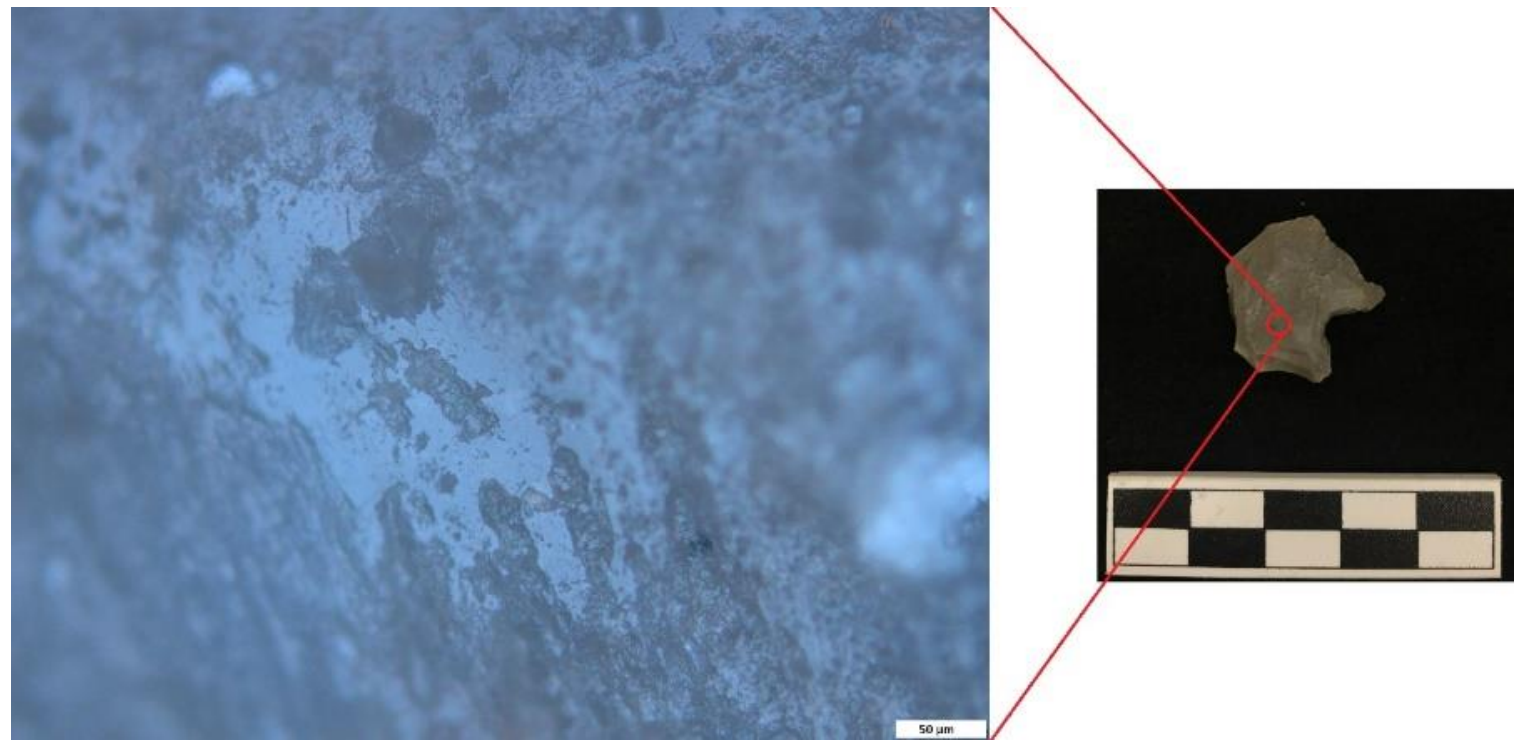

Figure 41: Hafting microwear trace on a retouched flake (\#3173) on the dorsal surface (200x) 


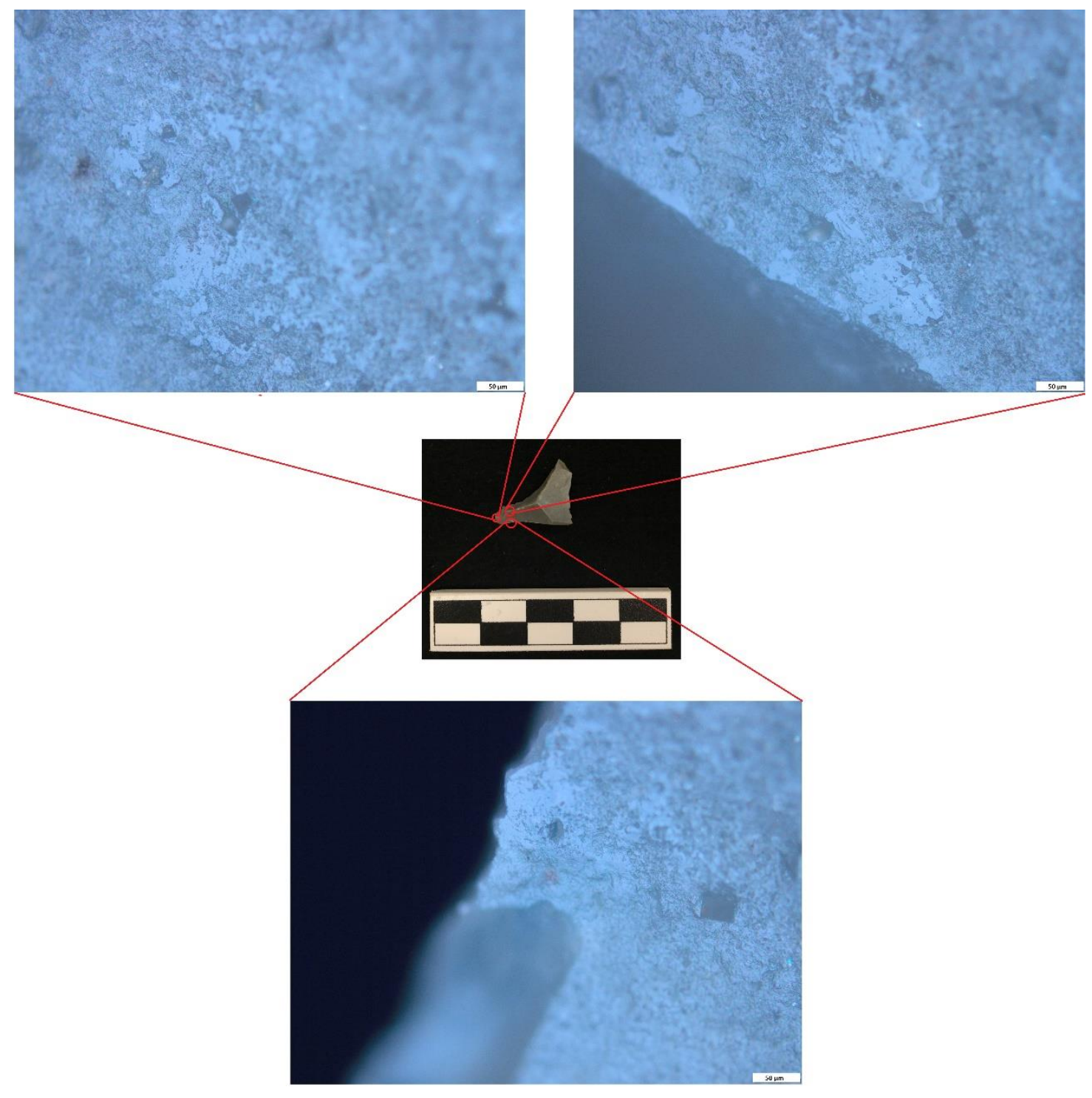

Figure 42: Hafting microwear traces on a retouched flake (\#4195) on the dorsal surface (top: 200x) and edge (bottom: 200x) 